Andrews University

Digital Commons @ Andrews University

\title{
The Impact of Family Satisfaction, Racial Identity and Perceived Ethnic Discrimination on African-American College Students' Vulnerability to Stereotype Threat
}

Erica Lynn Featherson

Andrews University, featherson@andrews.edu

Follow this and additional works at: https://digitalcommons.andrews.edu/dissertations

Part of the African American Studies Commons, and the Family, Life Course, and Society Commons

\section{Recommended Citation}

Featherson, Erica Lynn, "The Impact of Family Satisfaction, Racial Identity and Perceived Ethnic Discrimination on African-American College Students' Vulnerability to Stereotype Threat" (2018).

Dissertations. 1664.

https://digitalcommons.andrews.edu/dissertations/1664

https://dx.doi.org/10.32597/dissertations/1664

This Dissertation is brought to you for free and open access by the Graduate Research at Digital Commons @ Andrews University. It has been accepted for inclusion in Dissertations by an authorized administrator of Digital Commons @ Andrews University. For more information, please contact repository@andrews.edu. 


\section{ABSTRACT}

\section{THE IMPACT OF FAMILY SATISFACTION, RACIAL IDENTITY AND PERCEIVED ETHNIC DISCRIMINATION ON AFRICAN-AMERICAN COLLEGE STUDENTS' VULNERABILITY TO STEREOTYPE THREAT}

by

Erica Lynn Featherson

Chair: Elvin Gabriel, Ph.D. 


\title{
ABSTRACT OF GRADUATE STUDENT RESEARCH
}

Dissertation

\author{
Andrews University \\ School of Education
}

\section{Title: THE IMPACT OF FAMILY SATISFACTION, RACIAL IDENTITY AND PERCEIVED ETHNIC DISCRIMINATION ON AFRICAN-AMERICAN COLLEGE STUDENTS' VULNERABILITY TO STEREOTYPE THREAT}

Name of researcher: Erica Lynn Featherson

Name and degree of faculty chair: Elvin Gabriel, Ed.D.

Date completed: July 2018

\section{Problem}

Stereotype threat is something that has plagued the African-American community for decades. However, there is no direct research on the protective factors that could mitigate or exacerbate the effects of stereotype threat on African-Americans. The present study is intended to focus on the relationship between family satisfaction, racial identity, perceived ethnic discrimination and African-American college students' vulnerability to stereotype threat.

Method

This study used the Family Satisfaction Scale (FSS), The Black Racial Identity Attitude Scale (BRIAS), The Perceived Ethnic Discrimination Questionnaire (PEDQ) and 
the Stereotype Confirmation Concern Scale (SCCS) to explore the relationships between the four variables. A structural equation model was developed to examine the theoretical model to the empirical model developed from collected data. Four hundred and twenty African-American college students in the United States general population were used for this study.

\section{Results}

The original structural equation model suggested a poor fit with the collected data. The revised model eliminated some pathways and included additional paths based on theory found in the literature. The revised model showed an excellent fit with the data. There were significant relationships between perceived ethnic discrimination (PED), family satisfaction (FS) and stereotype threat. Black racial identity (BRI) was not correlated to stereotype threat in the final model but had a significant relationship with PED. The adjusted model accounted for $78 \%$ of variance for Stereotype threat.

\section{Conclusions}

The respecified model, based on the hypothesized theoretical model, was supported by findings from this study. The contribution of PED, BRI and FS were validated through statistical significance. The findings indicate that PED and FS have a direct relationship with African-American college students' vulnerability to stereotype threat. While BRI has an indirect relationship with stereotype threat through PED. These findings have implications for the field of counseling psychology, education, and society's understanding of protective factors that can impact and mitigate the vulnerability to stereotype threat in the African-American community. 
Andrews University

School of Education

\title{
THE IMPACT OF FAMILY SATISFACTION, RACIAL IDENTITY AND PERCEIVED ETHNIC DISCRIMINATION ON AFRICAN-AMERICAN COLLEGE STUDENTS' VULNERABILITY TO STEREOTYPE THREAT
}

\author{
A Dissertation \\ Presented in Partial Fulfillment \\ of the Requirements for the Degree \\ Doctor of Philosophy
}

by

Erica Lynn Featherson

July 2018 
(C) Copyright by Erica L Featherson 2018

All Rights Reserved 


\title{
THE IMPACT OF FAMILY SATISFACTION, RACIAL IDENTITY AND PERCEIVED ETHNIC DISCRIMINATION ON AFRICAN-AMERICAN COLLEGE STUDENTS' VULNERABILITY TO STEREOTYPE THREAT
}

\author{
A dissertation \\ presented in partial fulfillment \\ of the requirements for the degree \\ Doctor of Philosophy
}

by

Erica Lynn Featherson

APPROVAL BY THE COMMITTEE:

Chair: Elvin Gabriel

Member: Carole Woolford-Hunt

Member: Tevni Grajales

External: Lionel Matthews

Cember: Tevni Grajales
Dean, School of Education

Robson Marinho

\author{
External: Lionel Matthews
}

Date approved 
To him who is able to do, exceedingly abundantly above all we could ever ask or think, according to the power that worketh within us

-Ephesians 3:20, KJV 


\section{TABLE OF CONTENTS}

LIST OF FIGURES …..................................................................... viii

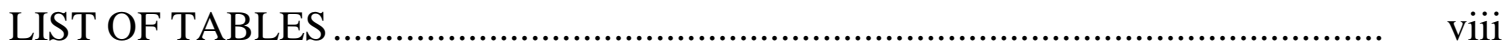

LIST OF ABBREVIATIONS ...................................................................... ix

ACKNOWLEDGEMENTS .....................................................................

Chapter

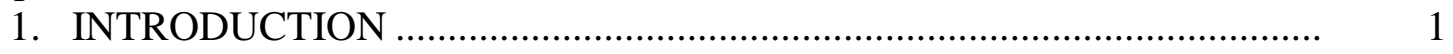

Background ..................................................................................... 1

Rationale for the Study ............................................................... 6

Statement of the Problem.................................................................. 7

Purpose of the Study ....................................................................... 8

Conceptual/Theoretical Framework.................................................. 9

Tajfel's Social Identity Theory ....................................................... 9

Group Membership (Racial Identity) Effect on

Stereotype Threat ........................................................... 10

Social Categorization, Uncertainty Reduction and

Stereotype Threat .............................................................. 11

Depersonalization, Categorization, Discrimination and

Stereotype Threat ................................................................ 12

Circumplex Model of Marital and Family Satisfaction ................... 13

Family Satisfaction Effects on Stereotype Threat .......................... 13

Cross’ Model of Black Racial Identity .......................................... 15

Racial Identity and Stereotype Threat............................................ 16

Research Question and Hypotheses .................................................. 17

Significance of the Study .......................................................... 18

Definitions of Terms ....................................................................... 21

Limitations .............................................................................. 23

Delimitations............................................................................... 23

Organization of the Study ............................................................... 24

2. REVIEW OF THE LITERATURE ...................................................... 26

Introduction .......................................................................... 26

Stereotype Threat, African-Americans \& College Settings.................... 28

A Conceptual Overview of Stereotype Threat............................... 28

Stereotype Threat Among African-Americans ............................... 33 
Stereotype Threat in Academic Institutions of Higher Education..... 36

Stereotype Threat Effects on African-American College Students ... $\quad 40$

A Conceptual Overview of Family Satisfaction .................................. 43

Family Satisfaction and the African-American Experience. ............. 45

The Relationship Between Family Satisfaction and Stereotype

Threat

The Relationship Between Family Satisfaction and Stereotype

Threat Among African-American College Students.

A Conceptual Overview of Racial/Ethnic Identity in the United

States

Types/Models of Identity.....

Racial Identity and the American Experience

Effects of Racial Identity on Stereotype Threat.

Racial/Ethnic Identity and African-Americans.

The Relationship Between Racial Identity and Stereotype

Threat Among African-American College Students...

A Conceptual Overview of Racial/Ethnic Discrimination.

A Conceptual Overview of Racial/Ethnic Discrimination

in the United States.

The Effects of Discrimination on African-Americans

The Relationship Between Ethnic Discrimination and

Stereotype Threat.

The Relationship Among Family Satisfaction, Racial Identity,

Ethnic/Racial Discrimination, and African-American Students'

Vulnerability to Stereotype Threat

Summary of the Literature.

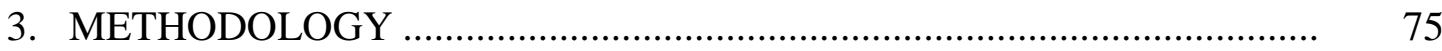

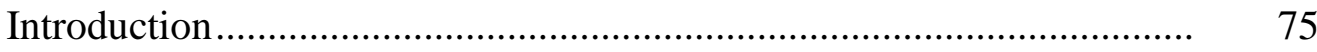

Research Question ........................................................................ 75

Research Design.................................................................... $\quad 76$

Population and Sample ................................................................ 78

Definition of Variables .................................................................... $\quad 79$

Instrumentation ........................................................................... 82

Black Racial Identity Attitude Scale ............................................ 82

Perceived Ethnic Discrimination Questionnaire ............................ 83

Family Satisfaction Scale.......................................................... 84

Stereotype Confirmation Scale ................................................ 85

Demographic Questionnaire ...................................................... 86

Procedures ............................................................................. 87

Treatment of the Data ...................................................................... 89

Data Analysis .............................................................................. 89

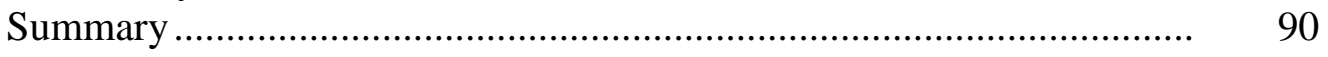

4. RESULTS OF THE STUDY ............................................................. 91 


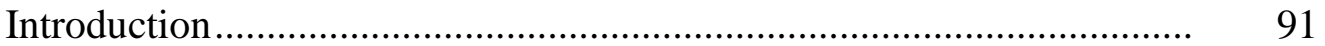

Demographic Characteristics ................................................................. 91

Description of the Variables .................................................................. 92

Hypothesis Testing ........................................................................... 95

Structural Model ........................................................................ 95

Respecified Structural Model .......................................................... 97

Analysis of Models ........................................................................... $\quad 99$

Summary of the Findings ..................................................................... 102

\section{SUMMARY, CONCLUSIONS, IMPLICATIONS AND}

RECOMMENDATIONS ...................................................................... 103

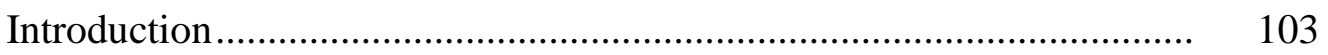

Research Problem ........................................................................... 103

Purpose of the Study ......................................................................... 105

Research Hypothesis ....................................................................... 106

Significance of the Study ................................................................ 106

Overview of the Literature................................................................... 108

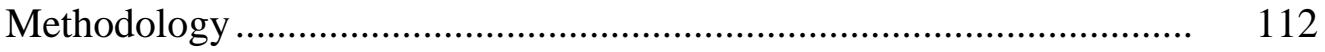

Findings and Discussion ................................................................. 112

Respondents Demographics.......................................................... 113

Research Hypothesis ................................................................... 114

Respecified Model Fit................................................................. 114

Respecified Model …….............................................................. 120

Family Satisfaction and Stereotype Threat ................................. 121

Black Racial Identity and Perceived Ethnic Discrimination........ 123

Perceived Ethnic Discrimination and Stereotype Threat............. 125

Black Racial Identity Level 1 and 2.......................................... 127

Black Racial Identity and Family Satisfaction............................ 128

Threat and Aggression and Black Racial Identity Level 1 ......... $\quad 130$

Black Racial Identity, Family Satisfaction, and Perceived

Ethnic Discrimination ....................................................... 131

Final Implications …............................................................. 132

Limitations ............................................................................... 132

Suggestions for Future Research ....................................................... 133

Appendix

A. CORRELATION TABLE …………………………........................... 136

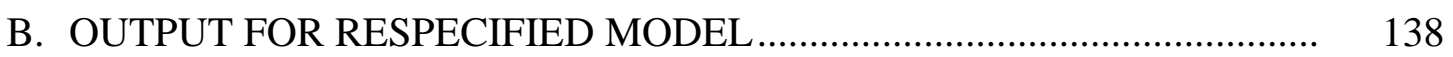

C. QUESTIONNAIRES AND SURVEYS ................................................... 149 
D. INFORMED CONSENT

E. APPROVAL LETTERS ...................................................................... 160

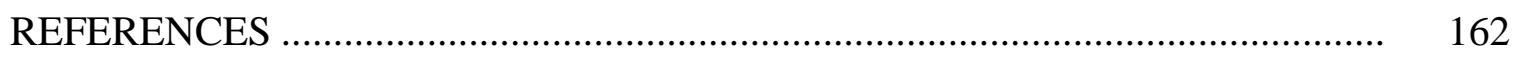

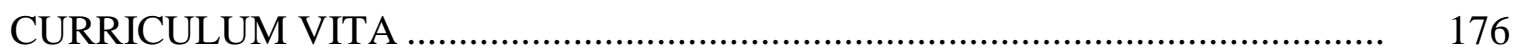




\section{LIST OF FIGURES}

1. Hypothesized Model of Variables ........................................................ 18

2. Respecified Model .............................................................................. 100

\section{LIST OF TABLES}

1. Respondents' Demographics Statistics .................................................. 92

2. Respondents' Descriptive Statistics....................................................... 93

3. Chi Square and Goodness of Fit for Models.......................................... 101 


\section{LIST OF ABBREVIATIONS}

\begin{tabular}{ll} 
AMOS & Analysis of a Moment Structure \\
AV & Avoidance \\
BRIAS & Black Racial Identity Attitude Scale \\
BRI & Black Racial Identity \\
BRI-InitialStages & Black Racial Identity Level 1 \\
BRI-LatterStages & Black Racial Identity Level 2 \\
CFI & Comparative Fit Index \\
DIS & Disvaluation \\
E\&D & Exclusion and Denial of Equal Treatment \\
FSS & Family Satisfaction Scale \\
FS & Family Satisfaction \\
GFI & Goodness of Fit Index \\
HBCUs & Historically Black Colleges and Universities \\
NFI & Normed Fit Index \\
PEDQ & Perceived Ethnic Discrimination Questionnaire \\
PED & Perceived Ethnic Discrimination \\
PWIs & Predominantly White Institutions \\
RMSEA & Root Mean Square Error of Approximation \\
SCCS & Stereotype Confirmation Concern Scale \\
\hline
\end{tabular}


SES

STC

SPSS

TAGG

VR
Socioeconomic Status

Stereotype Threat Concern

Statistical Package for Social Sciences

Threat and Aggression

Verbal Rejection 


\section{ACKNOWLEDGMENTS}

This dissertation process has been long and tedious and there were days where I did not believe I would finish. There were days that I thought I was done, only to get another revisal. Through it all, the end finally came and I must admit that the completion of this dissertation would not have occurred without the support and leadership of those around me and those who have gone before me.

Primarily, all glory to GOD because without his guidance I would have never finish this dissertation nor entered this program. There is no disillusion, I absolutely realize and confirm that without God I would not be where I am today. It is by his strength, guidance, grace, and love that this was possible at all. Lord, this dissertation, degree and my life is yours. Always, have your way. \#ILOVEJESUS

To my family, my parents and my sisters, you all have been my rock. You are the ones I call for prayer, the ones I complain to when I am overwhelmed, and the ones who I go to for simply everything. There is absolutely no way I would be here without your love. I love you all so much that even the most extraordinary words cannot express the gratitude, affection and love I have for you all.

A special thanks to my mother and father, just thinking of your love and support overwhelms me with emotions. You have no idea how much of my success I attribute to your love, leadership, relationship, discipline, and belief in me. You all have been my

number one cheerleaders, defenders, and correctors; and because of who you are as 
people, and who you are in my life, here we are together. You have raised me with such a faith in God and belief in myself that I truly believe the sky is the limit. I know you have both have spent an immeasurable amount of time on your knees on my behalf and this success is as much yours as it is mine.

To my committee: Dr. Gabriel, thank you for being my chair. I know you had retirement set in sight and did not need another dissertation weighing you down. Yet, you agreed (after much begging) and I am so grateful. The work you have put into this is astonishing and more than I could have ever asked. Also, thank you for always believing that I would get it done and for working as hard as me to meet deadlines. Your bright spirit and laughter always eased any worries I may have had when I entered your room. To be able to work with you has truly been an honor.

Dr. Grajales, thank you for all of your help, what you have done exceeded far beyond methodology. I am forever grateful for your prompt responses and honesty. As I have told others, you are from the Lord himself. Your efforts superseded all of my expectations and I am forever indebted to you. Thank you for pushing me to be and do my best.

In addition, Dr. Woolford-Hunt, thank you for helping me to develop this concept and to look at it from a number of angles. You have challenged me on a number of levels and because of it; I am not the same person I was when entering this program. Thank you for challenging my comfort level, I may not have appreciated then, but I certainly appreciate it now. 
Finally, to my church (Road to Life), my cohort, the GDPC family and best friend Tanya, you have all held my hand in some way through this process. You have challenged me to grow in varying ways and reminded me who I am, whose I am, and what I can do when I forgot. A special thanks to Brittany, I have always seen you as the one who came before me and you have helped me along this journey. Your leadership and guidance has had a large hand in where I am today, thank you.

As I close this chapter, I know I am starting a new one, with new perspectives and experiences and I thank all of you for going on this journey with me. 


\section{CHAPTER 1}

\section{INTRODUCTION}

\section{Background}

Racial inequalities form an unavoidable aspect of life in the United States of America. Segregation was legal in the United States for over a century and despite various protests it was not until Brown v. Board of Education that school segregation was outlawed. Despite the ruling, integration was met with much turbulence and opposition. Today there are no longer racists standing on the sidelines but the ghost of racism is still present within our society, especially among African-Americans. For African-Americans this ghost of racism stems from slavery and subjects these individuals to, 'racialized and discursive discourse that has socially constructed them as criminals and amoral human beings, which challenges their humanity and their right to a legitimate social and racial identity" (Mary, 2011). One way this "ghost" takes shape is through stereotype threat. Stereotype threat is defined as "a situational predicament in which individuals are at risk, by dint of their actions or behaviors, of confirming negative stereotypes about their group" (Shin, Pittinsky \& Ho, 2011, p. 5-6). There is a large body of literature on stereotype threat, racial identity and minority students in regards to academics, but little research has been done to test what factors influence one's susceptibility to stereotype threat. In fact, only one study has looked into resiliency's effect on stereotype threat (Bikmen, 2015). In addition, when looking at resiliency measures there are only a few 
articles that look at resiliency in regards to black racial identity (BRI), discrimination, and stereotype threat (Miller, 1998; Yakin \& McMahon, 2003; Welleto, 2000; LaMothe, 2012).

In the past, stereotype threat was viewed mainly as a factor that affected academic achievement and testing, and was overshadowed by something called an "achievement gap, [which is] an overall academic performance disparity" between African-Americans and their White counterparts (Davis, 2012; Steele \& Aronson, 1995). In addition, it was proven that factors such as poverty, parental style, and socialization play a major role in an individual's academic success (Cohen \& Sherman, 2005). Although, this may be true, there is an undeniable disparity between African-Americans in aptitude testing and college success that is not accounted for by the aforementioned factors and can have drastic effects on the students (Cohen \& Sherman, 2015). Davis (2012) contends that the reason African-Americans could not keep up on the college level was because of the inequities of the educational system of the United States or that the "life chances" of African-Americans, as compared to Whites, are more a function of socioeconomic status than race. Davis, continued that

class stratification does exist, but that it cannot be applied to the explanation of educational disparities because the problem of applying [class stratification] to the analysis of racial inequality lies in the temporality of class membership in contrast to the permanence of racial group membership. In other words, one can obtain some degree of economic success and alter one's socioeconomic status; one cannot, however, alter one's racial affiliation (Davis, 2012).

It seems evident that despite the other factors that can play into academic success, attitudes towards minorities plays a large role and these attitudes can affect minorities in a number of ways (Cohen \& Garcia, 2005). 
When students have to deal with the burden of stereotype threat on a regular basis, they begin to internalize these beliefs, which can lead to the loss of their desire to pursue their goals (Massey \& Owens, 2012). That is, students will actually "give up" their goals or desires because they do not fit into "their continuum of capabilities" according to the stereotype (Woodcock, Hernandez, Estrada, \& Schultz, 2012). This can cause a minority group, such as African-Americans, to place distance between itself and the stereotype domains, resulting in disidentification or divestment (Woodcock et al., 2012; Massey \& Owens, 2012; Yip, 2016). This fear of confirming a stereotype goes beyond the individual and reaches out to the collective group, meaning that AfricanAmericans may fear that if they confirm a stereotype, they are confirming it not only for themselves but for the group as well (Cohen \& Garcia, 2005). This then creates a collective threat, because if individuals do not see their own "in-group" in a positive light, they may disassociate from the group (Cohen \& Garcia, 2005). If one chooses to disassociate, this not only affects one's self-identity but also one's racial identity because the negative stereotypes have affected how they identify with their race (Cohen \& Garcia, 2005). It has been suggested that there are links between racial identity, stereotype threat, and racial discrimination (Dovidio, Brigham, Johnson, \& Gaertner, 1996).

Racial identity is defined as a, "sense of group or collective identity based on one's perception that he or she shares a common heritage with a particular racial group" (Chavez \& Guido-DiBrito, 2001). However, it is often seen that racial identity is simply defined by how people categorize themselves based on skin color, this in turn is the foundation of racism, because many use skin color as labeling tools or reason to distance themselves from another person or race (Chavez \& Guido-DiBrito, 2001). Some research 
supports the claim that if race is not a central aspect of an African-American's personal identity, then stereotypes may not have a significant effect on them (Okeke, Howard, Kurtz-Costes, \& Rowley, 2009). A study by Okeke et al, (2009) on racial salience, ideology, regard and centrality, hypothesized that those who have a stronger racial salience (the extent to which race is relevant to the self-concept) will more likely be influenced by stereotypes than those who do not identify strongly with the group (Okeke et al., 2009). The results of this study confirmed that an individual has to identify with a social group in order to be affected by the negative influences of stereotypes, meaning that there has to be salience and centrality in order for the stereotype to take effect (Okeke et al., 2009). However, in order for one to identify with a social group, one must develop a "social" identity, and part of that development involves developing a "racial" identity.

Racial identity development among African-American college students may be impacted by family satisfaction (FS). Which is defined as the degree to which family members feel happy and fulfilled with each other, based on cohesion, flexibility, and communication (Olson, n.d). Parental efficacy can serve as a critical buffer against adversity and efficacious parenting can have a positive impact on a child's self-image and self-reliance (Rodriguez, Umaña-Taylor, Smith, \& Johnson, 2009). Research also suggests that family structure has a relationship to youth resiliency and that AfricanAmerican families who are particularly close provide a "buffer against the negative images and stereotypes of blacks in western society" (Rodriguez et al., 2009). These negative images and stereotypes can have negative effects on African-American youth's racial identity, but that strong family relationships and interactions can help to counteract 
negative societal stereotypes and images. These relationships and interactions with youth can also provide strategies for dealing with blatant forms of racism and discrimination (Rodriguez et al., 2009). Although, research on the relationship between family structure and its relevance to stereotype threat is in its early stages, the research thus far has suggested that a strong, cohesive family unit assists students in buffering and defending against stereotypes, misconceptions, and negative images they may encounter (Linnabery, Stuhlmacher, \& Towler, 2014).

The African-American family unit has experienced bigotry and prejudicial treatment from the days of slavery to the present. The decline of two-parent homes, increase in premarital children, and negative stereotypes about over-masculine wives and controlling husbands have all resulted in disruptions in the African-American family unit (Kelly, Maynigo, Wesley, \& Durham, 2013). However, despite the challenges, the family unit still plays a major role in buffering against injustices that African-Americans experience on a daily basis through stereotypes and microaggressions (Kelly et al., 2013). This confirms that, despite its challenges, the African-American family unit exerts protection for individuals in society. Family support is known to have positive effects during adverse circumstances for African-Americans: it is known to decrease depression and serve as a buffer against the stereotypes that they face every day (Vera et al., 2008). It is also a predictor of subjective well-being and mental and physical health (Kelly et al., 2013; Linnabery et al., 2014). The African-American family unit has remained a source of strength and support for its members against adversity and discrimination.

Overt discrimination against African-Americans and other minorities characterizes large portions of United States history. Discrimination has greatly affected 
the African-Americans plight in American society, ranging from their ability to succeed because of institutional racism; how they are perceived because of subtle racism; and how they perceive one's self because of internalized racism. African-American children will have experienced at least one instance of racial discrimination involving racial slurs and verbal insults between the ages of 10 and 12 (Spears Brown \& Bigler, 2005).

Research has also shown that discrimination is a persistent barrier that affects the health and well-being of African-Americans (Hope, Hoggard, \& Thomas, 2015). For instance, chronic and cumulative experiences of racial discrimination are associated with a number of negative biological and health outcomes, such as high blood pressure, increased risk for heart and cardiovascular disease (Hope et al., 2015). Psychological effects of racial discrimination on African-Americans ranges from depression, suicide, violence, stress disorders, maladaptive coping strategies, and substance use (Hope et al., 2015). These physiological and psychological effects seem to stem from the discrimination and perceived discrimination that African-American individuals encounter, especially since the discrimination they face stems from negative stereotypes.

\section{Rationale for the Study}

Research tells us factors such as poverty, parental style, socialization, and so on play a major role in an individual's susceptibility to stereotype threat (Cohen \& Sherman, 2005). However, there are no research studies that directly look at how FS and racial identity effect stereotype threat, as discovered by an exhaustive search done through EBSCOhost.

Existing research about stereotype threat focuses more on its outcomes than on specific factors that can influence or exacerbate it (Aronson \& Inzlicht, 2004; Davis, 
2012; Johnson-Ahorlu, 2013; Woodcock et al., 2012). This is noteworthy because it has been proven that the effects of discrimination among African-Americans can have a detrimental effect on their mental and physical health (Wegmann, 2017). In addition, the development of identity seems to be most malleable in the early 20 s, which coheres with the age bracket of college students (Carlsson, Wängqvist, \& Frisén, 2016). There is therefore, a need to investigate factors that may mitigate one's susceptibility to stereotype threat.

\section{Statement of the Problem}

Stereotype threat has had many effects on the African-American community over the years, in areas such as disidentification (Woodcock et al., 2012; Massey \& Owens, 2012); disruption to academic performance (Johnson-Ahorlu, 2013); and undue pressure to "not be the bad guy" (Fischer, 2010). It is undeniable that African-American college students are dealing with the impact of stereotype threat they have experienced in the past or are experiencing right now (Okeke et al., 2009). As a result, they feel as though they cannot "achieve high" or that they "do not belong" (Johnson-Ahorlu, 2013). These students constantly face subtle judgments based on broad stereotypes, microaggressions, and the pressure to resist and disprove negative assumptions about their intelligence (Fries-Britt \& Griffin, 2007). The effects of these negative assumptions and subtle judgements have been seen in recent reports of African-American graduation rates.

The U.S. News (2016) reported a decline in African-American college students' graduation rates from $45.5 \%$ to $38.1 \%$. It was also reported that even in schools where overall graduation rates have increased; the African-American graduation rate still declined (Camera, 2016). This is of concern because in 2003 African-American college 
students' graduation rates had surpassed those of their White counterparts (Camera, 2016). However, the reports suggest that because of the Black Lives Matters movement, reported racial insensitivity, and lack of representation African-American graduation rates have dropped (Camera, 2016). This suggests that minority students can both externalize and internalize negative stereotypes about themselves (Owens \& Lynch, 2012). The combination of these factors make achieving success stressful, especially when there is lack of a strong minority presence or social support structure.

Having a strong racial identity has been stated to act as a buffer against stereotypes, but if African-American students do not enter their universities with a strong racial identity, it can cause an emotional strain and create a sense of "otherness," (feelings of not belonging to the group or like an outcast) (Campbell, 2010; Gordon, 2012). It is plausible that this emotional strain and sense of "otherness" can then exacerbate their susceptibility to stereotype threat. When stereotype is present, students may disengage or disidentify from a particular domain (i.e. goal or aspiration) as a selfprotective measure (Woodcock et al., 2012). Therefore, as the college environment becomes more diverse, there must be an understanding of how stereotype threat can affect students and communities. Even more so, there needs to be an understanding of what factors guard against or exacerbate this threat.

\section{Purpose of the Study}

The purpose of this study was to investigate the impact of racial identity, FS, and perceived discrimination relationship on African-American college students' susceptibility to stereotype threat. 


\section{Conceptual/Theoretical Framework}

The conceptual framework will explore the interrelationships among BRI, FS, Perceived Ethnic Discrimination (PED), and Stereotype Threat. The following three theories (a) Cross' Model for BRI, (b) Circumplex Model for Marital and FS, and (c) the social identity theory; will be analyzed as the main theories behind stereotype threat and discrimination. Perceived links between the theories and these three variables will be explored.

The social identity theory is a social psychological analysis of the role of selfconception in group membership, group process, and intergroup relations. The intersectionality of these theories provide the foundation for how FS and racial identity affect stereotype threat. These theories look at how development is affected on a large and small scale by the interactions and belief systems of those around us and in our environment. The theories also look at how identity is developed in a social context and how this affects group memberships and prejudice.

\section{Tajfel's Social Identity Theory}

Henri Tajfel developed the Social Identity Theory out of a personal interest in social perception, social categorization, social comparison, prejudice, discrimination and intergroup conflict (Hogg, 2006). His theory is relevant because his concept on social identity plays a major role in stereotype threat and how someone perceives themselves. For instance, his research stated that people desire to see themselves in a positive light and feel threatened when their group is viewed negatively (Cohen \& Garcia, 2005). One may distance one's self from in-group members whose behavior reflects negatively on their group and this creates a fear that they may be defined by others on the basis of their 
group, especially if the association is negative (Cohen \& Garcia, 2005). Since stereotype threat is basically a fear of confirming negative stereotypes about one's racial group based on their actions, it is clear to see that Tajfel's social identity theory forms the basis of stereotype threat. According to Tajfel's theory, individuals wish to maintain a positive image of themselves and their group; and they feel threatened when their group is viewed negatively, which is stereotype threat (Hogg, 2006). Therefore, stereotype threat cannot manifest without the social identity theory because, one's desire to have a positive selfand group-image generates fear when this image is compromised. This is the essence of stereotype threat.

Tajfel's theory is broken down into a number of different components that serve different explanatory functions. For the purpose of this research, the focus will be on the components of group membership, social categorization, uncertainty reduction, categorization, and depersonalization, and their relationships to stereotype threat.

\section{Group Memberships (Racial Identity) Effect on Stereotype Threat}

The component of group membership is formed through social identity and is defined as how one identifies and evaluates themselves with others that have similar definitions of who they are, what attributes they have, and how they relate to and differ from people who are not in their group. An individual can have a number of groups with which they identify and one of those groups is race. The idea of group membership and social group identity lends itself to how one categorizes oneself in terms of race. Research states that group memberships help to define the world for individuals (Weisbuch \& Ambady, 2008). In a sense, this is a key component to how identity is 
developed, which is why race and racial identity are results of this concept. Racial identity is how people categorize themselves based on skin color, meaning that individuals define themselves in groups based on race and develop an identity as a result of it (Chavez \& Guido-DiBrito, 2001). An individual's group membership is important because, as with any group, in-group members are evaluated more positively than outgroup members (Weisbuch \& Ambady, 2008). Group membership fosters categorization, which contributes to phenomena such as stereotypes, and therefore stereotype threat can become a reality.

\section{Social Categorization, Uncertainty Reduction and Stereotype Threat}

The concept of categorization signifies that when one is categorized as a certain group member, this will then define how others see that individual (Hogg, 2006). This concept is the underlying principle for stereotype threat, because stereotype threat comes from the fear of confirming a stereotype or beliefs that others may have about their group (Hogg, 2006). Furthermore, within the concept of social identity lies the concept of uncertainty reduction. Uncertainty reduction states that people try to reduce subjectivity about their social world, in order to reduce anxiety. Thus, social categorization takes place in order to describe how people will and ought to behave (Hogg, 2006).

Although these categorizations may help to reduce anxiety, they are also the catalyst for prejudice and stereotypes (Hogg, 2006). One could fairly claim that through this concept of uncertainty reduction, stereotypes have become the norm in society and as a result, stereotype threat has become the problem. Meaning that individuals in society lean toward predictability, because it is easy. Stereotypes are a product of predictability 
and because of this; those who are targets of stereotypes constantly find themselves on guard against them. Social categorization has a major impact on individuals because it is an unavoidable and ubiquitous factor in human life; and for those who face it, can lead to depersonalization and categorization.

\section{Depersonalization, Categorization, Discrimination and Stereotype Threat}

Depersonalization and categorization happens when categorizing someone as a group member transforms how one sees them (Hogg, 2006). Therefore, instead of being seen as idiosyncratic individuals, people are seen through the lens of the prototype; that is they are measured against the prototype, and prototype attributes are then assigned to them (Hogg, 2006). Depersonalization occurs when someone is viewed as having attributes of these categories, which can then produce either favorable, negative, and even degrading perceptions (Hogg, 2006). Depersonalization is commonly called stereotyping, which is the basis of discrimination.

Discrimination is unjust or prejudicial treatment of others and it goes hand in hand with prejudice and stereotyping (Dovidio et al., 1996). Discrimination may also arise from depersonalization, and it can produce antisocial and aggressive behaviors toward and within the depersonalized group (Hogg, 2006). It is even believed that stereotyping predicates discrimination and since racial attitudes are seen as precursors to discrimination, one can see how perceived discrimination can lead to stereotype threat (Dovidio et al., 1996).

Stereotype threat, has in some instances, been defined as perceived discrimination, and some even argue that stereotyping and discrimination go hand in 
hand (Wegmann, 2017). Since discrimination seems to be defined as acting upon a stereotype, it is clear that stereotype threat comes from the belief that someone feels they are or will be discriminated against. Overall, stereotype threat and discrimination exist co-morbidly and both can have severe effects on an individual. This is why support systems, such as the family, are so necessary to buffer against its effects.

\section{Circumplex Model of Marital and Family Satisfaction}

The Circumplex Model of Marital and Family Systems was developed by David Olson and was used to measure a number of family components, including FS. This model consists of three key concepts, which are cohesion, family flexibility, and communication (Olson, 2011). In this model, cohesion is defined as the emotional bonding families enjoy; flexibility is the quality and expression of leadership, organization and role relationship and communication refers to the positive communication skills utilized in the family system (Olson, 2011). This model ultimately hypothesizes that balanced levels of cohesion, family flexibility, and positive communication are most beneficial to family functioning; conversely unbalanced levels of cohesion and flexibility are associated with problematic family functioning (Olson, 2011). Therefore, according to the Circumplex Model, the balance of these three areas within a family unit determines FS. For the sake of this research, FS will be defined as the balance of flexibility, cohesion, and communication effect on stereotype threat.

\section{Family Satisfaction Effects on Stereotype Threat}

The Circumplex Model is sensitive to ethnic and cultural diversity, and states that, “if a family’s expectations support more extreme patterns, families will then operate in a 
functional manner as long as all the family members like the family that way" (Olson, 2000). This means that, ironically "unbalanced family systems" may not be dysfunctional, especially if the family expectation supports certain behavior extremes (Olson, 2000). This is imperative to understanding the African-American family structure because their family structure often extends beyond the immediate, nuclear family and includes uncles, aunts, cousins, and "fictive kin" (Kelly et al., 2013). There is currently no research on the direct relationship between FS and stereotype threat, but research does suggest the racial socialization that occurs in the family does affect how individuals respond to racial hostility (Kelly et al., 2013).

Racial socialization in the African-American family arises out of positive behaviors, communications, and interactions between parents and children that help children to understand how they should feel about their heritage and respond to racial hostility or confusion in America (Kelly et al., 2013). Research confirms that the most influential and primary socializing agent is the family (Anglin \& Wade, 2007). This is mainly because African-Americans who experience discrimination are more likely to prepare their children for these experiences, creating a vigilance and buffer in youth (Anglin \& Wade, 2007; Kelly et al., 2013). If these youth can then adapt their vigilance for discrimination to the discrimination they experience, this leads to positive adjustments (Kelly et al., 2013). Therefore, FS, based on the concepts of balancing flexibility, communication, and cohesion is seen in how the African-American family communicates based on racial socialization, youth and family adaptation, and the functionality of the family unit. When all of these factors are present, it seems the African-American family 
is then better equipped to handle discrimination and hostility, which may be seen when stereotype threat is present.

\section{Cross’ Model of Black Racial Identity}

Cross' BRI Attitude Model, goes through five statuses (depending on which research one looks at) when interpreting racial information about themselves, other people, and institutions (Bianchi, Zea, Belgrave, \& Echeverry, 2002). Each stage helps the individual to cope with relevant racial information that they may be receiving. These stages follow a certain ascending order of evolution and complexity of expression (Bianchi et al., 2002). In addition, at any time one stage can dominate over the others, based on its effectiveness for dealing with racial information (Bianchi et al., 2002).

Cross' model postulates five statuses or stages: the first status is pre-encounter, when an individual internalizes how White society defines their racial group (Pierre \& Mahalik, 2005). This is where internalized racism is experienced without the individual being aware of it, and this can lead to one devaluing their racial group and minimizing and denying events (Bianchi et al., 2002). This is also the stage where individuals denigrate black culture and values, and idealize White culture and values (Pierre \& Mahalik, 2005). The second stage is encounter, wherein an individual has a personal experience or challenge with White or Black society, which leads them to question their "blackness" (Pierre \& Mahalik, 2005). The third stage is immersion, and this occurs when one begins to learn the meaning and value of their race and unique culture (Pierre \& Mahalik, 2005). However, this newfound interest may not be authentic and can create a distrust of Whites (Pierre \& Mahalik, 2005). Individuals in this stage may begin to show a strong preference and commitment to their group; these individuals are often 
hypersensitive to racial stimuli and engage in dichotomous thinking (Bianchi et al., 2002). The fourth stage is emersion, which is when one develops emotional and social bonding with Black people (Pierre \& Mahalik, 2005). The fifth stage is internalization, here a positive racial self and ability to objectively assess and respond to members of the dominant group develops. Individuals in this stage are able to recognize and resist multiple negative stereotypes and messages about their group (Bianchi et al., 2002). This is where an individual's Black identity is a self-affirming and valued aspect of themselves (Pierre \& Mahalik, 2005). Therefore, as one evolves in their racial identity, so does their susceptibility to stereotype threat.

\section{Racial Identity and Stereotype Threat}

Studies have shown that "knowledge that one's behavior could be used to reinforce a negative stereotype about one's group," can be distressing (Cohen \& Garcia, 2005). However, in order to be affected by the negative stereotypes, one has to be aware of them and their impact on one's racial group. One could argue that, as racial identity increases, one may become more susceptible to stereotype threat. Yet, research has shown that increases in racial identity have been known to predict positive in-group attitudes and high levels of self-esteem (Corenblum \& Armstrong, 2012). This may be related to the fact as one comes to terms with their racial identity they tend to move toward acceptance, but if their racial identity development is stagnant this can be problematic. For instance, underdeveloped racial identity can result in self-hatred, lack of self-acceptance, and feelings of inferiority and personal inadequacy. This stands in contrast to those who have come to terms with their race and what that means on a societal level (Anglin \& Wade, 2007). Therefore, in relation to stereotype threat it seems 
that those who have underdeveloped racial identity may be more susceptible than those who have developed their racial identity.

There are few known research studies that examine racial identity and stereotype threat directly. Yet, research has confirmed that higher levels of racial identification do buffer African-Americans against self-esteem and social threats (Davis, Aronson \& Salinas, 2006). Research also confirms that those who develop an inclusive racial identity as opposed to an Afrocentric one tend to have an easier time integrating into society and buffering against stereotypes (Anglin \& Wade, 2007). However, racial identity statuses can either buffer or amplify racial experiences according to various racial identity theorists like Cross and Helm (Davis et al., 2006). The racial identity status that has been known to play a protective role against social threats is internalization, as opposed to preencounter, which has been known to make one more susceptible to social threats and stereotypes (Davis et al., 2006). The research between stereotype threat and racial identity is limited, but the intersectionality between racial identity and AfricanAmerican's ability to handle racial stereotypes and social threats suggests that depending on one's BRI developmental stage, racial identity can act as a buffer or an amplifier of stereotype threat.

\section{Research Question and Hypotheses}

This study will seek to answer: does racial identity, FS, and perceived discrimination impact African-American college students' susceptibility to stereotype threat? The study hypothesizes that the theoretical model will fit the empirical model. The theoretical model is based on literature that suggested the various relationships 
between BRI, FS, PED, and stereotype threat, as illustrated by the model. For model please refer to Figure 1.

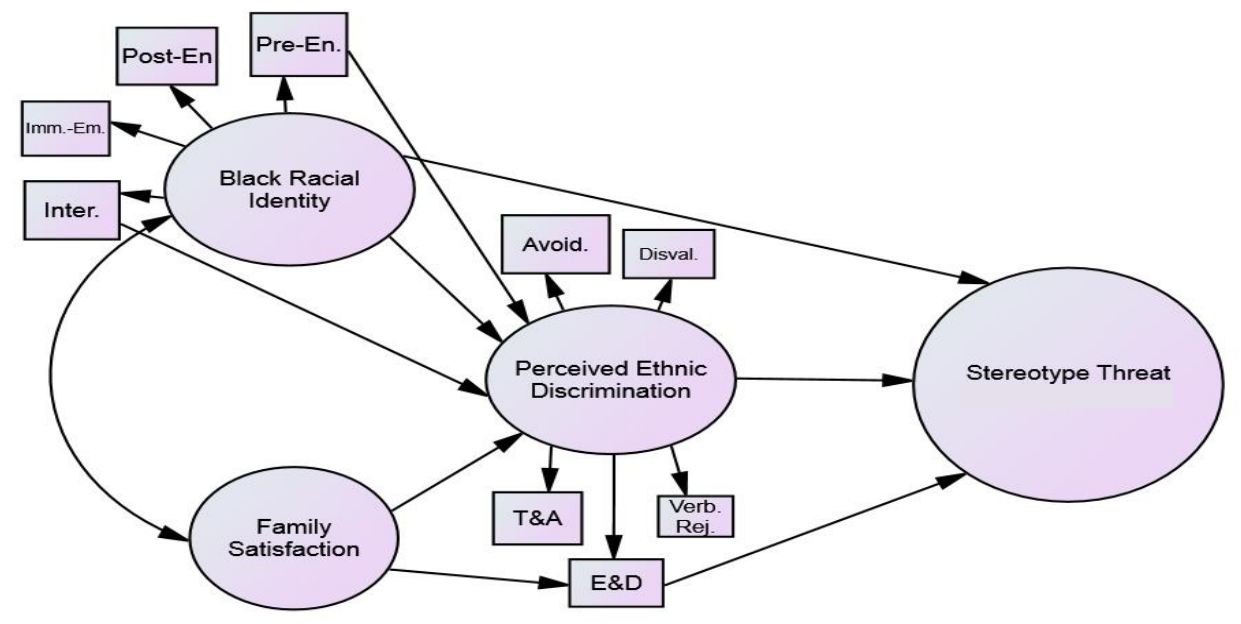

Figure 1. Hypothesized Model of Variables

\section{Significance of the Study}

The significance of this study is to contribute to the already growing body of research on stereotype threat and minority students, particularly African-American college students. Research has already shown that stereotype vulnerability hinders accurate self-knowledge, causing a blockage in intellectual ability (Aronson \& Inzlicht, 2004). These self-doubts and beliefs about one's self can cause unrealistic aspirations and fluctuation on "days of smartness" (Aronson \& Inzlicht, 2004). In addition, research has shown that African-American college students will disengage or disidentify from a particular domain (i.e. goal or aspiration) as a self-protective measure (Woodcock et al., 
2012). Therefore, as African-Americans engage in daily adversities, the question arises as to what can serve as a barrier against psychological vulnerabilities. Familial factors have been known to act as protective barriers for African-American students against stereotypes, and racial identity can serve as a buffering role against racial discrimination (Kelly et al., 2013; Lee \& Ahn, 2013). This study will add knowledge to the base by looking at racial identity and FS as factors that may contribute to African-American college students' susceptibility to stereotype threat. Therefore, this study will give further insight into the predictors of stereotype threat and possibly allow for further research to focus on: primary and secondary schooling, college and environmental factors such as home life and group membership.

Studying the correlations between FS, racial identity, and PED are essential because these are factors that are known to affect and correlate to African-Americans' susceptibility to microaggressions and adversities. This information can then be used as a catalyst to build programs to end (or at least buffer against) the phenomenon and, in some manner, level the playing field. It has been proven that the African-American family unit creates a "safe space" for African-American families to go to and discuss racial discrimination and disparities they may experience (Kelly et al., 2013). In addition, FS is one of the most important contributors to an adult's subjective well-being and life satisfaction (Baker, 1998). Racial Identity also serves as a buffer against discrimination, suggesting that when African-Americans view their own race as liked, they will have a higher regard for themselves despite discrimination (Lee \& Ahn, 2013). This is important because the psychological and physical effects of discrimination continue to grow and this is something with which African-American students routinely have to cope (Bourke, 
2010; Hope et al., 2015). It seems that these factors influence stereotype threat, in some fashion, and understanding their relationship to stereotype threat and addressing them in formative years (i.e., college) can potentially lead to ways to strengthen the mental and physical health of African-Americans.

This area of research is important for the Counseling Psychology field because it could expand the knowledge base about factors that make African-American students more susceptible to stereotype threat. This is important because there has been a decline in African-American graduation rates over the past 10 years. It has been suggested that this is because of the rise of racial tensions, racial insensitivities and lack of representation that these students experience at their schools (Camera, 2016). Therefore, knowing and understanding what factors affect and protect African-American college students from stereotype threat may provide schools with the knowledge to make the proper accommodations to ensure that these students are getting what they need on their campus and increase their graduation rates. Ultimately, this research can help academic institutions bolster the success of African-Americans and other minority students. Knowing what could buffer African-American college students from bearing the negative effects of stereotype threat could shield them from mental and medical health issues later on in life.

This study will also add to the field of Counseling Psychology by providing insight into the effects of discrimination faced by African-Americans. This knowledge will allow counseling professionals to create more informed interventions and increase their knowledge base. Overall, a number of groups will benefit from this study, including counselors, therapists, professors, and minority groups themselves. This study will enable 
these groups to provide services that can take into context the effects of stereotype threat and account for them in their intervention and teaching styles. In addition, this information could be beneficial in combating and buffering for stereotype threat factors for counseling psychologist, educators, advisors and administrators.

\section{Definition of Terms}

- Achievement Gap: an overall academic performance disparity (Davis, 2012).

- Black Racial Identity Level 1(BRI-InitialStages): Refers to the first three stages of BRI (conformity, dissonance, and immersion) and the correlation among them.

- Black Racial Identity Level 2 (BRI-LatterStages): Refers to the latter two stages of BRI (emersion and internalization) and the correlation among them.

- Collective Threat: individuals are concerned about the potentially stereotypeconfirming acts of other members of their group (Cohen \& Garcia, 2005).

- Disidentification: to place distance between themselves and the stereotype domains (Woodcock et al., 2012).

- Family Satisfaction: response to present family functioning as compared with an individual's inner sense of what is desirable (Olson, 1986).

- Group Membership: defined as a way one identifies and evaluates him or herself in the same way and has the same definition of who they are, what attributes they have, and how they relate to and differ from people who are not in their group (Hogg, 2006).

- Intercorrelations: correlation between the members of a group of variables and especially between independent variables (Intercorrelation, n.d.) 
- Microaggression: A subtle but offensive comment or action directed at a minority or other nondominant group that is often unintentional or unconsciously reinforces a stereotype: such as "I don't see you as Black."(Microaggression, n.d.)

- Perceived Discrimination: perceiving discrimination, depending on the position of one's group in the social structure. For members of disadvantaged groups, attributions to prejudice are likely to be internal, stable, uncontrollable, and convey widespread exclusion and devaluation of one's group. For members of privileged groups, the meaning of attributions to prejudice is more localized (Schmitt \& Branscombe, 2002).

- Race: a construct based on observable physical characteristics that have acquired socially significant meaning (Blank, Dabady, \& Citro, 2004).

- Racial Discrimination: actions executed by members of a dominant racial group that have negative or differential effects on members of nondominant racial groups (Hope et al., 2015).

- Racial Identity: How people categorize themselves based on skin color (Chavez \& Guido-DiBrito, 2001)

- Racism: The generalization, institutionalization, and assignment of values to real or imaginary differences between people in order to justify a state of privilege, aggression, and/ or violence (Bulhan, 2011).

- Stereotype Threat: a situational predicament in which individuals are at risk, by dint of their actions or behaviors, of confirming negative stereotypes about their group (Shin et al., 2011, p.5-6). 


\section{Limitations}

This study will face certain limitations because of time, money, and availability of subjects. Limitations include the variability of subjects, because subjects were taken at random from various colleges across the country the researcher cannot be certain of the location, gender and length of schooling of subjects. In addition, since subjects were assessed through self-report measures and surveys, honesty will be a variable because truthfulness of the subjects' cannot be certain. Meaning that it is possible for participants to adjust their answers to what they feel is acceptable, rather than their true-life experience. Yet, the nature of this study required self-report because it was based on personal experience. Finally, knowledge of the subjects' background, socioeconomic status, and experience with the majority race will be unknown and therefore cannot be controlled.

Several other limitations should also be considered with this study. One of the greatest being that my study utilizes a nonexperimental research design, meaning that my results speak to correlation and prediction but not causation. This particular design was appropriate for this study because it looked to measure variables that occur in the environment rather than an experimental context. In addition, experimental manipulation of the variables of interest, may have affected their authenticity.

\section{Delimitations}

Some delimitations that have been placed on this study due to time, money, ease of capture, and location. These delimitations are:

Students chosen had to be African-American and attending college, in order to ensure consistency and minimize extraneous variables. This study was also limited to 
only college students, which also limits my sample to those with the basic means and knowledge needed for getting to college. This may also limit my study to those who possess the minimal intellectual functioning needed to get to college.

My survey was also taken online, which limits my sample to those who have internet access, are comfortable with the internet, and are among Qualtrics pool of respondents that were recruited for the purpose of this study. Regardless, the online approach did allow for data collection from individuals who are heterogeneous in age, geographic location, socioeconomic status (SES), and sex.

My data was analyzed using structural equation modeling meaning that my results are based on the degree of fit observed between my resulting SEM model and the data from the current sample. Therefore, different models, with the same or similar variables, may be an even better fit for the data.

\section{Organization of the Study}

This study is organized into five chapters. Chapter 1 provides the background of the study and contains the statement of the problem, the purpose of the study, the significance of the study, limitations and delimitations of the study, research questions, definition of terms, conceptual framework, and the organization of the study.

Chapter 2 presents a review of literature related to the factors of racial identity and self-esteem as correlates of stereotype threat among African-American college students. The sections included in Chapter 2 are: overview of racial discrimination and stereotypes, overview of identity in the United States, types and models of identity, racial identity and the American experience, racial identity of African-Americans, racial identity of African-American college students, a conceptual overview of familial effects, 
FS and the African-American experience, FS and African-American college students, conceptualization of stereotype threat, stereotype threat and discrimination, AfricanAmerican susceptibility to stereotype threat, stereotype threat in academic institutions, stereotype threat among African-American college students, and the effects of stereotype threat among African-Americans.

Chapter 3 presents the sampling process, the population included in the study, and the methodology used: This includes the research questions, research design, instrumentation, data collection procedures, and administration of data collection and analysis.

Chapter 4 shows the results and the data analysis of the study, the statistical analysis, and the tables that show the relationship between the variables.

Chapter 5 contains a summary of the study and seeks to integrate the results based on current theory and research, highlights a brief discussion about the most important findings of the study, delineates conclusions, and makes recommendations for practice and future research. 


\section{CHAPTER 2}

\section{REVIEW OF THE LITERATURE}

\section{Introduction}

Stereotype Threat is a situational predicament in which individuals are at risk, by dint of their actions or behaviors, of confirming negative stereotypes about their group (Inzlicht \& Schmader, 2011, p.5-6). It comes out of prejudice and discrimination and is socially prevalent in the United States, especially among African-Americans. This is because the United States is a country steeped in racism, dating back to the colonial era, when enslaved Africans were ripped from their countries and forced to work in the "new" America. Race more than any other feature contributes to almost every life decision, opportunity, and circumstance, whether it is conscious or unconscious. It affects every facet of an individual's life. Though some have come to acknowledge and accept it, few have stopped to analyze how things, such as microaggressions, affect an individual selfesteem, success, and identity. One of the many aspects that make up a person's selfesteem is their racial identity, which is a "sense of group or collective identity based on one's perception that he or she shares a common heritage with a particular racial group" (Chavez \& Guido-DiBrito, 2001). This concept of self can have an effect on how one sees him or herself and how others see them. For instance, when it comes to race, one can easily be depersonalized from their idiosyncratic self and be negatively grouped. When this happens stereotype threat can occur. 
If stereotype threat becomes present when African-Americans are the minority and stereotypes are present, the question arises, what could buffer against the effects of stereotype threat. This is a question that this researcher seeks to answer, because it is interesting to see if stereotype threat can be eliminated or decreased, since it is evident that it is a real and affective variable. One way this could be explored is to see how factors such as, racial identity, FS, and PED affect one's susceptibility to stereotype threat. Therefore, this literature review seeks to assess the effects of racial identity, FS, and PED on African-American college students' susceptibility to stereotype threat.

While there are many articles on African-Americans, stereotype threat, racial identity, and discrimination, there were few found on FS. Therefore, the articles chosen reflected things like family functioning and family cohesiveness. In addition, articles that focused on stereotype threat and its effect on African-Americans academics or AfricanAmerican response to stereotype threat were also used. Articles were taken from only credible databases, such as ERIC and PsycARTICLES, Ebsco, PsycNet, PsycInfo, Google Search Engine, MelCat, and James White Library at Andrews University. Another main factor taken into account was the purpose of the study. Articles on the effects of racism and stereotypes, stereotype threat \& vulnerability, discrimination, PED, as well as racial identity and identity development were sought after and used. Although not every article mirrors the topic of study, every article contributes to the foundation and framework of this research study and is explained further below. Keywords used were as follows: Historically Black Colleges and Universities (HBCUs), blacks, stereotype threat, stereotype vulnerability, discrimination, PED, identity development, familial effects, academic success, vulnerability, resiliency, stereotypes, motivation, success, cultural 
awareness, and Predominantly White Institutions (PWIs). Articles were from both online and hardcopy, and they were located in a variety of journals such as The Journal of Counseling Psychology and The Journal of Race and Crime. Articles were eliminated if they were older than 50 years or not peer reviewed. It is my hope that this literature review will reveal the available background on this subject and reinforce the need for research in the study of The Effects of Racial Identity, FS, and PED on African-American college students' susceptibility to stereotype threat.

\section{Stereotype Threat, African-Americans \& College Settings}

A Conceptual Overview of Stereotype Threat

"A fearful reaction to dangerous things is one of the most fundamental human experiences" (Schaller, Park, \& Muller, 2003). When those reactions begin to be aimed towards people and not things, stereotypes are born and discrimination manifests. Stereotypes can be defined as gross generalizations that are usually applied to people that share some type of characteristics (Johnson-Ahorlu, 2013). It is puzzling to try to identify what causes stereotypes to come forth and flourish when the "evidence" backing these stereotypes have yet to be set in stone. Schaller, Park, and Muller (2003) state that "ego and realistic threats" can be a facilitators and activators of prejudice. Ego threat is seen as the challenge to a person's self-esteem, while realistic threat is a challenge to one's status, economic standing, or intergroup conflict (Schaller et al., 2003). A major tenet for the basis of stereotypes are "feelings of vulnerability to physical danger" (Schaller et al., 2003).

Some may state that racial stereotypes do not affect interaction or how one may be perceived. The reality is that these stereotypes have been proven to affect identity 
development in children (Okeke et al., 2009). In addition, research has shown that by middle school, African-American adolescents are aware of academic race stereotypes and some even have the tendency to endorse them and be affected by them (Okeke et al., 2009; Wasserburg, 2014). Stereotype threat has also been found to affect the neurological functioning of African-Americans (Thames, Hinkin, Byrd, Bilder, Duff, Mindt \& Streiff, 2013). Furthermore, a study that looked at how neighbors perceived criminality and the black population, it was found that racial stereotyping does not predetermine the "risk" in a neighborhood (Pickett, Chiricos, Golden, \& Gertz, 2012). The indication is that because people may have stereotypes about individuals in a certain area does not automatically make the area an undesirable place to live or a place with negative factors such as: high unemployment, crime, and/or drug use (Pickett et al., 2012). Despite these findings, it seems that stereotypes do have an effect on the perception and treatment of Blacks, leaving us with the question: how do these stereotypes affect those who receive them?

Stereotype threat is a powerful force that can have an effect on almost any minority group, especially in the academic setting. It seems that when stereotypes are present, there is an anxiety to resist confirming the stereotypes that causes the individuals who are victims of that stereotype to unconsciously depress the matter at hand (JohnsonAhorlu, 2013). Some research suggests that "individuals who belong to a group for which there is a negative stereotype about them, may be vulnerable to underperformance in the domain to which the stereotype pertains, especially if it is important to their identity" (Fischer, 2010). Research confirms that African-American adolescents are aware of the stereotypes about their race, and when in "stereotype threat conditions" individuals will 
underperform in comparison to those who are "nongroup members" (Okeke et al., 2009; Wasserburg, 2014).

In a qualitative study that held focus groups at seven different campuses consisting of 94 students per campus; campus climate, policies, and co-curricular environments were studied. The studies revealed that stereotype threat can actually decrease working memory capacity (Johnson-Ahorlu, 2013). This means that individuals who feel the stress of stereotype threat experience a hindrance in their ability to focus on a single task while remaining "unfocused on task-irrelevant thoughts" (Johnson-Ahorlu, 2013). Even when an individual attempted to "suppress" the emotion or anxiety that is the result of stereotype threat, the act of trying to ignore or suppress the anxiety or emotion still taxes the memory resulting in a hindrance of one's memory (JohnsonAhorlu, 2013). Therefore, it seems that the very presence of stereotype threat results in the "disruption of academic performance" (Johnson-Ahorlu, 2013). This disruption can lead to disidentification.

Leaving the group or divestment is something that can happen when AfricanAmericans succumb to stereotype threat (Massey \& Owens, 2012). African-American college students will disengage or disidentify from a particular domain (i.e., goal or aspiration) as a self-protective measure (Woodcock et al., 2012). This disidentification can eventually lead to abandonment, meaning that these individuals will give up a goal or desire because it "does not fit" into "their continuum of capabilities" according to the stereotype (Woodcock et al., 2012). For example, women may lose interest in doing well in math because of stereotypical beliefs, or blacks may cease to care about academics because stereotypes state that they cannot do these things. Thus, they disengage and 
eventually disidentify (Woodcock et al., 2012). This is a major issue because these students are not only putting themselves at a disadvantage but also disserving society as a whole because; as they disengage from challenging academics, they cripple themselves from being able to fulfill professions that require higher education. This results in these professions having a less diverse talent pool to pull from (Woodcock et al., 2012). Therefore, it could be said that disidentification is one of the more dangerous effects of stereotype threat.

Disidentification happens when a valued "social identity" is reduced or abandoned (Woodcock et al., 2012). Although social identities are constantly changing for groups that are stigmatized, they experience a high level of negotiating and renegotiating their "social identity" in order to maintain normal psychological functioning (Woodcock et al., 2012). It seems that the more one's identity and self-worth are placed within a particular "stereotyped" domain, the more threatening the stereotype becomes along with a greater fear of conforming to it (Woodcock et al., 2012). This leads to the individual putting (psychological) distance between the stereotyped domain and the threat, resulting in disidentification (Woodcock et al., 2012; Yip, 2016). It seems that where stereotype threat is present, domain disidentification takes place as a defense mechanism resulting in impaired performance and separation between the "stereotyped" domain and self (Woodcock et al., 2012). As this cycle continues, the individual will eventually abandon the domain when their "self-worth is no longer linked to performance in that domain" (Woodcock et al., 2012).

A study that looked at 1,420 African-American and Hispanic science students revealed that African-Americans' experience of stereotype threat did not have as strong a 
positive correlation with disidentification, as it did for the Hispanic students (Woodcock et al., 2012). This suggests that African-American students may buffer against stereotype threats by "discounting performance feedback" (Woodcock et al., 2012). However although the correlation was not as large as the Hispanic case does not mean that disidentification is invalidated. This is because, as long as stereotype threat is present, these students have an extra stress placed on them to push back and not conform to the stereotype.

Stereotype threat is not something that cannot stand on its own. Beliefs about the individual have to come from somewhere, and the individuals on the receiving end of them have to feel as if others have certain perceptions about them. Research, has suggested that negative beliefs about blacks can have "a subtle but biasing influence on the way that people perceive individuals, process information, and form judgments, even absent of any conscious bias on the part of those doing the perceiving (Najdowski, Bottoms, \& Goff, 2015). For example, it seems that teachers' stereotypes have a great effect on a students' success or failure. This is so because, as research suggests, "a student's awareness of stereotypes of one's group can create internal barriers to success and achievement by raising feelings of anxiety and self-doubt" (Chang \& Demyan, 2007). In fact, research suggests that teachers actually hold lower expectations for their black students when it comes to academic ability and performance (Chang \& Demyan, 2007). They also view black students as more likely to be disruptive, and they are more likely to refer such students for disciplinary action and special education services (Chang \& Demyan, 2007). Unfortunately, it seems that in the school setting, Black students are also more likely to be ignored even if they have a high academic performance or are 
considered gifted (Chang \& Demyan, 2007). In a study that focused on the stereotype vulnerability of Black students, it was discovered that priming racial identity caused black students to underperform on standardized test in comparison to their White counterparts, even when the test was not presented as a diagnostic of intellectual ability (Chang \& Demyan, 2007). Studies go on to reveal that in the academic context, the impact of social stereotypes is truly manifested and can be upheld easily if these stereotypes are seen to be perpetuated by those in authority, particularly the teacher (Chang \& Demyan, 2007).

Stereotypes and stereotype threat can create a pressure for students to feel that they have to be watchful of their own behaviors because they do not wish to confirm stereotypes (Fries-Britt \& Griffin, 2007). To some extent students may feel they have to "carry themselves" in a certain way in order to not confirm societal stereotypes (FriesBritt \& Griffin, 2007). Some students are even made to feel as if they are "tokens," meaning that they feel the only reason they are invited to a club or outing is because they are an "upstanding" black individual and can be considered the "black friend" (Fries-Britt \& Griffin, 2007). This causes a student not to be able to be his/herself because they may feel that they have to act counter to what the stereotypes portray, and purposely act incongruent to stereotypes to debunk myths. Having to constantly counter can place a great amount of stress on any minority group, but especially African-Americans.

\section{Stereotype Threat Among African-Americans}

Stereotype threat affects African-Americans on a number of scales, whether intellectual, physical, or mental. The fact that stereotype threat permeates so many areas of the life of African-Americans is astounding. It could be argued that minorities should 
be able to fight against and "rise above" stereotypes and discrimination, but this would take an extreme amount of energy (Inzlicht, Tullett, \& Gutsell, 2011). Using this amount of energy consistently can lead to a state of ego depletion, which is a state of compromised reserves of self-control, resulting in having little mental energy to overcome environmental temptations and override urges, emotions, and automatic response tendencies (Inzlicht et al., 2011). Research has shown that managing negative stereotypes involves coping strategies that engage executive function. However, because these resources are limited, having to use them on a regular basis can result in poorer self-control and can lead to a number of maladaptive behaviors (Jamieson \& Harkins, 2007). Some research suggests that stereotype threat occupies working memory resources, which inhibits one's ability to control impulse responses (Jamieson \& Harkins, 2007). In addition, having to be aware and fight stereotypes in certain domains can have "spillover" effects, which leads to maladaptive behaviors in unrelated domains (Inzlicht et al., 2011).

Having to cope with stereotype threat is "ego depleting," meaning that it has the capability to spill over into other domains of one's life (Inzlicht et al., 2011). Research has shown that coping with stereotype threat could lead to aggression, overeating, risky decision-making, and problems maintaining attention (Inzlicht et al., 2011). For example, in a study that looked at decision making when individuals were exposed to "threat" before a lottery task, they would make automatic, intuitive, and risky decisions, as opposed to those who experienced the "threat" afterward (Inzlicht et al., 2011). One study that looked at how Blacks respond to negative stereotypes about intelligence, reported that Black students will underperform when this stereotype is present (Najdowski et al., 
2015). In addition, stereotype threat or perceived discrimination can have long-term effects on those who have to cope with it on a daily basis (Inzlicht et al., 2011). The psychological, mental, and physical changes that occur can have serious effects on health.

Research has shown that perceived discrimination (or stereotype threat) predicts depressive symptoms later on. It has also been related to anxiety, rebellious behavior, post-traumatic stress disorder, and overall reduced well-being (Inzlicht et al., 2011). Even when factors such as socioeconomic status, education and employment are controlled for, the discrimination-health link is still valid (Inzlicht et al., 2011). For instance, there is a link between perceived discrimination and not only mental health, but also physical health (Inzlicht et al., 2011). Studies have proven that increases in disease, obesity, hypertension and self-reported poor health are related to higher levels of perceived discrimination (Inzlicht et al., 2011). For example, in a longitudinal study that looked at breast cancer, it was found that incidents of breast cancer were higher among women who reported frequent daily discrimination, even when controlling for breast cancer risks (Inzlicht et al., 2011). The effects of stereotype threat goes beyond academia, seeping into everyday life occurrences, affecting minority students' health and functioning (Inzlicht et al., 2011). Dealing with perceived discrimination or stereotype threat on a regular basis can have severe and detrimental impacts on the individuals who face it.

Criminality is one of the ways that stereotype threat has detrimental impact on Black Americans (Najdowski et al., 2015). Research has shown that the black criminal stereotype can influence entities of power, such as police officers (Najdowski et al., 2015). This stereotype has led to the concepts of race and crime to be linked, therefore associating one with the other (Najdowski et al., 2015). Which leads to Blacks being 
hyper-vigilant when around police officers and engage in self-regulatory behaviors that are perceived as indicators of deceptions, which makes blacks more likely than Whites to be misclassified as guilty by the police (Najdowski et al., 2015). A study that looked at the intersectionality of race and gender reported that Black participants as a whole report higher concerns of being racially stereotyped by the police, and Black men fear of being treated as criminals, while Black women become socially invisible (Najdowski et al., 2015). Environments that produce hyper-vigilance increase African-Americans' stereotype vulnerability and is particularly prevalent in academic institutions (Fries-Britt \& Griffin, 2007).

\section{Stereotype Threat in Academic Institutions of Higher Education}

Stereotype vulnerability is "the tendency to expect, perceive and be influenced by stereotypes about one's own social category" (Aronson \& Inzlicht, 2004). In a study that examined if African-American students have an unstable academic efficacy due to stereotype vulnerability, as a result of selling themselves short by believing they know less than they actually do (Aronson \& Inzlicht, 2004). The results yielded that AfricanAmerican students who experience stereotype vulnerability do in fact underestimate their academic ability and experience an unstable academic efficacy (Aronson \& Inzlicht, 2004). One may fairly concede that stereotype vulnerability hinders accurate selfknowledge causing a blockage in intellectual ability itself. These self-doubts and beliefs about one's self can cause unrealistic aspirations and fluctuation on "days of smartness" (Aronson \& Inzlicht, 2004). In addition, stereotype vulnerability can create a mistrust of performance feedback, sustain and heighten stereotype threat (Aronson \& Inzlicht, 2004). 
Having to deal with stereotype vulnerability and threat can cause African-Americans to under/overestimate their potential and to be hesitant to accept and ultimately grow from feedback, both of which work against their ability to excel in school (Aronson \& Inzlicht, 2004).

Since stereotype vulnerability creates a sense of inadequacy, it hinders a student's potential to excel in school. It also hinders academic potential because it affects students' self-concept, and self-concept is important to academic excellence (Okeke et. al., 2009). Research has indicated that a "child's perception of stereotypes directly influences perceptions of his or her own competence" (Okeke et al., 2009). Basically, if a child feels he/she will do well, he/she will, but the same holds for poor/low expectations. Therefore, positive beliefs will lead to greater striving in African-American youth (Okeke et al., 2009).

In a study that was used to grasp the beliefs of Asian, Black, and White students, 188 teachers were given surveys and asked to list six traits that best described Asian, Black, and White children. They were also given a list of adjectives and asked to judge the percentage of Blacks, Whites or Asians that possess each trait (Chang \& Demyan, 2007). The results strongly concluded that there was a uniform and pleasant stereotype about Asians; however, for Blacks and Whites, there were both strongly negative and strongly positive associations respectively (Chang \& Demyan, 2007). These findings suggest beliefs about Asians were congruent with the 'model minority' concept, but for Blacks and Whites, the beliefs did not fall into either one category but rather both. Suggesting that a teacher's beliefs about a certain race or "group of students" is more complex than once believed but it does not diminish the fact that these teachers still held 
automatic stereotypic beliefs about their students (Chang \& Demyan, 2007). Whether teachers hold a positive or negative stereotype about their students, the reality is that no stereotype is a "good" stereotype. Therefore, when a teacher comes into a classroom with anything other than a blank slate about their students, it puts undue pressure and hardship on their students and unfortunately upholds and perpetuates stereotype vulnerability and threat, especially for African-American students.

It has been observed that "virtually every measure of academic achievement taken at every level of schooling shows African-Americans trailing their White counterparts" (Aronson, Fried, \& Good, 2002). Stereotype threat creates an emotional burden for African-American students that manifests itself as a performance-disruptive apprehension (Aronson et al., 2002). Since stereotypes stem from racism, individuals who perceive them can incur a multitude of psychological stress responses (Clark, Anderson, Clark, \& Williams, 1999). These stress responses can include "anger, paranoia, anxiety, helplessness, frustration, resentment and fear" (Clark et al., 1999). These stress responses can lead to anger suppression, hostility, aggression, frustration, depression, distrust, or paranoia (Clark et al., 1999). Stereotype threat undermines academic achievement in the sense that it impairs performance by inducing anxiety and disidentification, especially if one does not have a high level of private regard (Arson et al., 2002; Yip, 2016). In fact, studies show that stereotype threat causes African-Americans to be more likely to divest from academics than Whites (Arson et al., 2002). One can conclude that since identifying with academics is essential for success in school and college, this threat acts as a barrier that blocks African-Americans from reaching their full academic potential. In a study that looked to prove the theory of malleability, the results showed that if African-Americans 
are encouraged and taught about malleability, then their attitudes toward their own intelligence change in a positive way and they do not feel crippled by stereotype threat (Aronson et al., 2002). However, it seems that even in this study, where stereotype threat was controlled for the effect of "suspicions of intellectual inferiority," it still caused these students to score significantly below their White counterparts (Aronson et al., 2002). This suggests that even though stereotype threat was controlled for past damage, it still affects students and in order to truly combat stereotype threat one must not only reduce the threat but also the negative responses and perceptions that it spurs (Aronson et al., 2002). African-American students have to find a way to deal with the side effects of the threat, even if the threat itself is reduced.

When an African-American student is in an environment, where they are made to feel inferior or under constant scrutiny because of stereotypes, their education is in jeopardy. This is because stereotype threat creates an unnecessary struggle for these students; these students will start an unnecessary internal war not to confirm stereotypes ascribed to them (Johnson-Ahorlu, 2013). In fact, in one qualitative study, students stated that because of the presence of stereotypes on campus, they had a "responsibility to prove that African-Americans are smart, intelligent, and legitimate members of campus (Johnson-Ahorlu, 2013). Being a minority can also have a great effect on whether stereotype threat is present (Johnson-Ahorlu, 2013). Overall, it is evident that stereotypes and stereotype threat can be harmful to African-Americans' academic performance, degree completion, and self-esteem (Johnson-Ahorlu, 2013). The reality of stereotype threat is that it comes at a high cost and adds another obstacle for African-American students. 


\section{Stereotype Threat Effects on African-American \\ College Students}

College represents a unique challenge for all incoming students mostly because it is a new setting with new freedoms. One unique challenge that African-American college students specifically face are the effects of racial discrimination and perceived racial discrimination in this new setting (i.e. college). Discrimination can have detrimental effects on African-Americans' psychological and physiological well-being especially in emerging adulthood, which is usually the developmental stage college students are in (Hope et al., 2015). In addition, research has shown that identity development continues into the late 20s, which is typically when students are in college (Carlsson et al., 2015). Therefore, the perceived effects that racial discrimination and stereotype threat have on African-American college students is especially salient in college years. This is exactly what African-Americans face when they encounter stereotypes in the academic setting; in fact, African-Americans are one of the only groups to highlight the issues of race as a barrier. The pressure not to confirm the stereotypes and the fear of falling into them can be so great at times that African-American students cannot work to the best of their abilities. In a study that interviewed African-American college students (at a 4-year university) about their academics, some replied that, "You're looked down upon or it is assumed that you're not going to achieve at a high level" (Johnson-Ahorlu, 2013). Others said, "Once you get into the university, there's an expectation that students of color are not going to do well” (Johnson-Ahorlu, 2013). Plainly having to deal with preconceived notions and opinions about one's race can create a disconnect between African-American students and their peers, and may even cause them to feel inferior (Johnson-Ahorlu, 2013). Having to deal with the constant quandry of "do they belong" can cause these 
individuals to feel rejection, anger, and sadness (Johnson-Ahorlu, 2013). Curiously, individuals on the receiving end of these stereotypes may not even believe the stereotype about themselves, but if they are aware of them, they may inevitably feel pressure to fight them off (Fischer, 2010). These emotions are usually the precursor to anxiety and pressure, and ultimately the foundation to stereotype threat.

The simple presence of stereotypes and stereotype threat can create a hostile atmosphere for African-Americans attending college. One could even go as far to say that these students do not get the luxury of "finding themselves" in college because they are too busy debunking racial stereotypes and proving their worth. In a study that examines the collegiate experience of a group of high achieving blacks, the results were quite intriguing and even saddening: the students observed these high achieving blacks have to constantly face subtle judgments based on broad stereotypes, micro aggressions, and the pressure to resist and disprove negative assumptions about their intelligence (Fries-Britt \& Griffin, 2007).

On college campuses, African-American students not only have to fight against the "affirmative action" stereotype but also prove their worth (Fries-Britt \& Griffin, 2007). These students stated that it seemed that White students felt the need to compare scores on tests to ensure they did better than Black peers (Fries-Britt \& Griffin, 2007). One student even claimed that her roommate stated that, "Blacks do worse on SAT because they're just dumber" (Fries-Britt \& Griffin, 2007). These instances of ignorance may be discounted for a while, but over time these circumstances do tend to 'chip away' at the self-confidence of African-American students, especially since their academic ability is being questioned (Fries-Britt \& Griffin, 2007). Some of the students who 
participated in the study showed that, despite trying to overcome the stereotypes, they would internalize and unconsciously have to deal with the anger and hurt that these stereotypes caused (Fries-Britt \& Griffin, 2007). Therefore, the mere presence of stereotypes and stereotype threat not only give black students a disadvantage but also create hurdles for these students that result in decreased self-confidence, alienation, and disidentification. At its worst, this can even lead to withdrawal from the academic atmosphere (Fries-Britt \& Griffin, 2007).

Stereotype threat may not be the only cause for the differences in AfricanAmerican success in the college setting. One study proved that to be true; it found that parents' educational background had a significant correlation to college GPA (Fischer, 2010). Yet when controlling for parental SES and college level, the results indicated black and Hispanic students fared less well than their White and Asian counterparts (Fischer, 2010). Although stereotype threat may not be the only factor-influencing outcome among this community, it is safe to say that stereotype threat puts an undue performance burden on African-American students (Fischer, 2010).

Performance burden occurs when students feel the pressure to perform a certain way in order not to succumb to stereotypes about their race or group of people with which they associate themselves (Fischer, 2010). This also has an effect on the individual's GPA and can be seen as another reason for lower GPAs. Students who felt performance burdens had lower grades, less motivation to study, and lower likelihood to enjoy college life and graduate on time (Fischer, 2010). Clearly being a minority in college may have a negative effect on the overall performance of black students; and studies have shown that having a same race professor actually moderates the impact of 
negative stereotypes on performance (Fischer, 2010). It is likely that when one is surrounded by their own race they may be less likely to experience stereotype threat, which is essential because stereotype threat has detrimental effects on both physical and mental health of African-Americans.

\section{A Conceptual Overview of Family Satisfaction}

Family is defined as a group of people who are related to one another; it can be made up of parents and children, or cousins, uncles and aunts (Family, n.d.). Some definitions even state that family is a group of people united by certain convictions or a common affiliation (Family, n.d.). Ultimately, "familiness" is a construct and some may argue that families are invisible (Bell \& Bell, 1989). This concept is based on the belief that one does not "see" families but instead a man or woman in the presence of children, and it is "infer[-red]" that they are a family (Bell \& Bell, 1989). This construct of "familiness" is something that affects how someone navigates through life and his or her well-being.

It has been found that FS is one of the most important contributors to an adult's subjective well-being and life satisfaction in children (Baker, 1998). The reason for this could be related to the interconnectedness that is demonstrated in family units and the effects it has on the members' thoughts, feelings, and actions (Kerr, 2000). Research has shown that families with at-risk and poor-achieving students experience many difficulties that make it difficult to support their children and school performance (Baker, 1998). Yet despite the difficulties that at-risk families face, they have been consistent with providing warmth, care, connection, structure, family cohesion, and autonomy that is linked to cognitive, emotional, and behavioral competence (Skowron, 2005). The structure and 
stability that these families provide seem to allow these children to flourish and confirms the concept of the family strengthening the individual.

The concept that one is a part of a whole comes from a systems theory, and in context of family, it signifies that in order to understand an individual, one must understand the family unit (Nichols, 2014). Signifying that who a person becomes, comes out of the relationships of those around them. For example, Bowen's Family Systems Theory views the family as an emotional unit and uses system thinking to describe the complex interactions in the unit (Kerr, 2000). It sees FS based on the emotional interdependence present in the family unit, which is consistent with the social construct theory that is commonly seen in family systems (Kerr, 2000).

Social constructionism points out that our interpretations are shaped by our context; that the attitudes and opinions that are absorb, become reality (Nichols, 2014). This is pertinent to the framework of family and FS because our families give us the basis for how the world is interpreted. This means that the language and culture that is picked up from one's family will affect the way the world is then interpreted (Nichols, 2014). Interpretation, from a constructionist viewpoint, believes that problems arise not because of one's circumstances but because of how those circumstances are perceived and received (Nichols, 2014). Yet social constructionism goes on to state that this interpretation is then mediated by the influence of talking to those around us (Nichols, 2014). For example, Research supports that connectedness among families can help with the recovery of eating disorders (Tantillo, 2006). Our family systems can exacerbate or deescalate how events in our lives are perceived. This causes one to wonder, if family systems can exacerbate or deescalate how events are perceived in our lives, then how 
might these affect family systems that have been ever-changing due to adversity and oppression, such as the African-American family unit?

\section{Family Satisfaction and the African-American \\ Experience}

Family structure has varied quite a bit over the years for African-American families. One of the reasons is that African-American families are disproportionately impacted by levels of poverty and financial strain (Kelly et al., 2013). For example, in 1950 married couples headed $78 \%$ of African-American families, but by 1996 this number dropped to only 34\% (Mandara \& Murray, 2000). The same happened for divorce rates: in 1960, only 78 per 1000 African-American women's marriages ended in divorce but by 1990, this number jumped to 358 (Mandara \& Murray, 2000). As for single mother homes the percentage jumped from 25 to 54 between 1960 and 1993 (Mandara \& Murray, 2000). This goes to show the dramatic changes that have happened in African-American families, which leads to the question: does this affect FS?

Since the African-American community has endured such staunch changes over the past decades, FS has been challenged. For example a study of 202 African-American couples showed that couples that had to endure economic disadvantage at the neighborhood level (i.e., "living in the hood") and financial strain, demonstrated lower levels of warmth and lower self-reported marital quality (Kelly et al., 2013). Research shows that disruptions within co-parenting between African-Americans single mothers and their co-parent can directly impact an adolescents' problem behavior by increasing their stress and arousal (Parent et al., 2013). It also shows that when there are amicable relationships between the mother and the co-parent, the adolescent shows lower levels of 
maladjustment (Parent et al., 2013). It seems that FS in the "African-American experience" may not be based solely on the concept of having a "two-parent" home. For instance, research has shown that African-American families have a history of having strong external networks (Parent et al., 2013). This means that African-Americans' families usually includes aunts, uncles, cousins, and grandparents; and this wider inclusion of family members tends to mean that more people have a role in the care of individuals especially the youth and young adults (Parent et al., 2013; Thomas \& Dansby, 1985). These family networks can extend beyond aunts and uncles and can extend into 'church families,' 'sports teams,' and 'after-school communities' (Thomas \& Dansby, 1985). Research has shown that family functioning is the biggest predictor of FS in African-American families (Parent et al., 2013).

When looking at FS, the family functioning theory has shed a lot of life on the African-American family in terms of self-esteem (Mandara \& Murray, 2000). In the family functioning model, FS is based on a cohesive home in comparison to a conflictive home that is independent of parental structure (Mandara \& Murray, 2000). In terms of how this affects children, research shows that African-American children's perception of their family environment affected their psychological adjustment and grade point average (Mandara \& Murray, 2000). In addition, higher levels of family cohesion and connectedness were associated with lower levels of depression and promoted positive interactions for African-Americans (Herman, Ostrander \& Tucker, 2007). Although family functioning may have a huge impact on the African-American community, so do income and family structure. 
It cannot be ignored that the plight of African-Americans in the history of America is one that is steeped with racism and inequity. It dates back to the days of slavery, extends to the days of segregation, and makes itself known through misrepresentation and racial injustice (Kelly et al., 2013). The disparities that AfricanAmericans face can extend into their families and affects their perceptions of FS (Kelly et al., 2013). For example, the fact that unemployment is higher for African-Americans than their White counterparts, and the challenges that relate to underemployment and unemployment, are associated with reports of lower family and couple satisfaction (Kelly et al., 2013). However, regardless of the economic strain, these families face factors such as discrimination that may have a big effect on their wellbeing.

Microaggressions, which are "everyday verbal, nonverbal and environmental slights, snubs or insults whether intentional or unintentional, that can have a substantial impact on family satisfaction" (Kelly et al., 2013). This is because microaggressions, alongside forms of race-based treatment, create stresses and can lead to poor mental health, which in turns leads to poor couple relationship quality (Kelly et al., 2013). It could be argued that poor relationship quality leads to a noncohesive home environment and lead to decreased FS. Unfortunately, racial bias and stereotypes that AfricanAmericans face can cause them to fall into the stereotype or become an opposite extreme; this obviously does little to help boost FS (Kelly et al., 2013). Research suggests that African-Americans couples consistently report lower relationship satisfaction than White couples, which in turn indicates that a couple's dissonance may lead to a decrease in FS (Kelly et al., 2013). Through all the hardships that these families face both internally and 
externally, there are still attributes of great strength that helps the family to thrive despite inequities and disparities.

Despite the many challenges that the African-American communities face, research show that their strengths have the power to "lessen the blow" and at time neutralize the inequity they face. For instance, the way that the family unit is conceived in and of itself is a strength. This is due to the respect that many African-American children are taught to have for their elders, the strong ties to extended family and the tendency to have "fictive kin" (i.e. close friends from community who are considered family) (Kelly et al., 2013). These tendencies strengthen family units and increase FS (Kelly et al., 2013). This owes something to the fact that these extended families provide assistance in the form of emotional closeness, working opportunities, chore sharing, child rearing and financial and support systems (Kelly et al., 2013).

These networks create a "safe space" for African-American families to go to and discuss racial discrimination and disparities that they may feel (Kelly et al., 2013). These safe spaces to the African-American family serves as a protective role in buffering African-American children from the harsh effects of environmental stress (Skowron, 2005). Research has reported that racial socialization happens within the AfricanAmerican family framework and the stronger that framework, the more likely a child is to develop a strong racial identity and self-concept (Armah, 2015; Kelly et al., 2013; Seaton, Yip, Morgan-Lopez \& Sellers, 2012; Skowron, 2005). However, if this familyunit lacks functioning, then the less likely a child is to develop a strong racial identity and ultimately strong self-concept (Armah, 2015; Kelly et al., 2013; Seaton et al., 2012; Skowron, 2005). 
More specifically, African-American families that allow their children more autonomy, maintain well-defined and age appropriate parent and child roles, and provide warmth and support, in turn have children who are self-confident, cognitively skilled, and higher achievers (Skowron, 2005). Research has also confirmed that both extended family members and parents are the primary components of instilling racial socialization, which is the precursor to racial identity (Seaton et al., 2012). Spirituality and religion are also strengths. For example, research shows that African-American families are more religious than other racial and ethnic groups (i.e., $76 \%$ pray daily and $53 \%$ attend religious services) (Kelly et al., 2013). This religious activity has been associated with positive family ties, positive adjustment, and improved mental health and family relationships (Kelly et al., 2013). Faith also provides a "church family" that allows African-Americans to experience high status roles, develop leadership skills, and engage in politics. These opportunities increase self-esteem and self-worth, which leads to an increase in couple satisfaction and ultimately FS (Kelly et al., 2013).

Despite the disparities that many African-Americans families' face, they possess many strengths that help them to live healthy family lives. Yet it cannot be ignored that African-American families face complex hurdles in finding FS, and it takes more family than the "average nuclear family" requires. Since the purpose of this study is to look at FS and African-American college students, it is imperative that the relationship between the two is examined. 


\section{The Relationship Between Family Satisfaction and Stereotype Threat}

There has yet to be any direct research that looks at FS and its effects on stereotype threat. However, research has indicated that the family unit for AfricanAmericans is a major buffering component against racially hostile environments (Kelly et al., 2013). Research also shows that family functioning is the biggest predictor of FS in African-American families (Parent, Jones, Forehand, Cuellar, \& Shoulberg, 2013). This indicates that a cohesive family unit among African-Americans correlates to a lower level of psychological maladjustment in African-American children (Mandara \& Murray, 2000). The basis of the family unit acting as a buffer against racially hostile environments indicates that it may act as a buffer against stereotype threat. However, in order to understand how the African-American family unit works, one must first understand the concept of family

The Relationship Between Family Satisfaction and Stereotype Threat Among African-American College Students

Research has shown that minority enrollment in higher education has increased significantly over the past two decades. Yet despite this growth, African-Americans are less likely to complete college than European Americans (Anglin \& Wade, 2007). Some studies have shown that academic adjustment for African-Americans is directly correlated to positive racial solicitation (Anglin \& Wade, 2007). This correlation stems from the idea that if African-American students can "buffer" against racist environments, then they are more likely to thrive in them (Anglin \& Wade, 2007). Studies on racial factors and African-American college students are limited, but some known factors are parental support and encouragement. 
Parental support and encouragement have been shown to assist African-American college students and correlate with positive academic experiences (Anglin \& Wade, 2007). Parental attachment has also been known to produce individuals with a greater level of attachment security, and these individuals are more likely to be able to adapt psychologically, emotionally, and socially (Love, Tyler, Thomas, Garriott, Brown, \& Roan-Belle, 2009). For instance, research that states that African-American parents who engaged with their children about cultural pride, strengthened their racial socialization and their sense of personal efficacy and cultural pride (Armah, 2015). As stated above, African-American families have not taken on the common 'nuclear' framework and often consist of extended family networks. In addition, the family unit has proven to be a buffer against hostile environments and injustice. For this reason, the relationships AfricanAmerican college students have with their peers and extended family may have some effect on their college success. Studies have shown that strong parental attachments can foster higher levels of self-esteem, strong peer attachments, and interpersonal connectedness needed to adapt and excel when away at college (Love et al., 2009). Parental and family support are important to African-Americans because they provide a buffer against the discrimination they face every day.

\section{A Conceptual Overview of Racial/Ethnic} Identity in the United States

Identity can be defined as "an individual's cognitive, behavioral and affective repertoire regarding who he or she is, to which groups he or she belongs and behaviors enacted as a result of these thoughts and beliefs" (Schwartz et al., 2013). Identity can be broken down into many subgroups, including cultural identity, personal identity, career, 
relationships, religious beliefs, etc. The number of possible identities is endless.

Especially in the United States of America, the country that is known as the "melting pot" because of its vast numbers of cultures, races, ethnicities, orientations, and religions. It is rare that an individual fits into one identity, which may be why some take years before they find their true identity. That is why identity in the United Stated cannot be summed up with a single definition, because the concept of identity is so colorful in and of itself. As individuals grow and advance, so does their identity; indeed individuals may need to reconstruct their identity over the course of their life in order to incorporate new elements. Therefore, to understand identity, one must first break down the different types and models of identity.

\section{Types/Models of Identity}

As stated above, identity can be broken down into many different aspects. For instance, personal identity is defined as a set of "goals, values and beliefs that one develops in areas such as career, relationships and religious beliefs" (Schwartz et al., 2013). Cultural identity is defined as, "ethnically or culturally based practices, values and identifications that one maintains" (Schwartz et al., 2013). Significant for our purposes is racial identity, which is defined as a sense of group or collective identity based on one's perception that he or she shares a common heritage with a particular racial group.

Therefore, it can be seen that identity can be broken down into many different facets and its complexity has spawned numerous theories.

The eclectic makeup of identity has caused many theories to be created. For instance, Erik Erikson and James Marcia have identity models that focus on the concept of' "constructing [an] ego identity" and the exploration of interest ranging from 
occupational and philosophical, to interpersonal and romantic (Sanchez, 2013). Their models and stages indicate how identity forms over the lifespan, and particularly in young people. Research has shown that the most progressive changes in identity development takes place during adolescence and young adulthood (Carlsson et al., 2015). This is because new experiences may challenge their sense of identity (Carlsson et al., 2015). For example, the identity status model states that identity operates in four realms, which are: identity diffusion, identity foreclosure, identity moratorium, and identity achievement (Carlsson et al., 2015). Research shows that young adults and adolescents are known to navigate through these statuses in hopes of reaching identity achievement, at which point identity becomes stable (Carlsson et al., 2015). As these young adults reach for identity achievement a major part of their developing identity is related to social group and ethnic identity, which also has a process of its own.

Phinney's developmental model of Ethnic Identity focuses on two stages of identity development, exploration, and commitment. This model states that a person first has to consider various identity alternatives, settle on one and accept it and everything that comes with it. Phinney's model understands that one's ethnic identity plays a role in understanding their individual identity (Syed \& Juang, 2014). One can see that the vastness of identity models is comparable to idiosyncrasies that come with identity. Despite how evolved models have become, early models received critique for not conceptualizing ego identity in a universal fashion without accounting for race and gender (Sanchez, 2013). After reviewing the models, one has to wonder what effect race has on an individual and if it is worthy of being an integral part of identity development. 
Race is a construct based on observable physical characteristics that have acquired socially significant meaning (Blank et al., 2004). Therefore, one could state that race is the first thing that is seen about a person; it is in a sense everyone's silent first impression. When it comes to identity development leaving out race constitutes a major oversight because they are our distinct features that are presented to the world every day. It can be argued that it is only fitting that racial identity be an integral part of identity development.

There are several models of racial identity but one of the more popular models of racial identity is the Cross Model. The Cross Model is a racial identity model that looks at the development of BRI in America (Cokley, 2002). It was originally developed in 1971 and then after much scrutiny was revised in 2001 (Cokley, 2002). The Cross model consist of five stages: pre-encounter (assimilation); pre-encounter (self-hatred); encounter; immersion-emersion (intense black involvement); and immersion-emersion (anti-White identity); and internalization (Cokley, 2002). Other racial identity models include: Helms' White Racial Identity model, which looks at White racial identity as a development of "successive racial identity statuses;" these in turn are "dynamic, cognitive, emotional and behavioral processes" (Behrens, 1997). Helms also had a People of Color racial identity model that explained the ways that people recognize the consequences of being socialized in racially oppressive environments and the traits that emerge as a result (Miller, Alvarez, $\mathrm{Li}$, Chen, \& Iwamoto, 2016). Of the many different models that look at racial identity, one thing that is evident, is that the models reflect where these individuals come from and since this research will focus on individuals in 
America, one must first understand how racial identity and the American experience go hand in hand.

\section{Racial Identity and the American Experience}

It is sometimes suggested that the appropriate analogy for the United States culture is not a melting pot but rather 'salad bowl.' In America, there are many different backgrounds, ethnicities, religions, and races but they do not all blend together to become "one race." Furthermore, one can conclude that being aware of one's race in America is not so much an option as it is an obligation. To live in the "land of the free" one has to embark on the journey of discovering racial identity, and where an individual lands can depend on many factors.

Many models have been based on racial identity and many have been normed on Americans. These models have been normed and essentially created based on themes that have been recurring in American society for people of color, African-Americans (Blacks), and Caucasians (Whites). To examine the relationship between racial identity and the American experience, one can look at the models of racial identity and where they intersect.

Looking at the models of racial identity, one can conclude that developing a racial identity in America begins with either no concept of race (if one is Caucasian) or having a low salience for one's race (if one is a person of color) (Behrens, 1997; Cokey, 2002; Miller et al., 2016). Whether White or non-White, the individual then moves into a state of disintegration, dissonance, or self-hatred, meaning that the individual either begins to hold negative views about their race and self or they get anxiety and confusion about

their race and race relations (Behrens, 1997; Cokey, 2002; Miller et al., 2016). Then, 
according to the models, White Americans then move into a state of reintegration where they idealize their "whiteness," and People of Color and Blacks go through a stage where they encounter discrimination or racial injustice and this leads to racial mistrust and hypersensitivity (Behrens, 1997; Cokey, 2002; Miller et al., 2016). White Americans will then go through a stage of pseudo-independence, which simply reinterprets racial information to justify their new "liberal" outlook (Behrens, 1997; Cokey, 2002; Miller et al., 2016). People of Color and Blacks go through a stage of emersion where they develop feelings of intense pride for their race (Behrens, 1997; Cokey, 2002; Miller et al., 2016). Whites end out their racial identity journey by going through a stage of immersionemersion and autonomy where they search for their own personal standards and try to redefine their whiteness, which may then lead to their ability to develop a flexible use of internalized non-racist standards (Behrens, 1997; Cokey, 2002; Miller et al., 2016). As for People of Color and African-Americans, their journey ends with developing an intellectual objectivity about race and a cognitive flexibility about race and racial issues (Behrens, 1997; Cokey, 2002; Miller et al., 2016). People of Color and AfricanAmericans may go through a stage where they embrace their race but reject anything White or "Eurocentric" as well (Behrens, 1997; Cokey, 2002; Miller et al., 2016). Overall, it seems that racial identity in the American experience starts with ignorance, then leads to harsh realities and realizations, and ultimately ends with an understanding of one's race and the issues it generates.

Racial identity in the American experience can be a rocky road that is harsh and eye opening. The reality is that not everyone makes it to the last stage of the model, and when one fails to do so it can cause a lot of dissonance. This is especially acute for 
African-Americans, whose very color and presence are associated with negative images and beliefs (Schaller et al., 2003). For any American, developing a racial identity is a painful process, especially since the catalyst is usually a moment of turmoil and confusion (Cokey, 2002). Yet one can argue that taking the racial identity journey is not an option and since race is such a large part of the American experience, one has to wonder what it is like for a minority such as African-Americans to take that long journey down the road of racial identity.

\section{Effects of Racial Identity on Stereotype Threat}

Cross has developed a model of racial identity that has been widely researched and cited in psychology literature (Davis et al., 2006). His model is focused on Black Identity development, and according to his research, Blacks go through five stages or "statuses" of Black identity development (Davis et al., 2006). These five stages are preencounter, encounter, immersion, emersion, and internalization. These stages are categorized by a de-emphasis or denigration of being Black, identity metamorphosis, afrocentricism, or embracing a non-exclusionary identity (Davis et al., 2006). These different stages of identity can dictate one's response to racially relevant situations and are therefore known to play a factor in moderating stereotype threat (Davis et al., 2006).

Research has shown that developing parts of one's racial identity can buffer against stereotypes (Davis et al., 2006). For example, research shows that gender identification moderated the effects of stereotype threat when gender identity was linked to math performance (Davis et al., 2006). In addition, higher levels of racial identification are thought to buffer African-Americans against self-esteem and social threats (Davis et al., 2006). However, research has also demonstrated that racial identity can have either 
buffering or amplifying effects for social threats (Davis et al., 2006). In particular, internalization-related attitudes have been presumed to play a protective role against social threats associated with race, such as stereotype threat (Davis et al., 2006). Contrary to those findings, research has reported that higher levels of racial identity are reported to result in higher levels of sensitivity to stigmatization, and increased distress related to discrimination and vice-versa (Lee \& Ahn, 2013; Sellers \& Shelton, 2003). In a study that sought to measure the relationship between stereotype threat and racial identity, it was found that internalization was a protective factor in low-stereotype threat conditions (Davis et al., 2006). It was also found that the stages that are the most vulnerable to the effects of stereotype threat are in pre-encounter and immersion-emersion (Davis et al., 2006). Therefore, from the research it seems that racial identity can act as a moderator to stereotype threat, but in order to fully understand how racial identity plays into stereotype threat, one must first understand how identity is developed in the United States.

\section{Racial/Ethnic Identity and African-Americans}

It is evident that racial identity affects our everyday lives, not to mention our selfesteem and self-worth. Therefore, one wonders, is racial identity affected by discrimination? Does it harm it or help it, and in what ways does it define or affect an individual? Different studies explore these questions and seek to answer them. For instance, in a study done to measure the correlations between racial identity, ethnic identity and racial socialization to discrimination and distress, it was proved that racial identity may be directly or indirectly related to the distress associated with discrimination (Lee \& Ahn, 2013). For example, Black Americans with a greater sense of belonging were more likely to perceive experiences of discrimination (Lee \& Ahn, 2013). This 
study suggests that those with a high racial identity will more perceptively feel the racism and microaggression that is still prevalent in society (Lee \& Ahn, 2013). In addition, research has shown that early and middle stages of racial identity development predicted higher levels of internalized racism, which can cause individuals to see themselves negatively, or believe stereotypes and prejudice about their own race (Cokley, 2005). It can lead one to believe that those who have a "less dramatic" racial identity will not perceive as many experiences of racial discrimination, and in order for an individual of African-American descent not to feel racial discrimination, they will have to have a low racial identity. However, the study went on to claim that racial identity could serve as a buffering role against discrimination, meaning that in terms of public regard, the more positive that African-Americans believe others view their own race, the less offense they take to discrimination (Lee \& Ahn, 2013). That is, when African-Americans view their own race as liked, they will have a higher regard for themselves despite discrimination. Yet how does one come to terms with their identity and what it means to be an AfricanAmerican? This past study demonstrated what helps to shape our racial identity and how factors such as discrimination and public regard affect it, but it does not touch on the subject that may be one of the most important components: Namely, becoming aware of being a "Black" American and what that means.

As individuals begin to develop their identity, all come to understand that identity is hard to develop without the inclusion of race. As identity develops and the concept of race strengthens, individuals come to understand that their color may be a source of privilege for some and disadvantage for others. It all depends on where one falls on the wide spectrum of colors. In one study of Black men titled, "I Won't let you Define Me," 
one individual mentioned that "America is definitely not blind to race. You can see it in just about anything you do. Race in some sense means separateness. Means a division. We might not want it to, but that's exactly what it is" (Walden, 2009). The realization that a color makes one different—one separate—is a hard reality to face, yet "Blacks" everywhere have to endure that realization daily. The study went on to state that in order for these men to come to terms with their "blackness," they had to accept stereotypes and realize that life was not going to be easy (Walden, 2009). When looking at Black women, it is evident that they go through many of the same realizations as the men and sometimes-harsher ones at that. For instance, those planning to become mothers may often experience anxiety for their children and the possibility of racism (Nuru-Jeter et al., 2009). Even without the aspect of children, women still experience psychological harm from racism, not to mention its adverse effect on their ethnic identity and emotional wellbeing (Nuru-Jeter et al., 2009). It is evident that the realization of "blackness" for African-Americans means the realization of discrimination, racism, and a harder road ahead, both interpersonally and personally (Broudy, Brondolo, Coakley, Brady, Casselles $\&$ Sweeney, 2007). What does this mean for education and, how can these individuals flourish when the odds are stacked against them? In, "I Won't Let You Define Me," one of the men stated,

We aren't supposed to be able to write, you know, and we're not supposed to be able to conduct research, and so I just kind of turned that around. I kind of took it as a challenge and a source of motivation. So, ok, they say we can't write. Let me show you we can write and we can do publications. (Walden, 2009)

It is astounding that African-Americans have to disprove odds that say so little about who they are and of what they are capable. As many Blacks go on to college, it is suggested that where they attend can have an effect on their racial identity. 
The Relationship Between Racial Identity and Stereotype

Threat Among African-American College Students

Erikson proposed that in adolescence, identity versus identity confusion was the core of development. However, it seems that identity formation and confusion is not something that stops in adolescence but instead lasts throughout the lifespan (Carlsson et al., 2015). The reason is that individuals may need to reconstruct their identities in order to incorporate new elements, and this may be especially true in college-age students (Carlsson et al., 2015). Emerging adulthood ranges from ages 18-29 and is a developmental period marked by extended identity exploration (Hope et al., 2015). African-Americans, in particular, experience emerging adulthood in the context of institutional racial discrimination; this hinders development because they have to manage the different forms of discrimination they face in combination with normative developmental tasks (Hope et al., 2015). In addition, the college years are known to be the time where one develops clarity and commitment to their ethnic group (Brittan, Kim, Armenta, Lee, Umana-Taylor, Schwartz, Hudson, 2015). Having to combat racial discrimination on a regular basis can have negative effects on individuals, including college students (Sellers \& Shelton, 2003). Researchers have suggested that having a strong sense of identification with one's group can serve as a psychological buffer; in other words, a connection to one's group compensates for the negative effects of discrimination (Sellers \& Shelton, 2003; Rhone, 2010). However, if one is not able to fully mature in their BRI, it can be detrimental and cause one to feel isolated and rejected (Rhone, 2010). For instance, research has shown that early and middle stages of racial identity development predicted higher levels of internalized racism, which can cause individuals to see themselves negatively, or believe stereotypes and prejudice about their 
own race (Cokley, 2005). Therefore, for African-American students in a college setting, it may be especially important to have a strong racial identity.

Research suggests that being a part of a minority group at a predominantly White campus can increase the pressure not to live up to the "group" stereotype (Fischer, 2010). In a study that followed 4,000 students at 28 different universities through their first year of college, students reported how they experienced race related problems. The study revealed that Black students by far have the highest average perceptions of a negative racial environment on campus (Fischer, 2010). In addition, Blacks were also recorded to have the lowest cumulative GPAs, lowest average ratings of social life satisfaction, and the lowest percentage of students who graduate on time (Fischer, 2010). The results collected in this experiment excluded other factors, such as parents' education level.

According to a study by Brower and Ketterhagen (2004), Black students have to work harder at PWIs in order to ensure success. The question arises: why do they have to work harder and what does this do to these individuals? It has been found that since these students feel the need to work harder at PWIs, they develop a racial identity that is parallel with a "sense of belonging-within-alienation" (Brower \& Ketterhagen, 2004). In a second study title Race Still Matters, which focused on how race influences success, the researcher concluded that "these schools make it noticeable when an individual is not 'White"” (Campbell, 2010).'This causes the individual to become more self-aware of their race, resulting in an increase in racial awareness which can lead to the inability to maintain high self-esteem when faced with discrimination" (Campbell, 2010). If these students do not come in with an established racial identity, theirs is subject to being compromised because, as they become more racially aware, discrimination will take its 
toll, devaluing not only self-esteem but also racial identity (Campbell, 2010). As AfricanAmerican strive to move forward and not be defined by race, the ability to attend PWIs and mainstream White schools may not be everything that it was hoped to be. The reality is that these students still develop a sense of "otherness" when dropped into these PWIs, and feeling like an outsider is never an asset to anyone's identity. This was exactly how African-American males in a White suburban school felt (Gordon, 2012). Yet this sense of "otherness" goes beyond African-American males and extends to African-American females as well.

In the novel The Unchosen Me, the writer dives into what it is like for AfricanAmerican women to have their identities forced upon them by stereotype and circumstance. The book brings to light that although some may deal with "otherness," others may deal with "twoness" (Hernandez, 2010). This "twoness" puts AfricanAmerican women at a crossroads of being seen as a "representative for the AfricanAmerican community," or not being seen at all (Hernandez, 2010). Although this book focuses on African-American women, this phenomenon that plagues all Blacks attending a PWI or in mainstream White America, shows what a great burden it is to have to choose to either be invisible or carry the weight of a whole race.

Beyond that, there is also the concept of "being too White" or "too ghetto" (Hernandez, 2010). These terms are not even operationally defined, yet they are assumed to mean that one is the "outsider" or an "alien." It is clear to see that attending a PWI can certainly have an adverse effect on African-American students, but does this mean that attending a HBCU will have the opposite effect? 
Historically Black College and Universities give Black students a greater academic and social support service, not to mention a greater sense of connectedness and well-being (Brower \& Ketterhagen, 2004). Some even feel that once at an HBCU as an African-American, there is "a feeling of excitement [and it is] just a great time to be Black" (Walden, 2009). These two statements are from two different studies that involve racial identity and African-Americans. These studies support the claim that an individual could be more likely to develop a strong racial identity at an HBCU because they have a connectedness to the world around them and they have the opportunity actually to be excited about their race. It was once also quoted that "Black success is inevitable in the presence of Black people [in a school setting]" (Patterson, 2009). This is further justified through a study that focused on high school students. In this study, the students expressed their beliefs that Black schools catered to the needs of all individuals, while PWIs present fewer opportunities for Black students to be successful (Patterson, 2009); reinforcing that HBCUs are still relevant in the $21^{\text {st }}$ century and are still needed in the US social and economic climate (Albritton, 2012). It is evident that HBCUs clearly have an impact on their students' ability to succeed but these schools also create a sense of self-worth in these students. This self-worth allows them to create a racial identity that is concrete enough to act as a buffer against racial discrimination (Patterson, 2009). Attendance also allows an individual to maintain their self-esteem by allowing them to develop a racial identity strong enough to buffer the negative effects of racial awareness, further indicating that having a strong racial identity provides a buffer for discrimination (Patterson, 2009). 


\section{A Conceptual Overview of Racial/Ethnic Discrimination}

The concept of race was developed in the $18^{\text {th }}$ century and was used to distinguish populations in different areas based on the different physical characteristics (Blank et al., 2004). It was once claimed that race was based on geographical region; however, the immense amount of variance indicates that there are no set of genes that correspond with the social conception of race. In fact, social science supports that race is a construct based on observable characteristics that have acquired socially significant meaning (Blank et al., 2004). The social meaning given to racial classifications activates beliefs and assumptions about people of a certain racial category (Blank et al., 2004). These assumptions and beliefs can create boundaries for people in these racially defined groups that can have a negative effect on people every day and one of the ways this happens is through discrimination.

Discrimination involves harmful actions performed toward others because of their membership in a particular group (Dovidio, Hewston, Glick, \& Esses, 2010).

Discrimination can involve actions that disadvantage people from minority groups or benefit people from majority groups (Dovidio et al., 2010). The reality of discrimination is that it is an overlapping concept and can involve the intersectionality of multiple groups; however, for the purpose of this study, the main focus will be on racial discrimination, and one way that discrimination takes place is through stereotypes and prejudice.

Stereotypes are related to associations and beliefs about attributes thought to characterize a group. They can be positive or negative and are powerful because they influence how members of a group are seen, how information is processed about the 
group, and how group members respond and are responded to (Dovidio et al., 2010). Stereotypes then create prejudice, which occurs when the perceiver evaluates other people based on their own stereotype and attitude (Dovidio et al., 2010). While stereotypes can carry a kernel of truth, stereotypes become problematic because they ignore the "within-group" heterogeneity and exaggerate the "between-group" differences Dovidio et al., 2010). Stereotypes and prejudice are the foundation for discrimination, which can be acted out in numerous ways.

Our society harbors a strong egalitarian ethos, which is a strong belief that everyone should be treated fairly and equally. However, this can only happen when the individual is very purposeful and motivated to be unbiased, meaning the individual has to be intentional about not being discriminatory (Dovidio et al., 2010). This is not a reality because it is rare that people are "on-guard" for discriminatory responses on a daily basis, and since overt racist claims are looked down upon, implicit discrimination becomes more prevalent.

The concept of implicit discrimination is when implicit bias, that operate under conscious awareness, has an impact on behavior. For example, social scientists have documented that Whites' have taken on a "lassiez-faire racism" which involves persistent negative stereotyping of African-Americans and contributes to persistent racial disparities (Lamont et al., 2016). Simply put, research has shown that some Whites are no longer attempting to be "on guard" or readily avoidant of discriminatory behavior.

Discrimination is something that affects behavior on a daily basis and if one is not aware of stereotypes and prejudices they accumulate over a lifetime, then it is easy for 
these beliefs to begin to affect behavior, which is something that has become an everyday experience in American society.

\section{A Conceptual Overview of Racial/Ethnic \\ Discrimination in the United States}

African-Americans have faced a number of socioeconomic obstacles and always seem to trail their White counterparts in wealth (Lamont et al., 2016). They have persistently faced housing discrimination, racial residential segregation, lower paying jobs and disproportionately high incarceration rates (Lamont et al., 2016). Yet these disparities did not occur in a vacuum; and there are many factors that contribute to the disadvantages that many African-Americans face today (Franklin \& Boyd-Franklin, 2000). For example, "the original experience of being brought over as slaves has been compounded by centuries of acts of the larger society to reinforce their status as inferior (Franklin \& Boyd-Franklin, 2000).” Being represented as three-fifths of a person, being considered property, and later, segregation all had an effect on the plight of AfricanAmericans in the United States (Franklin \& Boyd-Franklin, 2000). Even when cases like Brown v. Board of Education and the Civil Rights Act of 1964 attempted to give AfricanAmericans a semblance of equal citizenship, years of having been property and secondclass citizens undermined their efforts.

Arguably laws such as Civil Rights and rulings such as Brown v. Board of Education did not eliminate discrimination but instead hid it (Lamont et al., 2016). As stated above, social scientists have held that Whites' attitudes have shifted and have taken on a form of "laissez-faire racism" which involves persistent negative stereotyping of African-Americans and blaming Blacks for the White-black socioeconomic gap (Lamont 
et al., 2016). This attitude also creates resistance to meaningful policies intended to fight racist social conditions and institutions (Lamont et al., 2016). Some Whites subscribe to 'colorblind racism,' meaning that they do not believe that blacks are innately inferior to Whites and the end of Jim Crow eliminated all barriers for them (Lamont et al., 2016). It seems that discrimination went from being overt to covert, and Americans began to believe that the progress made erased any remnant of discrimination and its effects from American history. Although racially progressive laws are a step in the right direction, discrimination is far from being eradicated.

\section{The Effects of Discrimination on African-Americans}

Overt discrimination against African-Americans and other minorities makes up a large chunk of US history. Discrimination has greatly affected the African-American plight in American society. Research has shown that most African-American children will have experienced at least one instance of racial discrimination, involving racial slurs and verbal insults, between the ages of 10 and 12 (Spears Brown \& Bigler, 2005). Research has also shown that discrimination is a persistent barrier that affects the health and well-being of African-Americans (Hope et al., 2015). For instance, chronic and cumulative experiences of racial discrimination are associated with a number of negative biological and health outcomes, such as high blood pressure, increased heart risk, and risk for cardiovascular disease (Hope et al., 2015). Psychological effects of racial discrimination on African-Americans include depression, suicide, violence, stress disorders, maladaptive coping strategies, and substance use (Broudy et al., 2007; Hope et al., 2015). These physiological and psychological effects seem to stem from the discrimination and perceived discrimination that African-American individuals may 
encounter, especially since the discrimination they face stems from such negative stereotypes.

The word 'Black' is often associated with negative words such as "poison" or "cancer," and those who are especially racist sometimes make Blacks equivalent with any negative concept (Donders, Correll, \& Wittenbrink, 2008). In fact, black students routinely have to deal with stereotypes assigned to their identity and have to deal with the influence these negative stereotypes and images may have on their well-being (Bourke, 2010; Adams-Bass, Stevenson \& Kotzin, 2014)). Even if one were to cross the border of the United States, it would be easy to see that "people everywhere" associate darkness with, "evil, threat, and danger" (Schaller et al., 2003). It seems that Blacks are associated with negativity and it should come as no surprise that they are often perceived as "dangerous" (Donders et. al., 2008). In addition, the more a black individual is associated with "danger" the more likely they are going to be judged (Donders et. al., 2008). Unfortunately for Blacks, it seems they are at a disadvantage, because their dark skin may be the trigger to negative ethnic stereotypes that may lay dormant (Schaller et. al., 2003). A study that looked at how people would react to black individuals in reference to light and ambient darkness revealed that dark conditions had an effect on the activation of stereotypes towards black individuals, especially if the individual felt vulnerable to a physical threat. In another study that focused on attention, allocation, and stereotypes, performed a dot test to see if black faces captured and held attention more than White faces (Donders et. al., 2008). The study revealed that when a danger stereotype is present, there is an increase in the attention holding of a black individual over a White individual (Donders et. al., 2008). This means that when concepts such as murder, rape, and 
violence come up, people are more likely to associate them with "blackness" than with "whiteness" (Donders et. al., 2008). These negative associations can make positive identity formation difficult for African-Americans.

The negative associations that occur for African-Americans on a regular basis, also seep into the college setting. When this happens it can spark identity exploration, in particularly ethnic identity exploration (Brittan et al., 2015). This indicates that when one feels there are negative feelings held about their ethnic group it may cause him or her to want to understand and explore their identity within that context (i.e. ethnic or racial) (Brittan et al., 2015). Confirming, that the presence of discrimination can cause one to explore who they are and what it means to be their "race" or "ethnicity" within their society (Brittan et al., 2015). Ethnic identity development and exploration may seem as a positive for African-Americans; however, it can also bring on depression if it is sparked by a negative experience, such as discrimination (Brittan et al., 2015).

\section{The Relationship Between Ethnic Discrimination and Stereotype Threat}

Discrimination has been proven repeatedly to have significant effects on physical and mental health and overall well-being (Wegmann, 2017). Recent studies have shown that children who report high levels of discrimination are more likely to experience mental health problems and poor physical health, such as high blood pressure and insulin resistance (Wegmann, 2017). In fact, a study that looked at African-Americans in the context of a PWI found that perceived racial discrimination was associated with academic, interpersonal, psychological/emotional, and existential concerns (Chao, Mallinckrodt \& Wei, 2012). In addition, perceived discrimination has also had high 
correlations with substance abuse, such as alcohol, drug, and tobacco use (Wegmann, 2017). The effects of discrimination on African-Americans are broad and discrimination takes on many forms, one of which is stereotype threat.

Stereotype threat can be considered a form of perceived discrimination: when stereotype threat is present one perceives that there is a negative stereotype (or discrimination) about them, and this will affect how they are perceived and therefore affect their performance (Wegmann, 2017). Research shows that although primarily intellectual abilities are one of the main abilities affected by stereotype threat, physical abilities are also affected (Wegmann, 2017). In addition, perceived discrimination in the form of stereotype threat has direct and indirect effects on children's well-being and their influence extends in adolescence and young adulthood. These negative affects can also control for one's income and occupation (Wegmann, 2017). Stereotype threat takes discrimination to the next level; not only is one perceiving it, they are also trying to fight against. This is especially true for African-Americans.

The Relationship Among Family Satisfaction, Racial Identity, Ethnic/Racial Discrimination, and African-American Students' Vulnerability to Stereotype Threat

There is no doubt that African-Americans' plight in America has been one of struggle and triumph and they still face many disparities every day among which, discrimination may be the most detrimental. As a result of discrimination and stereotypes, African-Americans have come to a place where they "perceive discrimination" on a daily basis in the form of stereotype threat. This perceived discrimination starts at a young age and affects individuals in multiple ways. Their mental and physical health are put at risk, 
their executive functioning is exerted, and their ability to "believe they can do anything" is stifled.

This research study seeks to explore how FS, racial identity, and perceived discrimination impact African-American college students' susceptibility to stereotype threat. This is important because it seems that the African-American community has been paying the price for discrimination with their health and abilities. This study examines if there are any protective factors that can act as "buffers" against the discrimination that they face every day. Family satisfaction has not been studied at all in relationship to stereotype threat. However, it has been seen time and time again that the AfricanAmerican family unit has significant positive effects on individuals' being able to deal with racism and racially hostile environments. Perceived discrimination has a high correlation with stereotype threat and is seen as a precursor to stereotype threat. Racial identity has been shown to act as a buffer to discrimination, depending where one is in the Cross model, but it has not been studied in depth.

Racial Identity is important for minorities and can be seen as an aspect of the racial minority self-concept (here racial identity and ethnic identity will be interchangeable) (Mossakowoski, 2003). In fact, some see ethnic identity as a coping resource, because research shows that having a salient ethnic identity can act as a buffer to the stress of discrimination (Mossakowski, 2003). This occurs by preventing negative stereotypes from affecting one's sense of self-worth (Mossakowski, 2003). Some may argue that the stronger one's racial/ethnic identity is, the more susceptible they are to negative stereotypes and discrimination and the more damage these will cause (Mossakowski, 2003; Brittan et al., 2015). However, it is also argued that a strong 
racial/ethnic identity is beneficial to health because it provides a sense of belonging and acts as a buffer (Mossakowski, 2003). Having a strong racial identity can affect an individual for good or ill. Some research has even reported that higher levels of racial identity results in higher levels of sensitivity to stigmatization, and increased distress related to discrimination, and vice-versa (Lee \& Ahn, 2013; Sellers \& Shelton, 2003). For the purpose of this research, the benefits of a strong racial identity will be explored.

Research shows that when looking at other minorities, such as Asians, the stressbuffering effects of racial/ethnic identity is not as profound (Mossakowski, 2003). In fact, having a strong racial/ethnic identity can actually exacerbate mental health among other minorities (Mossakowski, 2003). However, when looking at African-Americans, racial/ethnic identity significantly buffered against the stress of acute and chronic discrimination (Mossakowski, 2003). Indeed, health problems, such as depression, declined with higher levels of racial/ethnic identification (Mossakowski, 2003; Herman et al., 2007). Although it seems that ethnic/racial identity does not have significant effects on buffering against stress related factors in some minorities, among African-Americans and blacks it has significant effects (Mossakowski, 2003). Some of the effects that racial/ethnic identity has for buffering against stress could be due in part to the family unit.

The family unit has been noted to be a source of strength for the AfricanAmerican community. Research has reported that the African-American FS can attribute to buffering against hostile environments and discrimination (Kelly et al., 2013). The family unit also creates "safe spaces" for African-Americans to communicate and process discrimination they have encountered or concerns they may have (Kelly et al., 2013). In 
addition, FS can result in a more positive college experience and increase racial identity (Anglin \& Wade, 2007). Studies have also shown that a strong family unit, with high levels of communication and satisfaction can be the foundation for a well-developed racial identity (Armah, 2015; Kelly et al., 2013; Seaton, Yip, Morgan-Lopez \& Sellers, 2012; Skowron, 2005).

\section{Summary of the Literature}

This study seeks to explore whether FS actually has a relationship to stereotype

threat. It also seeks to strengthen the research that suggests that racial identity can act as a buffer against stereotype threat and look at the relationship between stereotype threat and perceived discrimination. College students are analyzed because identity continues to change and develop through these years and the African-American graduation rates have dropped over the past 10 years (Camera, 2016). Ultimately, being able to identify what can assist African-Americans fight against discrimination may allow teachers, families, organizations, and individuals themselves to provide an environment where AfricanAmericans can thrive. This may be accomplished by ensuring African-Americans have a safe place to find and grow into their racial identity through "family-unit" safe spaces. The goal is that from this research, schools, families, organizations, and individuals are more aware of factors that influence and have a relationship to stereotype threat, in the hope that steps will be taken to create buffers that reduce the influence of discrimination on the well-being of African-Americans. 


\section{CHAPTER 3}

\section{METHODOLOGY}

\section{Introduction}

The present study investigated the role of FS, racial identity and PED on AfricanAmerican students' susceptibility to stereotype threat. The dependent variable examined in the current study is susceptibility to stereotype threat, which was measured as perceived racial discrimination. The independent variables examined in the current study were: racial identity, FS and PED. The demographics included in this study were age, type of college attending, year in college, and race.

This chapter highlights the methodological approaches used for the study including the research design, population, instrumentation, reliability and validity of the instrument, sampling and data collection procedures, and analysis procedures.

\section{Research Question}

Question: Will the theoretical models for the relationship between racial identity, FS and PED of African-American college students' susceptibility to stereotype threat fit the empirical model?

Hypothesis: The study hypothesized that the theoretical model (Figure 1) will fit the empirical model. 


\section{Research Design}

This study examined the impact between FS, racial identity, PED on AfricanAmerican college students' susceptibility to stereotype threat using a quantitative structural equation analysis alongside an online survey research methodology. Quantitative analysis was utilized because it facilitated the development of mathematical models, theories, or hypotheses that relate to the phenomena being observed (Thomas, 2003). Structural Equation Analysis was also used to find the "best fit" model in research. This was done through finding a model that: fits well, has easily interpretable parameters, can be used as a basis for inference and prediction, and approximates reality in a parsimonious fashion (Preacher \& Merkle, 2012). A structural analysis was beneficial because it allowed the researcher to look at the latent constructs of stereotype threat, FS, PED and racial identity and derive a unbiased estimate for the relationship between them (Gopinath, 2014). In other words, using structural analysis allowed multiple measures to be related to a single latent construct, which in this case was susceptibility to stereotype threat (Gopinath, 2014).

This study relied on interpretation, observations, or interactions in order to draw conclusions that determined the extent to which the variables are related (McMillan \& Schumacher, 2010). This was achieved by using survey instruments to quantify the variables within the study. It should be noted that the researcher did not implement treatment, manipulate a variable, or use random assignment procedures, and the data collected reflected African-American college students' susceptibility to stereotype threat (McMillan \& Schumacher, 2010). 
A survey design was used because it facilitated a quantitative description of trends, attitudes and characteristics of a population sample. In addition, generalizations were made from a sample to a population through survey research (Creswell, 2008). For this study, the surveys were particularly preferential because of their accessibility, costeffectiveness, time efficiency, quick distribution, and response cycle. Survey research allows the researcher to choose a particular population and then administer to this population standardized questionnaires for the purpose of collecting data. Online surveys, in particular, give the researcher the ability to use questionnaires systematically through organization, audience selection, and the ability to outsource to a survey research company. These surveys are also very time efficient when compared to pencil and paper and face-to-face interviews. Utilizing online surveys is more cost effective and ideal when trying to reach a broad audience because it can reach a variety of different groups of people all around the world. Some additional benefits include decrease in data errors, increase in response rates, and flexibility of design.

Some disadvantages of online surveys are limited sampling and respondent availability (Wright, 2005). For instance, certain populations may not have internet access, be computer literate, and less likely to respond to surveys online (Wright, 2005). Surveys also have no interviewer, making surveys unsuitable for open-ended questions because there is no trained interviewer to clarify and explore the answers of the respondents. Lastly, survey fraud may be one of the largest disadvantages because individuals may be motivated to participate in online research because of an incentive. 


\section{Population and Sample}

Description of Population: The population consisted of African-American college students from around the United States of America. According to the U.S. Department of Education, National Center for Education Statistics (2017), 20.5 million students attended in the Fall of 2016. There was no report on the number of African-American students, however, 14.5\% of students that attended college in 2014 were black ("Fast Facts," n.d.). The number of students that attended college in 2014 was 20.2 million, if blacks totaled $14.6 \%$ of the students, one can assume a rough estimate of black college students in the United States for 2014 of: 2,949,200, or close to three million.

Sampling: Convenience sampling was used to recruit African-American college students from a number of institutions across the country. Since the population size for African-American students is exceptionally large with an estimate of 3,000,000 students enrolled in college; the sample size of 420 students exceeded the minimum of 300 students, which was needed to maintain a high confidence of results. The sample collected was through Qualtrics, which is a subscription software for collecting and analyzing data for market research, customer satisfaction and loyalty, product and concept testing, employee evaluations, and website feedback. Their samples come from traditional, actively managed market research panels.

The intent of this study was to collect data from 400 participants to ensure a statistically significant effect size. The target audience included adults 18 and above who identified as African-American and were currently enrolled in college. 


\section{Definition of Variables}

Black Racial Identity- Is a multi-faceted concept that consists of five stages/statuses, which are: pre-encounter, post-encounter, immersion, emersion and internalization. An ordinal scale was used to measure this independent variable. The predictor BRI was measured using the Black Racial Identity Attitude Scale (BRIAS) with a Likert response format, ranging from 1-5 ( 1 = strongly disagree, $5=$ strongly agree $)$ (Helms, 2010). Statuses that receive the highest scores were referred to as dominant statuses and used most frequently for interpreting racial stimuli in one's internal and external environment (Helms, 2010). Statuses that receive the lowest scores were referred to as recessive statuses and were infrequently used for interpreting racial stimuli (Helms, 2010). The BRIAS consists of 60 items on the following four sub-scales: pre-encounter, post-encounter, immersion-emersion \& internalization (Helms, 2010).

Pre-Encounter- Idealization of White people and White culture, and denigration of black people and black culture, measured by questions.

Post-Encounter- Attitudes, behaviors, and emotions that follow from personally troubling or impacting racial events.

Immersion - Psychological withdrawal into black environments, characterized by denigration of White people and White culture, and idealization of black people and experiences.

Emersion- the emotional and social bonding among black people.

Internalization- a humanist orientation derived from a positive commitment to Black people and Black culture, and a consequent valuing of the life experiences of other non-dominant groups. 
Perceived Ethnic Discrimination (PED) - A multi-faceted concept that consists of Disvaluation (DIS), Threat and Aggression (TAGG), Verbal Rejection (VR), Avoidance (AV), and Exclusion and Denial of Equal Treatment (E\&D.) The predictor variable PED will be measured using the Perceived Ethnic Discrimination Questionnaire (PEDQ) with a Likert response ranging from 1 to 7 ( 1 = event "never" and 7 = "very often"). The total score was computed by taking the mean of the four subscales DIS, TAGG, VR, and AV. E\&D were excluded from the total score because they did not factor in well in initial research, but they were used to look at how one fares in those areas. The subscale scores were computed as the mean of the item responses. It consisted of 22 items on the following five subscales: DIS, TAGG, VR, AV, and E\&D.

$D I S$ - Measures items such as, "how often have others had low expectation of you because of your ethnicity." Items 12-17 measure the subscale DIS with a mean of 1 being the lowest and 7 the highest. The higher the mean the more DIS one has experienced.

$A V$ - Measures items such as, "How often have others avoided physical contact with you because of your race." Items 4-6 measure the subscale AV with a mean of 1 being the lowest and 7 the highest. The higher the mean, the more stigmatization one has experienced.

$V R$ - Measures items such as, "How often have you been subjected to offensive ethnic comments..." Items 1-3 measure the subscale VR with a mean of 1 being the lowest and 7 being the highest. The higher the mean the more discrimination one has experienced.

$T A G G$ - Measures items such as, "How often have others threatened to hurt you because of your ethnicity." Items 18-22 measure the subscale threat/aggression with a 
mean of 1 being the lowest and 7 being the highest. The higher the mean the more threats and aggression one has experienced.

$E \& D$ - Measures items such as, "How often have you been denied access to a public facility or organization because of your ethnicity?" Items 7-11 measure the subscale E\&D, with a mean of 1 being the lowest and 7 being the highest. The higher the mean the more E\&D one has experienced. This scale does not factor into the total score.

Family Satisfaction: This measures the degree family members feel happy and fulfilled with one another. This predictor variable will be measured by the Family Satisfaction Scale (FSS) with a Likert response of 1-5 (1 = very dissatisfied to $5=$ extremely satisfied). The sum of all the items will give the total score ranging from 1050.

- Raw Score: 45-50 (56-99\%) = Very High: Family members are very satisfied and really enjoy most aspects of their family.

- Raw Score: 40-44 (61-85\%) = High: Family members are satisfied with most aspects of their family.

- Raw Score: 36-39 (36-60\% = Moderate: Family members are somewhat satisfied and enjoy some aspects of their family.

- Raw Score: 30-36 (21-35\%) = Low: Family members are somewhat dissatisfied and have some concerns about their family.

- Raw Score: 10-29 (10-20\%) = Very Low: Family members are very dissatisfied and are concerned about their family.

Stereotype Confirmation Concern Scale (SCCS): This is defined as the relatively enduring experience of stereotype threat. This is broken into two extremes; one extreme 
consists of those who chronically experience uncertainty and apprehension about appearing to confirm a stereotype about a group to which they belong. The other extreme consists of individuals who are free of such concerns. The outcome variable susceptibility to stereotype threat will be measured by the Stereotype Threat Concern (STC) Scale which has a Likert scale of 1-7 (1 = never to $7=$ always $)$. The sum of the items will give a total score ranging from 11 to 77 ; the mean of all responses will then be taken. A higher score equals a higher level of concern.

\section{Instrumentation}

In this section, the measurement instruments are outlined and discussed. In order to obtain psychometric data for this study, four measurement instruments and a demographic questionnaire were utilized. The instruments are as follows: (1) BRIAS; (2) PEDQ, (3) SCCS (4) FSS; (5) A demographic questionnaire.

\section{Black Racial Identity Attitude Scale}

The BRIAS (Parham \& Helms, 1981) is designed to assess the types of attitudes of the five phases in Cross' (1978) model of Nigrescence, which is one of the primary models of racial identity (Vandiver et al., 2002). The original scale consists of 60 items in which the participant responds using a 5 -point Likert scale $(1=$ strongly disagree, $5=$ strongly agree) to indicate the degree to which they can relate to the item (Helms, 2010; Parham \& Helms, 1985). However, the final scale used consisted of 29 items as determined by exploratory factor analysis. The higher the individual factor scores, the more attitudes a person possess from that particular factor (Parham \& Helms, 1985). This scale measures internal consistency estimates for the Pre Encounter, Encounter, 
Immersion/Emersion, and Internalization factors have been reported as .76, .72, .69, and .80 respectively.

The research behind the BRIAS suggests a number of redundant links between racial identity development, personality, and counseling-related variables (Fischer, Tokar, $\&$ Serna, 1998). Some of these variables include coping, depression, psychological functioning and well-being, self-actualization, affective states, self-esteem, perceived sensitivity of counselor, and race preference for a counselor (Fischer et al., 1998). Parham and Helms provided a measure of construct validity for the BRIAS by documenting its relation to counselor racial preference (Ponterotto \& Wise, 1987). Research has demonstrated some predictive and construct validity for the Racial Identity Attitude Scale relating the different stages to diverse counseling variables (Ponterotto \& Wise, 1987). In addition, an exploratory factor analysis revealed that a three-factor model of Cross' stages corresponded within the areas of pre encounter, immersion-emersion, and internalization (Fischer et al., 1998).

Parham and Helms conducted multiple research studies that investigated the relationship between racial identity attitudes and self-actualization of African-American college students, as well as racial identity and self-esteem in college students (Weeks, 1998). The results were congruent between the two studies, indicating that pre encounter and immersion/emersion attitudes were associated with low self-esteem, feelings of hostility, inferiority, and anxiety (Weeks, 1998).

\section{Perceived Ethnic Discrimination Questionnaire}

The PEDQ is a 22-item measure of ethnic discrimination that was developed using conceptual analyses, journalistic descriptions, and qualitative analyses (Contrada et 
al., 2001). It was designed to measure seven forms of discrimination, represented in a total of 22 items that refer to ethnicity as the basis of discrimination (Contrada et al., 2001). These items are broken down into the following subscales: VR, AV, E\&D, DIS, and TAGG. Scores are on a 7-point Likert scale ranging from 1 (never) to 7 (very often) and indicate how often over the past 3 months each form of discrimination has been experienced (Contrada et al., 2001).

A factor analysis revealed four relevant scales out of the initial seven (Contrada et al., 2001). These five scales are VR, AV, E\&D, DIS, and TAGG (Contrada et al., 2001). The Cronbach alphas ranged from .91 to .74 for the full sample, .90 to .73 for non-White individuals, and .89 to .71 for White individuals (Contrada et al., 2001). The PEDQ had been compared to other measures of discrimination, such as the Schedule of Racist Events and the Perceived Racism Scale (Contrada et al., 2001). The PEDQ, although similar, differs from these scales because it can be used in research involving any ethnic group, item content, and response format (Contrada et al., 2001).

\section{Family Satisfaction Scale}

The FSS was developed by Dr. David Olson to assess overall FS, including the two main dimensions of the circumplex model: cohesion and flexibility (Olson, n.d.). This scale has been frequently used in conjunction with the FACES instruments and was normed on a study that involved 1,000 families across the life cycle. It has since been used in studies covering a wide variety of family phenomena (Olson, n.d.). The FSS contains 10 items, which differs from the original 14-item scale. The 10-item scale was designed to assess satisfaction with various aspects of family functioning, including 
family closeness, flexibility, and communication (Olson, n.d.). Higher scores correlate to higher FS.

Validity was measured by looking at the intercorrelations of satisfaction variables and the results indicated that FS accounted for nearly half of the variance in quality of life, mirroring the findings of marital satisfaction and overall life satisfaction (Olson, n.d.). Family satisfaction also seems to follow the same $\mathrm{U}$ curve across the family life cycle that was found for marital satisfaction in previous studies (Olson, n.d.). The reliability of the scale is based on a sample of 2,465 family members and yielded an $\alpha=.92$ and test-retest of .85 (Olson, n.d.).

\section{Stereotype Confirmation Scale}

The SCCS was design to assess the relatively enduring and recurring experience of stereotype threat. This scale was developed in accordance with previous research on stereotypes (Contrada et al., 2001). Stereotype confirmation concern is defined as one's uncertainty and apprehension about appearing to confirm to a stereotype about a group to which they belong (Contrada et al., 2001). A pilot study was conducted using respondents to describe situations in which they felt they might be seen as conforming to a stereotype associated with their ethnic group (Contrada et al., 2001). Based on the results, the SCCS was constructed as a set of 11 items, where respondents are asked to use a 7-point scale ranging from 1 (never) to 7 (always) to indicate how often they have been concerned about confirming a stereotype over the past three months (Contrada et al., 2001). Total scores range from 11 to 77, and higher scores represent greater concern (Johnson \& Anderson, 2014). The SCCS indicated a significant ethnic group effect $F(3,325)=$ 
14.68, $p<.001$ and it demonstrates excellent internal consistency, $\alpha=.91$ (Contrada et al., 2001; Johnson \& Anderson, 2014).

\section{Demographic Questionnaire}

The demographic questionnaire used in this study collected information regarding the participant's gender, college major, age, and year in college (i.e., freshman, sophomore, etc...). The researcher used this questionnaire for narrowing down participants' background and other information. The questionnaire was also used as a qualifier for those who may take the surveys. This is because the study was based on African-American college students, and in order to limit outliers, a student needed to be identified as African-American before participating. This was done through five questions based on research on what it means to be African-American. The 2010 U.S. Census stated that, "Black or African-American" refers to a person having origins in any of the Black racial groups of Africa" (Census, 2011). In addition, U.S. law states that, "African-Americans are citizens or residents of the United States who have origins in any of the black populations of Africa" (US Legal, 2016). Therefore, in order to determine if the student fell within the bounds of what the United States considers African-American, the following questions were asked:

- Do you consider yourself African or "Black"-American?

- Are you of African or Black descent?

- Were you born in America \& are you a US citizen?

- Have you lived the majority of your life in the United States of America?

- Are both your parents of African or Black descent

- Are you currently enrolled full time in college?

The respondent had to answer yes to these questions in order to proceed with the survey. The participant also had to answer yes to the question: Have you spent your entire life 
here, excluding vacations? Are your parents of black or African descent, or considered African-American? The reason for this is that socialization happens mainly through family at a young age and having parents who in some way identify with their experience may affect their socialization (Demo \& Hughes, 1990). Since development is ongoing, if someone has not spent the majority of their life in the United States, it may affect their socialization and even identification with being African-American, therefore this study looked for individuals who have spent the majority of their lives in the United States (Schwartz, Donnellan, Ravert, Luyckx, \& Zamboanga, 2012). Respondents needed to answer yes to all five questions (listed above) to move forward.

\section{Procedures}

Data was gathered through Qualitrics, which sent potential respondents email invitations informing them of the survey's purpose, length, and available incentives. Participants were selected based on the researcher's qualifiers, which were AfricanAmerican college students age 18 and older. The surveys used for this research were anonymous and participants were issued a virtual informed consent that described the participation procedures. Those who agreed to participate were instructed to check the "yes" consent box and proceed to the next page to start the surveys. In order to ensure that the participants met the researcher's demographics, a questionnaire that contained five qualifiers was utilized. This questionnaire came directly after the respondents consented to the informed consent. These questions were as follows:

- Do you consider yourself African or "Black"-American?

- Are you of African or Black descent?

- Were you born in America \& are you a US citizen?

- Have you lived the majority of your life in the United States of America?

- Are both your parents of African or Black descent? 
- Are you currently enrolled full time in college?

Respondents had to answer "yes" to all of these questions to proceed forward, if they answered "no" to any one of these questions, they were eliminated. Once screened they were allowed to take the BRIAS, FSS, PEDQ, and SCCS online simultaneously. The estimated time for completion was 11-30 minutes, which was stated in the informed consent. Participants were informed about their right to withdraw participation at any time without permissions and their right to contact the researcher of the study or Andrews University IRB in case they had any questions about the study. Participants were also assured of confidentiality and anonymity. Participants were asked to read and agree to the informed consent, which informed participants of the study, the risk, and the time allotted to take the surveys. Respondents received incentives through Qualtrics, based on the length of the survey, the panelist profile, and target acquisition difficulty. These incentives ranged from cash, airline miles, gift cards, redeemable points, and sweepstakes entry. In order to ensure quality checks, Qualtrics replaced respondents who "straightline" through surveys or finished in less than $1 / 3$ of the average survey completion length. To the best of the researcher's knowledge, no research participants were harmed in the process of this study.

The researcher of this study submitted a request to the Institutional Review Board (IRB) of Andrews University for research approval. IRB approval was received in October of 2017 and Qualitrics began data collection in February of 2018. Responses were collected from 420 participants within the span of 4 weeks. Qualtrics was utilized because it is known worldwide for its survey technology and has a vast array of online panel partners to ensure an array of diverse quality respondents worldwide. 


\section{Treatment of the Data}

Data was transferred from Qualitrics to the Statistical Package for Social Sciences (SPSS) through a formatting option that ensured accurate data transfer and eliminated error from human data entry. The principle researcher, committee members, and Qualtrics project team were the only entities with access to the data. The study utilized descriptive, inferential, and multivariate statistical analysis. The research question utilized Structural Equation Modeling.

\section{Data Analysis}

Data gathered from the survey was analyzed using SPSS for Windows and the Analysis of a Moment Structures (AMOS) computer software, which has been specifically designed to perform path analysis. Descriptive statistics were performed by frequency, mean, and standard deviation, alongside Pearson $r$ correlations and exploratory analysis. These were used to test significant differences in variables of interest and to determine relationships between independent variables and any interaction between different groups of variables. Structural Equation Modeling was the data analysis technique that was used in this study to assess how well the theoretical interrelationships between the variables (racial identity, FS, PED, and susceptibility to stereotype threat) match the empirical interrelationships between the variables (racial identity, FS, PED, and susceptibility to stereotype threat). Structural Equation Modeling

determined that the hypothesized model was not the best fit. Since the model was not the best fit, other factors were explored, analyzed and modified, in order to find the best fit model. The estimates of the structural model was specified and calculated, using the Full Maximum Likelihood Estimation. The fit between the structural model and the observed 
data were determined by Chi Square and the other fit indexes such as: The Goodness of Fit Index (GFI), Normed Fit Index (NFI), Comparative Fit Index (CFI), and Root Mean Square Error of Approximation (RMSEA) (Meyers, Gamst, \& Guarino, 2013). The CFI, GFI, and NFI needed to be $\geq .90$ to be considered acceptable, and the value of the RMSEA needed to be $\geq .05$ to be considered acceptable (Meyers et al., 2013). The hypothesized relationships and inter-relationships between the latent and observed variables with each other were examined in order to determine intensity, direction, and statistical significance from the correlation coefficients that were generated in the regression weights and estimates tables.

\section{Summary}

This chapter described the methods that were used in this study. This study investigated the relationship of FS and racial identity on African-American college students' susceptibility to stereotype threat. These variables were measured by the following measures: FSS, BRIAS, PEDQ, SCCS, and the Demographics questionnaire.

Participants were chosen at random through convenience sampling, utilized through the Qualitics program. After data collection was completed, analysis was conducted using the SPSS and AMOS computer software, which has been specifically designed to perform path analysis. This chapter discussed the research question and research design as related to the study, the population, and sample size. It also explained the related procedure, treatment of data, and method of data analysis. Chapter 4 explains the results of the research, while Chapter 5 explores the implications of the results as it relates to the original research question and literature. 


\section{CHAPTER 4}

\section{RESULTS OF THE STUDY}

\section{Introduction}

This chapter examined the results of the study through an analysis of the data. The purpose of this study was to investigate the impact of racial identity, FS, and PED on African-American college students' susceptibility to stereotype threat. The research hypothesized that the theoretical model, presented in chapter 1 will fit the empirical model. Structural Equation Modeling was used to test this hypothesis and analyze the relationship between and among the variables.

\section{Demographic Characteristics}

Survey responses were collected from 420 individuals, who identified themselves as African-American college students. Eighty-eight percent of participants completed all items on the survey, while $12 \%$ of participants did not respond to items pertaining to 'gender' and 'college year'.

Of the $N=420,225$ were between the ages of $18-20(53.6 \%), 180$ were between the ages of $21-23(42.9 \%)$, eight were between the ages of $24-26(1.9 \%)$ and seven were 27 and older (1.5\%). Responses indicated that 85 (20.2\%) were male and 295 (70.2\%) were female, $9.6 \%$ is missing because 40 responses did not record gender because it was absent from the questionnaire, during the soft (test) launch. The college 
students ranged in tenure with 173 being in their first year (41.2\%), 124 being in their second (29.5\%), 74 being in their third (17.6\%), 42 being in their fourth (10\%), 21 being in their fifth year or greater (5\%) and 11 choosing not to answer $(2.6 \%)$; see Table 1.

Table 1

Respondents’ Demographic Statistics

\begin{tabular}{|c|c|c|}
\hline Demographic & $N$ & $\%$ \\
\hline \multicolumn{3}{|l|}{ Gender } \\
\hline Male & 85 & 20.2 \\
\hline Female & 295 & 70.2 \\
\hline \multicolumn{3}{|l|}{ Age } \\
\hline $18-20$ & 225 & 53.6 \\
\hline $20-22$ & 180 & 42.9 \\
\hline $22-24$ & 8 & 1.9 \\
\hline 25 and up & 7 & 1.5 \\
\hline \multicolumn{3}{|l|}{ Year in College } \\
\hline $1^{\text {st }}$ & 173 & 41.2 \\
\hline $2^{\text {nd }}$ & 124 & 29.5 \\
\hline $3^{\text {rd }}$ & 74 & 17.6 \\
\hline $4^{\text {th }}$ & 42 & 10 \\
\hline $5^{\text {th }}$ and up & 21 & 5 \\
\hline
\end{tabular}

\section{Description of the Variables}

The description of the variables, including mean, standard deviation, and skewness, are reported in Table 2. BRI variable scores were obtained from the BRIAS for dissonance (post-encounter), conformity (pre-encounter), internalization, immersion, and emersion. Family satisfaction variable scores were obtained from the FSS (11 items in total) and three subset of items were created based on factor analysis: FS1 (items 42, 40, and 35), FS2 (items 36, 37, 39, and 43), and FS3 (items 44, 34, 38, and 41). For the 
Table 2

Respondents' Descriptive Statistics

\begin{tabular}{|c|c|c|c|c|c|c|}
\hline Variable & $N$ & Mean & $S D$ & Min & Max & Skewness \\
\hline \multicolumn{7}{|l|}{ BRI } \\
\hline Conformity & 420 & 2.39 & .838 & 1.00 & 5.00 & .810 \\
\hline Dissonance & 420 & 2.49 & .898 & 1.00 & 5.00 & .486 \\
\hline Immersion & 420 & 2.85 & .764 & 1.00 & 5.00 & .072 \\
\hline Emersion & 420 & 3.67 & .832 & 1.00 & 5.00 & -.523 \\
\hline Internalization & 420 & 3.89 & .676 & 1.00 & 5.00 & -.909 \\
\hline \multicolumn{7}{|l|}{ PED } \\
\hline VR & 420 & 3.14 & 1.53 & 1.00 & 7.00 & .611 \\
\hline$E \& D$ & 420 & 2.57 & 1.51 & 1.00 & 7.00 & .975 \\
\hline TAGG & 420 & 2.32 & 1.54 & 1.00 & 7.00 & 1.24 \\
\hline DIS & 420 & 3.38 & 1.79 & 1.00 & 7.00 & .369 \\
\hline $\mathrm{AV}$ & 420 & 3.00 & 1.62 & 1.00 & 7.00 & .622 \\
\hline FS total & 420 & 3.17 & .904 & 1.00 & 5.00 & -.106 \\
\hline FS1 & 420 & 3.37 & 1.06 & 1.00 & 5.00 & -.057 \\
\hline FS2 & 420 & 3.13 & .980 & 1.00 & 5.00 & -.099 \\
\hline FS3 & 420 & 3.37 & .920 & 1.00 & 5.00 & -.322 \\
\hline STC total & 420 & 3.16 & 1.56 & 1.00 & 7.00 & .405 \\
\hline STC1 & 420 & 3.51 & 1.86 & 1.00 & 7.00 & .303 \\
\hline STC2 & 420 & 2.92 & 1.60 & 1.00 & 7.00 & .552 \\
\hline STC3 & 420 & 3.12 & 1.65 & 1.00 & 7.00 & .483 \\
\hline
\end{tabular}

variable PED, scores were obtained from the PEDQ for five different types of discrimination, which are (a) VR, (b) AV, (c) E\&D, (d) DIS, and (e) TAGG. For the stereotype threat variable scores were obtained from the SCCS with 11 items in total, and three subset of items were created based on factor analysis: STC1 (items 23, 24, and 25), STC2 (items 26, 27, 28, and 29), and STC3 (items 30, 31, 32, and 33).

The BRIAS scores were based on the means of each subscore, which ranged from 1-5 $(1=$ strongly disagree, $5=$ strongly agree $)$. Subscores that received the highest scores 
are referred to as dominant statuses and subscores that received the lowest scores are referred to as recessive statuses. For the conformity (post-encounter) aspect of BRI, respondents achieved an average rating of 2.49 with a standard deviation of .898 . The dissonance (pre-encounter) scale, respondents indicated an average rating of 2.39 with a standard deviation of .838. For the immersion scale, respondents indicated an average of 2.85 with a standard deviation of .764 , and for the emersion scale; respondents indicated an average of 3.67 with a standard deviation of .832 . For the internalization scale, respondents indicated an average of 3.89 with a standard deviation of .676 . The skewness statistics indicate that all five of the subscales are normally distributed, with all values falling between -1 and 1 .

The PEDQ, scores were based on the mean of each subscore, which ranged from 1 to 7 ( $1=$ less perception of discrimination and $7=$ higher perception of discrimination $)$. For the VR scale, respondents indicated an average of 3.14 with a standard deviation of 1.53 and for the AV scale, respondents indicated an average of 3.00 with a standard deviation of 1.62. For the E\&D scale, respondents indicated an average of 2.57 with a standard deviation of 1.51. For the DIS and TAGG scales, respondents indicated an average of 3.38 and 2.32 with a standard deviation of 1.79 and 1.54 respectively. The skewness statistics indicate that all five of the subscales are normally distributed, with all values falling between -1 and 1 , or near one.

The FSS is usually based off the total score, but for the purpose of this research, FS was based off the mean of the total score, which ranged from 1 to 5 , which means that the higher the score the more FS. For this scale, respondents average was 3.16, with a standard deviation of 1.56. The skewness statistic indicates that all four of the scales and 
subscales are normally distributed, with all values falling between -1 and 1 . Means, standard deviations, range, and skewness for each of the three subscales (FS1, FS2, and FS3) are included in Table 2.

The SCCS scores were also based on the mean of the total score, which ranged from 1 to $7(1=$ never to $7=$ always $)$. For this scale, respondents indicated an average of 3.16 with a standard deviation of 1.56 . The skewness statistics indicate that all four of the scale and subscales are normally distributed, with all values falling between -1 and 1 . Means, standard deviations, range, and skewness for each of the three subscales (STC1, STC2, and STC3) are included in Table 2.

\section{Hypothesis Testing}

\section{Structural Model}

The conceptualized model previously discussed in Chapters 1 and 3 included the predictor variables, BRI, FS, and PED; and the outcome variable stereotype threat. A direct path was drawn from BRI to PED and stereotype threat, since research suggests BRI can moderate both PED and stereotype threat. BRI has five indicator variables: Preencounter, post-encounter, emersion, immersion, and internalization. A direct path was drawn from pre-encounter and internalization to PED based on research from two separate studies (Cokely, 2005; Lee \& Ahn, 2013). Their findings suggested that individuals in early and middle stages (i.e post-encounter and emersion) or with high levels of racial identity (i.e internalization), experience more internalized racism, racism and microaggressions, which may affect their susceptibility to PED (Cokley, 2005; Lee \& Ahn, 2013). A direct path was also drawn from FS to PED, as research suggest higher 
levels of FS could influence the levels of PED experienced by an African-American individual.

The PED component has five indicator variables: VR, AV, E\&D, DIS, and TAGG. There is a direct path from FS to the indicator variable E\&D. Research by Skowron (2005) revealed that the family unit could protect against environmental stress, such as E\&D. Another direct path was also drawn from PED to stereotype threat and the indicator variable $\mathrm{E} \& \mathrm{D}$ to stereotype threat as research suggests that increased vulnerability to PED and E\&D could make one more susceptible to stereotype threat. Stereotype threat has indicator variables STC1. STC2, STC3, and FS has indicator variables FS1, FS2, and FS3.

Structural equation modeling was used to analyze the proposed theoretical model This procedure allows one to examine to what extent the indicator variables predict or define the latent variables. This technique captures both types of models simultaneously by combining a measurement model (model based off of the population sample) and a structural model (model based off of the literature).

The hypothesized model showed a significant chi square of $953.069(d f=96, p=$ .000). Although a significant $p$ value is generally an indicator of poor fit, with a large sample size such as the one used in this study $(N=420)$, it is typical for the $p$ value to indicate false positives $(p>.05)$. Therefore, the resultant indicator might not be accurate representations of good or acceptable model fit. However, the model also yielded poor fit indexes for the GFI $=.747, \mathrm{NFI}=.829, \mathrm{CFI}=.843$, and $\mathrm{RMSEA}=.146$. For a good fit, the GFI value should be at or above .90 , the NFI and CFI values at or above .95, and the 
RMSEA value at .05 or below. Based on these results from the original model the model was not found to be significant, therefore, a respecification was conducted. See Figure 1.

\section{Respecified Structural Model}

Because the original hypothesized model did not achieve an acceptable fit to explain the relationship between BRI, FS, PED, and stereotype threat, the model was revised. Several paths were added to improve fit, based on consultation with standardized residuals and modification indexes. One of the most notable changes to the model is the fact that the latent variable BRI was separated into BRI-InitialStages and BRILatterStages. The BRI-InitialStages contained immersion, dissonance, and conformity; and BRI-LatterStages contained emersion and internalization. New research that conducted a multilevel exploratory factor analysis of BRI revealed that BRI-InitialStages had a strong correlation between conformity, dissonance, and immersion $(r=.82$ and $r$ =.90) (Grajales et al., 2018). Additionally, BRI-LatterStages showed a strong correlation between emersion and internalization ( $r=.94$ and $r=.88$ ) (Grajales et al., 2018). Between

BRI-InitialStages and BRI-LatterStages, a negative correlation was observed, suggesting a clear distinction between the initial stages of racial identity and latter stages of identity (Grajales et al., 2018). This is confirmed by literature that indicates that different levels of racial identity could have different effects on one's vulnerability to stereotype threat (Lee \& Ahn, 2013; Davis et al., 2006).

Correlations were added from both BRI-InitialStages and BRI-LatterStages to FS although there is limited research on the relationship between BRI and FS, research suggests that higher levels of FS can boost racial socialization, which is congruent with how one travels through racial identity (Mandara \& Murray, 2000). Correlations were 
also added from the BRI-InitialStages to the BRI-LatterStages, which is to be expected since both BRI-InitialStages and BRI-LatterStages represent the single construct, BRI. A pathway was added from BRI-InitialStages to TAGG, this is consistent with the literature stating that depending on one's developmental stage within their racial identity, TAGG can be exacerbated or controlled (Thomas et al., 2015). Paths were also added from BRIInitialStages and BRI-LatterStages to PED, which is consistent with the literature that states ethnic identity can act as a buffer to the stress of discrimination, and racial identity can affect how one receives and perceives discrimination (Walden, 2009; Mossakowoski, 2003).

Several paths were eliminated in order to find a good fit for the respecified model. The pathway from BRI to stereotype threat was eliminated, although research has shown that there is a consistent relationship between BRI-InitialStages and BRI-LatterStages and stereotype threat, this could be attributed to the fact that, in the respecified model, BRI-InitialStages and BRI-LatterStages are seen to have direct effects on PED, which is the main precursor to stereotype threat. According to previous research findings, racial identity can exacerbate or buffer against discriminatory situations or hostile environments (Lee \& Ahn, 2013; Davis et al., 2006). Suggesting that there is in fact an indirect relationship between BRI and stereotype threat, indicating that there is justification to eliminate the pathway from BRI to stereotype threat. The path from FS to E\&D was eliminated, which is not surprising because although research on this relationship was present it was limited, suggesting that the relationship was not strong enough to remain in the respecified model. Lastly, paths from FS, Internalization, and Pre-Encounter (dissonance) to PED were also eliminated; however, it should be noted that the separation 
of the latent variable BRI into two levels, complicates the commonalities between the initial model and the respecified model. In the initial model, statuses from both BRIInitialStages and BRI-LatterStages had pathways to PED. However, the respecified model broadens these relationships to look at the whole level instead of the individual statuses. Therefore, the initial pathways from FS, Internalization, and pre-encounter to PED, were not as much eliminated as they were broadened.

The model was further respecified by adding correlation between error terms due to large covariances. Two total correlations were added, which were among the PED subgroups.

As a result of these changes, the respecified model produced a significantly improved fit as shown by the fit statistics. The chi-square decreased to $419.555(d f=93)$, but was still statistically significant $(p=.000)$. As suggested early, this may be due to the large sample size used for this study. The GFI increased to .880, the NFI increased to .919 , the CFI increased to .936 , and the RMSEA decreased to $.092(90 \mathrm{CI}=.083 \& .101)$. These statistics indicate an excellent fit for the respecified model. The final model is shown in Figure 2; Table 3 shows the GFI.

\section{Analysis of Models}

The model was analyzed to examine the hypothesized relationship between BRIInitialStages, BRI-LatterStages, FS, PED, and stereotype threat. Using an alpha level of .05 to determine statistical significance, this model confirmed the hypothesized relationships based on theory. BRI-InitialStages and BRI-LatterStages were both positively correlated with FS $(r=.237, p<.001 ; r=.179, p<.001$, respectively). While 


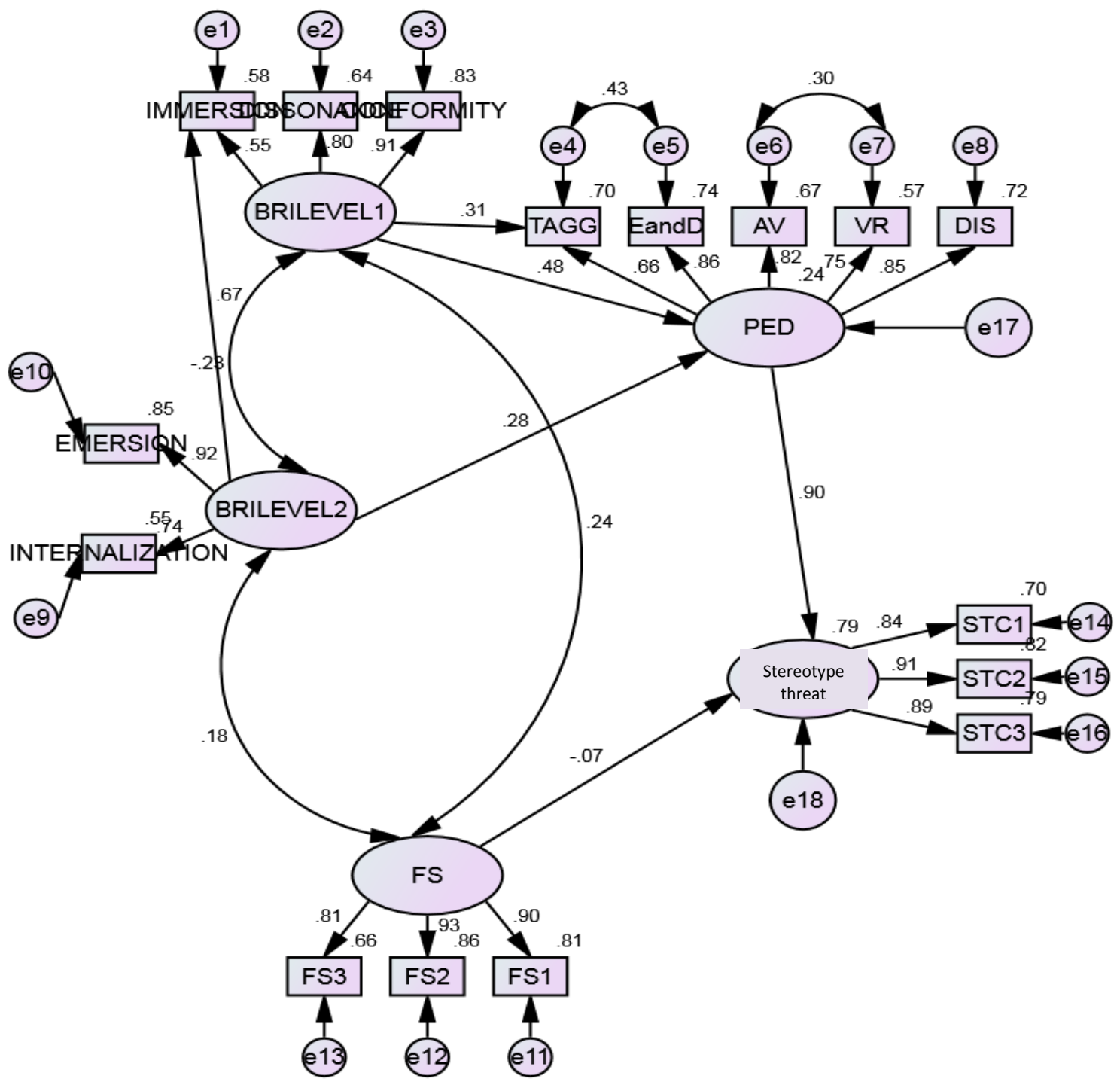

Figure 2. Respecified Model. BRILEVEL 1 and BRILEVEL 2 are used instead of BRIInitialStages and BRI-LatterStages to refer to Black Racial Identity Level 1 and Black Racial Identity Level 2, respectively. 
Table 3

Chi Square and Goodness of Fit for Models

\begin{tabular}{lrccccc}
\hline Factor Model & $X^{2}$ & $d f$ & GFI & NFI & CFI & RMSEA \\
\hline Original Model & & & & & & \\
$\quad$ Hypothesized & 953.069 & 96 & .747 & .829 & .843 & .146 \\
$\quad$ Adjusted & 419.555 & 93 & .880 & .919 & .936 & .092 \\
\hline
\end{tabular}

BRI-InitialStages and BRI-LatterStages were negatively correlated with each other $(r=-$ $.235, p<.001)$. BRI-InitialStages and BRI-LatterStages both have positive direct effect on PED $($ beta $=.477, p<.001 ;$ beta $=.276, p<.001$, respectively $)$ PED also has positive direct effect on stereotype threat $($ beta $=.900, p<.001)$. In addition, BRI-InitialStages had positive direct effects on, the sub-variable for latent variable PED, TAGG (beta= $.306, p<.001)$. FS had negative direct effects on stereotype threat (beta $=-.067, p<$ $.001)$. Results from the final model indicate that it explains $79 \%$ of the variance of stereotype threat.

Effect sizes were also calculated to determine the magnitude of the differences and the strength of the relationship between variables. Rosenthal (1996) suggests using the following thresholds to determine the size of effect: small $=.10$; medium $=.30$; large $=.50$; very large $=.70$. The path coefficient between FS and stereotype threat suggests a small effect size $\left(\beta^{2}=.004\right)$, indicating there is about $.4 \%$ of shared variance between FS and Stereotype Threat. PED and stereotype threat had a very large effect size, with the two variables sharing about $81 \%$ of variance $\left(\beta^{2}=.81\right)$. The paths from both BRIInitialStages and BRI-LatterStages to PED both suggested small effect sizes $\left(\beta^{2}=.228\right.$, .076 , respectively), with $22 \%$ and $7.6 \%$ of explained variance respectively. 
The separation of the BRI variable resulted in the addition of multiple pathways. The added paths from BRI-LatterStages to Immersion suggested a medium effect size $\left(\beta^{2}\right.$ $=.445)$ with $44.5 \%$ of explained variance. In addition, the path from BRI-InitialStages to TAGG suggested a small effect size $\left(\beta^{2}=.076\right)$ with $7.6 \%$ of variance explained.

\section{Summary of the Findings}

The study hypothesized that the theoretical covariance matrix proposed would be equal to the empirical covariance matrix developed from collected data. The fit statistics gathered from the structural equation model disproved the hypothesis, resulting in a respecification. The respecified model indicated a good fit. Most effect sizes were low to moderate $\left(\beta^{2}=>=.10\right.$ to .30$)$. Although, some low level correlations were present, they were necessary for higher-order items and to the overall fit of the model. The respecified model explained $79 \%$ of the variance of stereotype threat. A more detailed discussion of the findings, as well as the influence of other contributing factors, will be discussed in the next chapter. 


\section{CHAPTER 5}

\section{SUMMARY, CONCLUSIONS, IMPLICATIONS,}

\section{AND RECOMMENDATIONS}

\section{Introduction}

This chapter provides the reader with a brief overview of the study, including information regarding the research problem, hypothesis, purpose, literature review, research method, and significance of the study. It discusses the key findings from the study, and suggests implications for clinical psychologists, counseling psychologists, and educators.

\section{Research Problem}

In the past, stereotype threat was viewed mainly as a factor that affected academic achievement and testing, and was overshadowed by something called an "achievement gap, [which is] an overall academic performance disparity" between African-Americans and their White counterparts (Davis, 2012; Steele \& Aronson, 1995). In fact, some research attempts to contend that the reason African-Americans could not keep up on the college level was because of the inequities of the educational system of the United States or that the "life chances" of African-Americans, as compared to Whites, are more a function of socioeconomic status than race (Davis, 2012). This indicates that despite the other factors that can play into academic success, attitudes towards minorities play a large 
role and these attitudes can affect minorities in a number of ways, including through stereotype threat (Cohen \& Garcia, 2005).

Stereotype threat has had many effects on the African-American community over the years, in areas such as disidentification (Woodcock, et al., 2012); disruption to academic performance (Johnson-Ahorlu, 2013); and undue pressure to "not be the bad guy" (Fischer, 2010). It is undeniable that African-American college students are dealing with the impact of stereotype threat they have experienced in the past or are experiencing right now (Okeke et al., 2009). As a result, they feel as though they cannot "achieve high" or that they "do not belong" (Johnson-Ahorlu, 2013). These students constantly face subtle judgments based on broad stereotypes, microaggressions, and the pressure to resist and disprove negative assumptions about their intelligence (Fries-Britt \& Griffin, 2007). This makes achieving success stressful, especially for these students, which in part is due to the absence of a minority presence, or a social support structure.

Having a strong racial identity acts as a buffer against stereotypes, but if AfricanAmerican students do not enter their universities with a strong racial identity, it could cause an emotional strain and create a sense of "otherness" (Campbell, 2010; Gordon, 2012). It is plausible that this emotional strain and sense of "otherness" can then exacerbate their susceptibility to stereotype threat. When stereotype is present, students may disengage or disidentify from a particular domain (i.e. goal or aspiration) as a selfprotective measure (Woodcock et al., 2012). Therefore, as the college environment becomes more diverse, there must be an understanding of how stereotype threat can affect students and communities. Even more so, there needs to be an understanding of what factors guard against or exacerbate this threat. 
Studying the relationships between FS, racial identity, and perceived

discrimination are essential because these are factors that are known to have an impact on African-Americans' susceptibility to microaggressions and adversities. This information can then be used as a catalyst to build programs to end (or at least buffer against) the phenomenon and, in some manner, level the playing field. In addition, it has been shown in previous research studies that the effects of discrimination among African-Americans can have detrimental effects on their mental and physical health (Wegmann, 2017). It has also been shown that the African-American family unit creates a "safe space" for African-American families to discuss racial discrimination and disparities they may experience (Kelly et al., 2013). Not to mention, FS is one of the most important contributors to an adult's subjective well-being and life satisfaction (Baker, 1998).

Racial identity could also be a protective factor against effects of discrimination. Specifically, when African-American perceive their own race to be liked, they tend to have a higher regard for themselves despite experienced discrimination (Lee \& Ahn, 2013). Given that African-American are at increasing risks of discrimination, which may result in psychological and physical consequences. Understanding of protective factors that may mitigate impacts from stereotype threat is very important to support the growth and mental and physical well-being of African-Americans

\section{Purpose of the Study}

The purpose of this study was to examine FS, racial identity, and PED as predictors of vulnerability to stereotype threat among African-American college students. 


\section{Research Hypothesis}

The research hypothesis for this study was that the present empirical model, based on collected data would satisfactorily fit the model, developed based on theory and previous research findings. The hypothesized model was expected to achieve a good fit with the actual, observed data, which then would validate the explanation of the phenomenon stereotype threat among African-American college students through the predicted relationships of the latent variables.

\section{Significance of the Study}

The significance of this study is to contribute to the already growing body of research on stereotype threat and minority students, particularly African-American college students. Research has already shown that stereotype vulnerability hinders accurate self-knowledge, causing a blockage in intellectual ability (Aronson \& Inzlicht, 2004). These self-doubts and beliefs about one's self can cause unrealistic aspirations and fluctuation on "days of smartness" (Aronson \& Inzlicht, 2004). In addition, research has shown that African-American college students will disengage or disidentify from a particular domain (i.e. goal or aspiration) as a self-protective measure (Woodcock et al., 2012). Therefore, as African-Americans engage in daily adversities, the question arises as to what can serve as a barrier against psychological vulnerabilities. Familial factors have been known to act as protective barriers for African-American students against stereotypes, and racial identity can serve as a buffering role against racial discrimination (Kelly et al., 2013; Lee \& Ahn, 2013). This study will add knowledge to the base by looking at racial identity and FS as factors that may contribute to African-American college students' susceptibility to stereotype threat. Therefore, this study will give further 
insight into the predictors of stereotype threat and possibly allow further research to focus on: primary and secondary schooling, college, and environmental factors such as home life and group membership.

Studying the correlations between FS, racial identity, and PED are essential because these are factors that are known to affect and correlate to African-Americans' susceptibility to microaggressions and adversities. This information can then be used as a catalyst to build programs to end (or at least buffer against) the phenomenon and, in some manner, level the playing field. It has been proven that the African-American family unit creates a "safe space" for African-American families to go to and discuss racial discrimination and disparities that they may experience (Kelly et al., 2013). In addition, FS is one of the most important contributors to an adult's subjective well-being and life satisfaction (Baker, 1998). Racial Identity also serves as a buffer against discrimination, suggesting that when African-Americans view that their own race as liked, they will have a higher regard for themselves despite discrimination (Lee \& Ahn, 2013). This is important because the psychological and physical effects of discrimination are continuing to grow and this is something with which African-American students routinely have to cope (Bourke, 2010; Hope et al., 2015). It seems that these factors influence stereotype threat, in some fashion, and understanding their relationship to stereotype threat and addressing them in formative years (i.e., college) can potentially lead to ways to strengthen the mental and physical health of African-Americans.

This area of research is important for the Counseling Psychology field because it could expand the knowledge base about factors that make African-American students more susceptible to stereotype threat. This is important because there has been a decline 
in African-American graduation rates over the past 10 years. It has been suggested that this is because of the racial tensions that have risen over time and the racial insensitivities and lack of representation these students experience at their school (Camera, 2016). Additionally, the findings from the present research could provide insights as to how universities could foster safe and non-judgmental learning space that encourage growth and expression of black racial identity, which might then reduce the effects of stereotype threats on African-American students.. Ultimately, this research can help academic institutions bolster the success of African-American and other minority students. Not to mention, knowing what could buffer African-American college students from bearing the negative effects of stereotype threat could shield them from mental and medical health issues later on in life.

This study will also add to the field of Counseling Psychology by providing insight into the effects of discrimination faced by African-Americans. This knowledge will allow counseling professionals to create more informed interventions and increase their knowledge base. Overall, a number of groups will benefit from this study, including counselors, therapists, professors, and minority groups themselves. This study will enable these groups to provide services that can take into context the effects of stereotype threat and account for them in their intervention and teaching styles. In addition, this information could be beneficial in combating and buffering for stereotype threat factors for counseling psychologist, educators, advisors, and administrators.

\section{Overview of the Literature}

A literature review regarding this topic indicated that FS, racial identity, and PED all impact STC/vulnerability among African-American college students. However, in 
order to fully understand the scope of this study and its basis, one must first understand the literature that was reviewed to develop the first model and validate the respecified model. Therefore, in this overview of literature, multiple theories and relationships was looked at bringing us to our proposed model and hypotheses. Initially, the specific themes and theoretical framework will be reviewed, followed by an in-depth look into each of the variables and their relationship to African-Americans and stereotype threat. The researcher felt that overviewing the literature in this manner would provide the proper foundation for the discussion in relation to the initial model, results, and implications. First, an understanding of the underlying theoretical framework should be reviewed and understood.

The Henri Tajfel's social identity theory forms the basis of stereotype threat because it states that, "individuals wish to maintain a positive image of themselves and their group and they feel threatened when their group is viewed negatively"(Hogg, 2006). Since one desires to have a positive self and group image fear is generated when this image is compromised. The Circumplex Theory asserts that FS is based on the concepts of balancing flexibility, communication and cohesion, which is seen in the AfricanAmerican family's communication styles, especially in response to, racial socialization, youth and family adaptation and the depth of the family unit (Anglin \& Wade, 2007; Kelly et al., 2013). The BRI Theory affirms that those who have underdeveloped racial identity may be more susceptible to stereotype threat than those who have developed their racial identity (Anglin \& Wade, 2007). In addition, higher levels of racial identification do buffer African-Americans against self-esteem and social threats (Davis 
et al., 2006). It has become evident from the literature, that all these factors work together to either increase or decrease one's vulnerability to stereotype threat.

When an individual attempts to "suppress" the emotion or anxiety associated with stereotypes it both taxes and hinders one's memory (Johnson-Ahorlu, 2013). Stereotype threat can also lead to disidentification, meaning that students will disengage or disidentify from a particular domain as a self-protective measure (Woodcock et al., 2012). In addition, stereotypes and stereotype threat can create pressure for students to feel that they have to be watchful of their own behaviors because they do not wish to confirm stereotypes (Fries-Britt \& Griffin, 2007). This may trigger feelings among students that they have to act counter to what the stereotypes portray. Stereotype threat affects African-Americans in many ways and it is impacted by numerous factors, such as, racial identity, FS and PED.

Cross' BRI Model identifies five stages that have been shown to dictate a person's response to racially relevant situations and are known to play factors in moderating stereotype threat (Davis et al., 2006). Research has shown that developing parts of a person's racial identity can buffer against stereotypes (Davis et al., 2006). For example, higher levels of racial identification are thought to buffer African-Americans against self-esteem and social threats (Davis et al., 2006). Studies have shown that racial identity could serve as a buffering role against discrimination, meaning that in terms of public regard, the more positive that African-Americans believe others view their own race, the less offense they take to discrimination (Lee \& Ahn, 2013). Therefore, from the research it seems that racial identity can act as a moderator to stereotype threat, especially among African-American college students. 
Minority groups at a PWI can increase the pressure not to live up to the "group" stereotype (Fischer, 2010). Studies have shown that Black students have to work harder at PWIs in order to ensure success (Brower \& Ketterhagen, 2004). In addition, college could cause students to become more self-aware of their race; therefore, if these students do not come in with an established racial identity, discrimination will take its toll, devaluing not only self-esteem but also racial identity (Campbell, 2010). Racial identity impacts stereotype threat on more than one level but FS is also an impacting factor for vulnerability to stereotype threat.

Research has indicated that the family unit for African-Americans is a major buffering component against racially hostile environments (Kelly et al., 2013). Research has also shown that family functioning is the biggest predictor of FS in African-American families, indicating that a cohesive family unit among African-Americans correlates to a lower level of psychological maladjustment in African-American children (Mandara \& Murray, 2000; Parent et al., 2013). In acting as a buffer against racially hostile environments, the family unit may also act as a buffer against stereotype threat.

Stereotype threat can be considered a form of perceived discrimination: when stereotype threat is present one perceives that there is a negative stereotype (or discrimination) about them, and this will affect how they are perceived and therefore affect their performance (Wegmann, 2017). In addition, perceived discrimination in the form of stereotype threat has direct and indirect effects on children's well-being and with influence extending into adolescence and young adulthood. These negative effects can also control one's income and occupation (Wegmann, 2017). Stereotype threat can be seen as a defense mechanism against discrimination because not only is the person 
perceiving discrimination, but they are also trying to fight against it by disproving the stereotype within it.

\section{Methodology}

This study employed a quantitative, non-experimental, correlational research design using self-report surveys. A convenience sample was used to analyze the relationship between the variables FS, racial identity, PED, and stereotype threat among African-American college students in the general population. The sample consisted of adults, 18 years or older, who resided in the United States of America and who considered themselves African-American (based on the demographic survey). The current study collected survey responses from 420 adults. Participants were individuals recruited through Qualtrics, an online research platform.

Participant self-report quantified all variables. Participants completed four surveys: (a) BRIAS, (b) FSS (c) PEDQ, and (d) SCCS. The BRIAS was used to assess the stage an individual was in, in terms of BRI. The FSS and the PEDQ were used to assess an individual's level of FS and occurrences with PED. The SCCS was used to assess an individual's vulnerability and sensitivity to stereotypes as a measure of stereotype threat. The data was analyzed using SPSS and AMOS to formulate a structural equation model in order to examine the relationships among the variables and determine the model fit.

\section{Findings and Discussion}

The findings of this study are based on results from a structural equation model analysis. The intent of this study was to analyze the impact of racial identity, FS and PED on African-American college students' vulnerability to stereotype threat. The SCCS 
sought to assess the degree to which individuals, "experience uncertainty and apprehension about appearing to confirm as a self-characteristic, a stereotype about a group to which they belong" (Contrada et al., 2001). Higher scores represent greater concern, while lower scores represent less concern. FS was assessed using the FSS. BRI was assessed by analyzing one's stage of racial identity they were in: either Dissonance, Conformity, Immersion, Emersion, or Internalization. PED was assessed using five subscales: DIS, AV, TAGG, E\&D, or VR. The structural equation modeling hypothesistesting procedure suggested an acceptable fit with the actual, observed data. Findings for the research question are discussed below.

\section{Respondents Demographics}

The researcher collected survey responses from 420 individuals, who identified themselves as African-American college students. Participants completed all items on the survey, except in the case of gender and year in college where $9.6 \%$ and $2.6 \%$ did not answer respectively.

Of the $N=420,225$ were between the ages of $18-20(53.6 \%), 180$ were between the ages of $21-23(42.9 \%)$, eight were between the ages of $24-26(1.9 \%)$ and seven were 27 and older (1.5\%). Responses indicated that 85 (20.2\%) were male and 295 (70.2\%) were female, $9.6 \%$ is missing because 40 responses did not record gender because it was absent from the questionnaire, during the soft launch. The college students ranged in tenure with 173 in their first year (41.2\%), 124 in their second (29.5\%), 74 in their third (17.6\%), 42 in their fourth (10\%), 21 in their fifth year or greater $(5 \%)$ and 11 choosing not to answer (2.6\%). 


\section{Research Hypothesis}

The researcher hypothesized that the theoretical model for the relationship between racial identity, FS and PED of African-American college students' susceptibility to stereotype threat fit the empirical model.

The model was revised and several paths were added to improve fit, based on consultation with standardized residuals and modification indexes. The respecification included both adding and eliminating paths between observed variables, and resulted in an excellent fit for the data $(\mathrm{GFI}=.880, \mathrm{NFI}=.919, \mathrm{CFI}=.936$, and $\mathrm{RMSEA}=.092$ $(90 \mathrm{CI}=.083 \& .101) ;$ see Figure 2.

\section{Respecified Model Fit}

Structural equation modeling was used to evaluate whether the hypothesized relationships among variables in the original model were supported by this sample. Structural equation modeling revealed the original model was a poor fit for the data, so revisions were made on the basis of the modification indices and theory.

First, BRI was separated into two levels. This resulted as new research arose that utilized mutli-level exploratory factor analysis (Grajales et al. 2018). This factor analysis broke down the original 60-item BRIAS to 29-items, while still measuring the five dimesions. The 29-item scale divided the stages down into two levels: BRI-InitialStages and BRI-LatterStages. BRI-InitialStages showed a strong correlation between conformity, dissonance, and immersion yielding a Pearson's $r$ correlation of $r=.82$ and $r$ $=.90$ (Grajales et al., 2018). BRI-LatterStages showed a strong correlation between emersion and internalization yielding a Pearson's $r$ correlation of $r=.94$ and $r=.88$ (Grajales et al., 2018). Between the two levels, a negative correlation was observed, 
suggesting a clear distinction between the initial schemas of racial identity and advanced schema levels of identity, further providing evidence for the two levels of BRI (Grajales et al., 2018).

Second, a correlation adjoined BRI-InitialStages and BRI-LatterStages. The correlation between the two levels is consistent with the research that states there is a distinction between the initial schemas of racial identity and the advanced schemas (Grajales et al., 2018). This correlation is supported by the research that demonstrated that the earlier and middle stages of BRI predict internalized racism in contrast to the latter stages (Thompson, Anderson, \& Bakeman, 2000). This suggests that earlier stages have a different effect on individuals than the latter stages of BRI. Research has even confirmed that high levels of racial consciousness versus low levels of racial consciousness can have an effect on factors, such as, counselor preference (Townes, Chavez-Korell, \& Cunningham, 2009). This confirms the significant correlation between BRI-InitialStages and BRI-LatterStages, which suggests that different levels of racial identity, yield different results. These results often fall opposite of one another further supporting the negative correlation between the two levels.

Third, the correlation between BRI (for both levels) and stereotype threat was eliminated, disproving the initial hypothesized relationship. The respecified model showed, that based on this population, BRI and stereotype threat do not have a direct relationship. In fact, very few studies in the past had examine the influence of BRI on stereotype threat directly. As such, BRI was postulated to both buffer and exacerbate social threats, stereotypes and one's ability to handle stereotypes (Anglin \& Wade, 2007; Davis et al., 2006), rather than having a direct, one-way influence on stereotype threat 
Furthermore, it was postulated that BRI influences stereotype threat through PED. For examples, researchers such as Lee and Ahn (2013), Molina, Phillips and Sidanius (2015) illustrated in their respective research that there is a direct relationship between BRI and perceived discrimination with respect to distress and perception. Moreover, in the present study, the respecified model illustrated significant, direct effects between BRIInitialStages, BRI-LatterStages and PED, and then PED to have a direct, significant main effect on stereotype threat. Taken together, previous research and the present study provides further evidence that different stages of BRI have an indirect relationship with stereotype threat through PED, and thus, strengthening justification for the elimination of the direct pathway from BRI to stereotype threat.

Fourth, the correlations between internalization, pre-encounter, and PED seem to be eliminated, however they were substituted due to the separation of BRI. Since BRI was broken down into two latent variables, the relationships each variable had were able to be more concentrated on the stages that they represented. Therefore, instead of having direct pathways from internalization and pre-encounter to PED, the pathways were drawn from each of new BRI latent variables (BRI-InitialStages and BRI-LatterStages) to PED. It could also be concluded that in this nonclinical sample, internalization and preencounter did not have strong relationships with PED. However, review of the literature suggested a relationship between PED and these factors. For example, higher levels of BRI are reported to result in higher levels of sensitivity to stigmatization, and increased distress related to discrimination (Lee \& Ahn, 2013; Sellers \& Shelton, 2003). Further research is needed to identify why this relationship was not significant for this sample. One possibility is that much of the research focused on college students at PWIs and this 
research study looks at a mix of institutions, which could mitigate some of the effects that outliers of racial identity have on PED. Another possibility is that the breakdown of the latent variable BRI complicates the commonalities between the initial model and the respecified model. In the initial model, statuses from both BRI-InitialStages and BRILatterStages had pathways to PED. However, the respecified model broadened these relationships to look at the whole level instead of the individual statuses. Therefore, the initial pathways from internalization \& pre-encounter to PED were not as much eliminated as they were broadened.

Fifth, FS's pathway to PED was also eliminated. There was limited research on the direct relationship of FS to PED. However, research reported that a strong family unit created "safe spaces" for African-American families to go and discuss racial discrimination and disparities, which act as a buffer against discrimination and hostile environments (Kelly et al., 2013; Skowron, 2005). In addition, when research based in family support and perceived racial discrimination for other minority groups was examined, findings conclude that low family support and satisfaction put students at risk for psychological distress, depression, and low-self-esteem, which makes one more vulnerable to perceived discrimination (Cumsille \& Epstein, 1994; Wei, Yeh, Chao, Carrera, \& Su, 2013). This research inferred that FS served as a buffering role against perceived discrimination, but this model did not support those findings. This could be due to fact that the majority of these research studies were based on case studies and qualitative research. Since this research was quantitative in nature, this may affect the outcomes that are seen. In addition, quantitative research used different satisfaction measures and/or populations; these factors may affect the strength of the relationship in 
this study, therefore, resulting in insignificance. Research from these sources were used because there was no direct research on African-Americans' FS and the scale utilized, although normed to the population, does not have a great deal of research within the population.

Sixth, the pathway from FS to E\&D and the pathway from E\&D to stereotype threat were eliminated. Research does support that connectedness among families can serve a protective role in buffering environmental stress (Skowron, 2005). However. since research is limited the insignificance between these variables could be due to multiple factors. For example, lack of research in regards to this specific population, phenomenon, and research style could all attribute to the elimination of these pathways..

Seventh, several pathways were expanded upon because BRI was split into two levels. One of those expanded relationships were from BRI-InitialStages and BRILatterStages to PED. In the original model, there was a pathway from BRI (as a single unit) to PED and in the respecified model, there is a significant relationship between BRI-InitialStages and BRI-LatterStages and PED. This confirmed the hypothesized path that there is a relationship between BRI and PED, regardless of the differing levels. This is congruent with the literature that states that racial identity is a coping resource, and can act as a buffer to the stress of discrimination (Mossakowoski, 2003). These relationships also supported the argument that the stronger an individual's racial/ethnic identity is, the more susceptible they are to negative stereotypes and discrimination, and the more damage these will cause (Mossakowoski, 2003). In addition, research has reported that higher levels of racial identity are reported to result in higher levels of sensitivity to stigmatization, and increased distress related to discrimination and vice-versa (Lee \& 
Ahn, 2013; Sellers \& Shelton, 2003). This further supported the findings that both levels of BRI (all stages) had a significant relationship with PED.

The second expansion revealed a relationship between both levels of BRI and FS, resulting in correlations added from both BRI-InitialStages and BRI-LatterStages to and from FS. As stated previously, since BRI was broken down into two levels, pathways were added from each level to FS. However, in the original model there was a predicted relationship between BRI (as a whole) and FS, and in the respecified model there remains a significant relationship between BRI-InitialStages and BRI-LatterStages and FS. This confirmed the hypothesized relationship between BRI and FS and demonstrates that there is a significant relationship between the two variables regardless of their BRI classification. This is consistent with the research that states that African-American parents who engaged with their children about cultural pride strengthened their racial socialization and their sense of personal efficacy and cultural pride (Armah, 2015). In addition, these finding supports the research that racial socialization is evident within the African-American family framework, and the stronger that framework, the more likely a child is to develop a strong racial identity and self-concept (Armah, 2015; Kelly et al., 2013; Seaton et al., 2012; Skowron, 2005). Research has also confirmed that both extended family members and parents are the primary components of instilling racial socialization, which is the precursor to BRI (Seaton et al., 2012). This socialization comes through the means of communication, which is a main component for FS (Olson, n.d.). However, if this family-unit lacks functioning, then the child is less likely to develop a strong racial identity and ultimately strong self-concept (Armah, 2015; Kelly et al., 2013; Seaton et al., 2012; Skowron, 2005). Therefore, the significant correlation that 
is seen between FS and BRI-InitialStages and BRI-LatterStages confirmed past research (Armah, 2015; Kelly et al., 2013; Seaton et al., 2012; Skowron, 2005).

Eighth, is the addition of the pathway from BRI-InitialStages to TAGG. In the initial model, this relationship was negated, which could be attributed to the fact that BRI was one single construct. Therefore, the effect that earlier stages of BRI had on other factors could not be easily defined. Therefore, it could be concluded that this relationship was added because the separation of BRI allowed this relationship to be realized. This relationship is consistent with the research that identified that a strong BRI may be more aware of aggressive behavior and outcomes, but because of the understanding that comes with increased racial identity, they are able to mediate the effects of such behaviors (Thomas et al., 2015). This also supports the research that those with a "less dramatic" racial identity will not perceive as many experiences of racial discrimination, suggesting that those with "dramatic" racial identities may be more aware to these experiences (Cokley, 2002; Lee \& Ahn, 2013).

\section{Respecified Model}

After the modifications addressed above, the resulting model was well fit to the data. As a result BRI, FS, and PED explained 78\% of variance in regards to stereotype threat. PED had positive direct effects on stereotype threat, FS had positive effects on STCs and BRI was not directly correlated to stereotype threat in this model but had direct positive effects on PED. PED explained $81 \%$ of variance in regard to STC, while BRIInitialStages and BRI-LatterStages explained about $30 \%$ of variance in regards to PED. These findings suggest that the more discrimination a person feels, the more likely they are to fear confirming a stereotype about their race; and the more developed they are in 
their BRI development, the more aware they will be of discriminatory acts. These findings also suggest that the greater a person's FS, the less likely they will fear confirming negative stereotypes about themselves or their group.

With over a third of the variance in stereotype threat explained, this study significantly supports the important role of PED, BRI, and FS on one's susceptibility to stereotype threat. Yet, there remains a significant portion of unexplained variance among the factors. Future researchers might use this model as a foundation and include additional variables that might contribute to explain further variance for stereotype threat vulnerability. Models which best represent human behavior are often complex and involve many variables, but this simpler model serves as an important foundation. Below are the breakdown, explanations, and implications of the relationships found in the respecified model.

\section{Family Satisfaction and Stereotype Threat}

FS had statistically significant negative direct effects on stereotype threat, with an explained variance of $.4 \%$. These findings indicate that as predicted, FS has an impact on African-American college students' vulnerability to stereotype threat. The statistical correlations are negative, which suggests that the more dissatisfaction one feels with their family the more likely they are to fear confirming stereotypes about their group or that higher levels of FS result in a lower vulnerability to stereotype threat, or less concern with confirming a negative stereotype about their group. Although, the researcher was not able to find a wide array of research in relation to FS, African-American college students and stereotype threat; this study further strengthens existing research that states the African-American family unit serves as a buffer and a protective factor against hostile 
environments (Kelly et al., 2013; Mandara \& Murray, 2000; Parent et al., 2013). This relationship is also congruent with the research that suggests a strong family basis acts as a "safe space" to discuss discrimination and disparities and buffer against hostile environments and discrimination (Kelly et al., 2013). In addition, these findings also aligned with research that suggests parental support and encouragement have been shown to assist African-American college students and correlate with positive academic experiences, producing students that are more likely to be able to adapt psychologically, emotionally, and socially (Anglin \& Wade, 2007; Love et al., 2009). It should be noted that the African-American family unit extends beyond the nuclear family framework, which may have effects on how they interpret FS.

The African-American family structure has been noted to extend beyond the "nuclear family" framework, this is because the family unit extends beyond "mom, dad and siblings," (Kelly et al., 2013; Thomas \& Dansby, 1985). Oftentimes there are others that are strong factors in the family unit such as: aunts, uncles, grandparents, godparents, church family, close friends, etc.; these members of the family are referred to as "fictive kin” (Kelly et al., 2013; Thomas \& Dansby, 1985). The expansive networks and people that make up the African-American family unit can make it a hard variable to test. Nonetheless, research has consistently found that the support of the African-American family is necessary for coping in an antagonistic society (Anglin \& Wade, 2007; Kelly et al., 2013; Love et al., 2009; Matlin, Molock, \& Tebes, 2011; Thomas \& Dansby, 1985). Although the relationship between FS and stereotype threat may not be immediately recognizable or have a huge effect size, it seems the present study provided support for the hypothesis that FS influences African-American college students' 
vulnerability to stereotype threat. This implies that if African-American college students have high levels of FS they may be less vulnerable to stereotype threat and have less fear of confirming negative stereotypes about their group. The findings of this study show that FS acts as a buffer for African-American college students against stereotype threat. Additionally, creating a "family atmosphere" that provides a place for cohesion, communication, and flexibility may reduce the risk of vulnerability to stereotype threat on college campus. Students with family support such as this, are at a distinct advantage, and are more likely to matriculate through college much easier than students without such support.

\section{Black Racial Identity and Perceived Ethnic Discrimination}

Black racial identity was broken down into two levels and both did not have direct effects on stereotype threat in the revised model. However, both BRI-InitialStages and BRI-LatterStages had direct effects on PED, with a combined explained variance of about $30 \%$ of PED, which had the largest direct effect on stereotype threat. The positive relationship that was present between BRI and PED implies that as an individual becomes more advanced in their BRI they also become more aware of discrimination and therefore more susceptible to instances of discrimination and stereotype threat. This both strengthens and weakens past research because studies have shown a person's increased identification with race can lead to intensifying the injustices that plague them (Campbell, 2010; Davis et al., 2006). This would explain the positive direct effects that BRI-InitialStages and BRI-LatterStages have on PED. This relationship suggests that as a person progress through to higher levels of their BRI, their susceptibility to PED 
increases. Yet, some research has shown that, internalization, the final status of BRI, may actually buffer against stereotype threat, if an individual has reached full maturity within that stage (Lee \& Ahn, 2013; Schaller et al., 2003; Thomas et al., 2015). Other research goes on to explain that, although being in latter stages of BRI does buffer against stereotype threat, it does not decrease one's ability to perceive discrimination, instead it allows them to handle it in a healthy manner (Thompson et al., 2000).

Results also suggest that BRI has an effect on stereotype threat through its impact on PED, which is consistent with the research that states that racial identity may be directly or indirectly related to the distress associated with discrimination (Lee \& Ahn, 2013). Research also states that Black Americans with a greater sense of belonging are more likely to be perceptive to discrimination (Walden, 2009). On the other hand, an under-developed racial-identity may cause an individual to perceive less experiences of racism (Walden, 2009). It has also been found that ethnic identity can also act as a buffer from discrimination because it gives someone a sense of belonging (Mossakowoski, 2003). Therefore, the research confirms that as racial identity develops, it can exacerbate or mitigate one's perception of discrimination and have a negative effect on how one responds to stereotypes.

Black racial identity can affect the way one responds to stereotype threat depending on what stage they are in within their BRI development. For example, if one is not at a more advanced stage in their BRI development, then BRI can serve as an amplifying force for stereotypes, rather than a silencer (Davis et al., 2006; Thompson et al., 2000; Walden, 2009). Yet, for college students, BRI is something that can take longer 
to develop because with development, comes the realization of what it means to be "Black" in America and this can elicit pain, anxiety, and confusion (Walden, 2009).

This is particularly important in college students because most college aged students are in the developmental stage of emerging adulthood (18-29), which is a developmental period marked by identity exploration (Hope et al., 2015). AfricanAmericans, in particular, experience emerging adulthood in the context of institutional racial discrimination; this hinders development because they have to manage the different forms of discrimination they face in combination with normative developmental tasks (Hope et al., 2015). The model confirmed that no matter where one is in BRI (level 1 or 2) it would have direct effects on PED. This adds to research that stated that one's BRI can exacerbate or minimize the perception of discrimination and affect how one responds to the discrimination perceived (Campbell, 2010; Davis et al., 2006; Hope et al., 2015; Lee \& Ahn, 2013; Schaller et al., 2003; Thomas et al., 2015; Thompson et al., 2000).

The BRI status of an individual is also important for counseling psychologists and educators because developing a mature racial identity will help to buffer against discrimination. This then is something that counseling psychologists can use to assist their clients to develop and be aware. In addition, if racial identity creates a clearer, picture of the world for students, then psychologists can help their clients cope with the discrimination and stereotype threat they now perceive.

\section{Perceived Ethnic Discrimination and Stereotype Threat}

Perceived ethnic discrimination had positive direct effects on stereotype threat, with $81 \%$ explained variance. This implies that the more discrimination one feels the 
more vulnerable they become to stereotype threat. This could be because discrimination has had ill effects on African-Americans since slavery and as a result, the psyche of African-Americans has been affected; making this population more susceptible to a number of negative factors, such as, but not limited to, poor physiological health, low impulse control, poor mental health, hyper-awareness and sensitivity (Hope et al., 2015). There are number of studies that show how perceived discrimination induces hypervigilance and causes individuals to work towards not confirming a stereotype about their group (Hogg, 2006). This suggests that the very presence and perception of discrimination affects an individual's mental functioning because it causes them to exert mental resources to work against a stereotype that they perceive is being placed on them.

The large effect size in my study could also be attributed to how closely defined PED and stereotype threat are to one another. For instance, PED, "reflects exposure to individual, institutional or cultural events or conditions." In other words, the act of perceiving being discriminated against (Brondolo et al., 2005). Stereotype threat looks at the "apprehension of appearing to confirm, as a self-characteristic, a stereotype about a group to which they belong" (Contrada et al., 2001). Both are looking at the effect of outside beliefs on self. Regardless, the impact that PED has on stereotype threat is congruent with the literature that states stereotype threat can be considered the aftermath of perceived discrimination (Wegmann, 2017). This is because when stereotype threat is present one perceives there is a negative stereotype (or discrimination) about them, and will affect how they are perceived, therefore affecting their performance (Wegmann, 2017). The effect size between PED and stereotype threat is one of the largest in the model, and this could be attributed to the belief that stereotype threat, in a sense, takes 
discrimination to the next level; because not only is one perceiving it, they are also trying to fight against it (Wegmann, 2017).

This study implies that controlling for risk factors such as PED may have the largest effect on stereotype threat. For counseling psychologists this implies that providing clients, who fit this demographic, the coping mechanisms to deal with discrimination may reduce their vulnerability to stereotype threat. In addition, helping these individuals to have a stronger self-concept so that the experience of discrimination may not be as detrimental to their mental health is also something that can be explored. In the education realm, ensuring that teachers and staff have the training needed to prevent the perpetuation of stereotypes or microaggression may also help to reduce vulnerability to stereotype threat.

\section{Black Racial Identity Level 1 and 2}

Results from the model indicated a negative correlation between BRIInitialStages (conformity, dissonance, and immersion) and BRI-LatterStages (emersion and internalization). This suggests that the stronger an individual's BRI is in level one (early stages), the weaker it is in level two (the latter stages); and the stronger it is in level two, the weaker it is in level one. This is consistent with the research that states those with a high racial identity will be more perceptive to the racism and microaggression that is still prevalent in society (Lee \& Ahn, 2013; Thompson et al., 2000; Walden, 2009). This indicates that individuals may have opposite experiences when it comes to racism depending on where they are in their BRI development, supporting the findings of the model. This relationship also furthers the research that stated, earlier and middle stages of BRI predict internalized racism in contrast to the latter stages (Thompson et al., 2000). 
Furthermore, this relationship strengthened and confirmed research that stated there is a distinction between the initial schemas of racial identity and the advanced schemas (Grajales et al., 2018).

These results imply that a person may have completely different experiences in the early stages of BRI compared to the later stages of BRI. This is important to understand because in the field of psychology and even among educators, being able to identify and understand where a student or client is in their racial identity development coincides with competent care. This can also be useful when trying to find how to reach a child or find appropriate interventions for a client.

\section{Black Racial Identity and Family Satisfaction}

The positive correlation between both levels of BRI and FS suggested that the more advanced someone is in their BRI development the greater satisfaction they have with their family. This supports the hypothesized relationship between BRI and FS. This is consistent with the literature that suggests the family unit serves as a buffer against racially hostile environments and indicates that it may act as a buffer against stereotype threat (Mandara \& Murray, 2000). These findings also supported research that revealed a well-developed BRI starts with the family unit, where positive racial solicitation is developed, or can be hindered by poor family functioning (Anglin \& Wade, 2007; Armah, 2015; Kelly et al., 2013). Furthermore, this significant relationship reinforced the research that revealed racial socialization happens within the African-American family framework; the stronger that framework the more likely a child is to develop a strong racial identity and self-concept (Armah, 2015; Kelly et al., 2013; Seaton et al., 2012;

Skowronn, 2005). This implied that FS and BRI have a strong relationship, and since the 
African-American family unit extends beyond the nuclear framework, it opens the door for various ways that counseling psychologists, school systems, and educators can open the door for positive BRI development. However, one must first understand how family is defined within the African-American unit.

The African-American family structure has been noted to not take on a strong nuclear framework, this is because the family unit extends beyond "mom, dad, and siblings" (Kelly et al., 2013; Thomas \& Dansby, 1985). Often times there are others that are strong factors in the family unit such as: aunts, uncles, grandparents, godparents, church family, close friends, etc.; these members of the family are referred to as "fictive kin" (Kelly et al., 2013; Thomas \& Dansby, 1985). The uniqueness of the family unit can make it a hard variable to test, but research is consistent that the support of the AfricanAmerican family is one that is necessary for coping in an antagonistic society (Matlin et al., 2011). In fact, the family structure can have ill-effects on African-Americans when there are economic disadvantages and financial strains resulting in lower levels of warmth and higher levels of stress arousal (Kelly et al., 2013). In addition, disruptions with co-parenting can impact adolescent problem behaviors (Cokley, 2005). This research further supports the model findings because it indicates that low levels of FS, or family units with high stress levels and disruption can negatively affect or halt BRI development.

Understanding how extensive the family unit can be among African-Americans is something that is useful for the implications of these relationships. The relationship between FS and BRI-InitialStages and BRI-LatterStages implies that a strong family unit can help to develop a strong racial identity and vice versa. This is imperative to 
counseling psychologists, educators, and school systems because if they can help students or clients to develop a strong BRI, they may be able to help these individuals tap into extended family networks of their own. In addition, school systems and educators can create a family dynamic within their framework (i.e. school setting) that may help students with their development of a positive BRI. This is important because, understanding the uniqueness of the family structure among African-Americans can help them to help clients identify positive family structures to tap into. In addition, they could utilize the vastness of the family structure to help African-Americans pull from "family experiences" to develop their BRI.

\section{Threat and Aggression and Black Racial Identity Level 1}

Results from the model also indicated that BRI-InitialStages had positive direct effects on TAGG with a variance of $9.4 \%$ and a positive correlation. This suggests that as BRI increases, a person's awareness of TAGG does also. This is consistent with research that identified a strong BRI may be more aware of aggressive behavior and outcomes, but because of the understanding that comes with increased BRI they are able to mediate the effects of such behaviors (Thomas et al., 2015). This also supported the research that those with a "less dramatic" BRI will not perceive as many experiences of racial discrimination, suggesting that those with "dramatic" racial identities may be more aware of these experiences (Cokley, 2002; Lee \& Ahn, 2013). These results seem to contrast with the literature that stated early and middle stages of racial identity lead to an increase in internalized racism (Cokley, 2005). However, because internalized racism is when racist beliefs about a person's group is believed about one's self, it could presume that 
these internalized beliefs do not exacerbate TAGG because they are believing the same beliefs as the stereotype. Yet, as an individual matures, they begin to realize their internalized racism and as a result may become even more aware of the discrimination and stereotypes in the environment, resulting in an increase of TAGG (Lee \& Ahn, 2013). This scenario could reinforce the model implying that as racial identity increases in BRI-InitialStages, so does TAGG.

This relationship implied that for teachers and psychologists who work with African-American clients, they should be aware that as one develops and matriculates through their racial identity, they may be more prone to and aware of hostile behaviors and aggressions towards themselves. Although those with higher levels are able to moderate these occurrences, both psychologists and educators should be prepared to process the emotions that accompany this awareness. In addition, understanding this relationship should also prompt psychologists and educators to be prepared to offer coping mechanisms to help those who are in the middle stages of racial identity. This is because individuals in these stages are becoming more aware of hostility but do not have as much control or understanding.

\section{Black Racial Identity, Family Satisfaction, and Perceived Ethnic Discrimination}

The model suggests that there are multiple ways that the factors of BRI, FS, and PED impact and are affected by one another, which was also discovered in a review of the literature and can be found in the literature review. Therefore, further research could look into the interworking of these factors and the effect they may have on the functioning of African-American college students. 


\section{Final Implications}

Overall, vulnerability to stereotype threat in the current study showed correlation with all factors tested (BRI, PED, and FS). This is an important finding because stereotype threat affects the African-American plight in a number of facets from academics to health; and understanding what factors impact this phenomenon may help to remedy or control it in the future. This is important for both educators and counseling psychologists alike, because this study indicates there are factors at play that can help with the overall well-being of African-American college students and help to reduce or eliminate the barrier that is stereotype threat.

\section{Limitations}

Several limitations should be considered with this study. One of the greatest being that my study utilizes a nonexperimental research design, meaning that my results speak to correlation and predication, but not causation. This particular design was appropriate for this study because it looked to measure variables that occur in the environment rather than in an experimental context. In addition, experimental manipulation of the variables of interest, may have affected their authenticity.

The models tested were based on the literature review overviewed in Chapter 2. The literature on the inter-correlations of these items were limited, therefore many of the correlations had to be inferred based on studies that measured similar relationships. However, enough data suggested that a relationship between these variables exist and were worth inquiry.

The variables were assessed using self-report measures and this may have caused the participant to curve their answers to what they feel is acceptable, rather than their 
true-life experience. Yet, the nature of this study required self-reporting because it was based on the personal experience of the participant.

My survey was also taken online, which limits my sample to those who have internet access, are comfortable with the internet, and are among Qualtrics' pool of respondents who were recruited for the purpose of this study. Regardless, the online approach did allow for data collection from individuals who are heterogeneous in age, geographic location, SES, and sex.

This study was also limited to only college students, which also limited my sample to those with the basic means and knowledge needed for getting to college. This may also limit my study to those who possess the minimal intellectual functioning needed to get to college. Structural equation modeling was a good choice for this research because it allowed the observation and assessment of multiple latent variables simultaneously.

My data was analyzed using SEM, meaning that my results are based on the degree of fit observed between my resulting SEM model and the data from the current sample. Therefore, different models, with the same or similar variables, may be an even better fit for the data.

\section{Suggestions for Future Research}

The findings of this study have suggested five suggestions for further research

1. The literature review suggests that there are gaps in the literature when it comes to looking at stereotype threat as a social concept. Since stereotype threat was originally introduced as an academic phenomenon, much of the research reflects this concept (Davis, 2012; Steele \& Aronson, 1995). The research is limited when looking at 
stereotype threat in terms of social effects and development. Understanding the social conceptualization outside of academics would be exceptionally useful and may give understanding to a number of different fields, such as criminality, aggressive behavior, self-esteem, poverty, and success.

2. The literature review also revealed a number of gaps and no direct research in regards to FS among African-Americans. Research was available on family support, structure, functioning and factors; but even the research in these areas was inadequate. Research has suggested, thus far, that family support, structure, functioning and factors, when positive, buffer against hostile environments and even creates a strong sense of self- esteem (Kelly et al., 2013; Mandara \& Murray, 2000; Parent et al., 2013). Therefore, it would be beneficial to understand how satisfaction in the African-American family unit occurs, what it provides, buffers against, and its effects.

3. Research has indicated that stereotype threat is prominent in PWIs. AfricanAmerican students that attend these schools have reported feeling like, "the other" or like they had to "prove themselves" to their peers (Brower \& Ketterhagen, 2004; Campbell, 2010; Gordon, 2012; Hernandez, 2010; Patterson, 2009; Walden, D. L., 2009). However, there has been no research asking if students are susceptible to stereotype threat at HBCUs. Future research may benefit from looking at the prevalence of stereotype threat between the two different types of colleges HBCUs and PWIs because this may give understanding to the factors that affect the prevalence of stereotype threat for AfricanAmerican college students.

4. The current study focused on three factors that impact stereotype threat, the results indicated that there are interrelationships between the factors BRI, FS, and PED. 
Research has suggested that both BRI and FS have effects on PED and since PED is one of the strongest determinants of stereotype threat, understanding the factors that effect it would be beneficial when trying to control for it. Further research on the relationship between these three factors would therefore be beneficial to the field.

5. Finally, it is also important to replicate this study with different cultural groups to examine any group differences. Gender and age differences were not investigated as part of this study, and all participants resided in the United States. The results from this study cannot necessarily be generalized to all racial or ethnic groups, or to populations outside of the United States. Other different types of demographic information could be considered as well, such as socioeconomic status and location (i.e. metropolitan, rural, country, etc.). 
APPENDIX A

CORRELATION TABLE 


\section{Table 4}

Correlation of Matrix Variables

\begin{tabular}{|c|c|c|c|c|c|c|c|c|c|c|c|c|}
\hline Variable & 1 & 2 & 3 & 4 & 5 & 6 & 7 & 8 & 9 & 11 & 12 & \\
\hline VR & 1 & & & & & & & & & & & \\
\hline AV & $.728 * *$ & 1 & & & & & & & & & & \\
\hline E\&D & $.666^{* *}$ & .741 & 1 & & & & & & & & & \\
\hline DIS & $.662 * *$ & $.690 * *$ & $.712 * *$ & 1 & & & & & & & & \\
\hline TAGG & $.554 * *$ & $.609 * *$ & $.812 * *$ & $.636 * *$ & 1 & & & & & & & \\
\hline STC & $.617^{* *}$ & $.682 * *$ & $.700 * *$ & $.753 * *$ & $.686^{* *}$ & 1 & & & & & & \\
\hline FS & .075 & .020 & .080 & -.033 & $.153^{* *}$ & -.013 & 1 & & & & & \\
\hline BAINT & $.117 *$ & .088 & -.021 & $.106^{*}$ & -.092 & .088 & $.305^{* *}$ & 1 & & & & \\
\hline BAINM & $.383 * *$ & $.394 * *$ & $.447 * *$ & $.428 * *$ & $.510^{* *}$ & $.473^{* *}$ & $.149 * *$ & $.320 * *$ & 1 & & & \\
\hline BAPRE & $.245^{* *}$ & $.271 * *$ & $.385 * *$ & $.288 * *$ & $.527 * *$ & $.347 * *$ & $.207 * *$ & $-.130 * *$ & $.542 * *$ & 1 & & \\
\hline BA & $.217 * *$ & $.176^{* *}$ & $.133^{* *}$ & $.225^{* *}$ & .062 & $.236^{* *}$ & $.155^{* *}$ & $.717 * *$ & $.570 * *$ & -.004 & 1 & \\
\hline BAPOS & $.219 * *$ & $.241 * *$ & $.349 * *$ & $.271 * *$ & $.459 * *$ & $.345^{* *}$ & $.100^{*}$ & $-.107 *$ & $.531 * *$ & $.833 * *$ & .017 & 1 \\
\hline
\end{tabular}

**. Correlation is significant at the .01 level (2-tailed). *. Correlation is significant at the 0.05 level (2-tailed). VR-Verbal Rejection; AV- Avoidance; E\&D - Exclusion and Denial of Equal Treatment; DIS- Disvaluation; TAGG- Threat and Aggression; STC- Stereotype Threat Concern; FS- Family Satisfaction; BAINT- Internalization; BAINM- Inmersion; BAPREPre-Encounter; BA-Emmersion; BAPOS- Post Encounter 
APPENDIX B

OUTPUT FOR RESPECIFIED MODEL 


\section{Respecified Model}

Models

Default model (Default model)

Notes for Model (Default model)

Computation of degrees of freedom (Default model)

Number of distinct sample moments: 136

Number of distinct parameters to be estimated: 43

Degrees of freedom (136 - 43): 93

Result (Default model)

Minimum was achieved

Chi-square $=419.555$

Degrees of freedom $=93$

Probability level $=.000$

Group number 1 (Group number 1 - Default model)

Estimates (Group number 1 - Default model)

Scalar Estimates (Group number 1 - Default model)

Maximum Likelihood Estimates

Regression Weights: (Group number 1 - Default model)

\begin{tabular}{|c|c|c|c|c|c|c|c|}
\hline & & & Estimate & S.E. & C.R. & $\mathrm{P}$ & Label \\
\hline PED & $\begin{array}{l}<-- \\
\end{array}$ & BRILEVEL2 & .463 & .090 & 5.135 & $* * *$ & \\
\hline PED & $<--$ & BRILEVEL1 & .979 & .127 & 7.704 & $* * *$ & \\
\hline STC & $<--$ & FS & -.108 & .052 & -2.076 & .038 & \\
\hline STC & $<--$ & PED & 1.377 & .091 & 15.118 & $* * *$ & \\
\hline IMMERSION & $<--$ & BRILEVEL1 & 1.000 & & & & \\
\hline DISSONANCE & $<--$ & BRILEVEL1 & 1.564 & .126 & 12.379 & $* * *$ & \\
\hline CONFORMITY & $<--$ & BRILEVEL1 & 1.774 & .139 & 12.754 & $* * *$ & \\
\hline TAGG & $<--$ & PED & 1.000 & & & & \\
\hline E\&D & $<---$ & PED & 1.282 & .059 & 21.619 & $* * *$ & \\
\hline AV & $<---$ & PED & 1.307 & .080 & 16.324 & $* * *$ & \\
\hline VR & $<--$ & PED & 1.138 & .076 & 14.997 & $* * *$ & \\
\hline DIS & $<--$ & PED & 1.501 & .088 & 16.994 & $* * *$ & \\
\hline INTERNALIZATION & $<--$ & BRILEVEL2 & 1.000 & & & & \\
\hline
\end{tabular}




\begin{tabular}{|c|c|c|c|c|c|c|}
\hline & & Estimate & S.E. & C.R. & $\mathrm{P}$ & Label \\
\hline EMERSION & $\begin{array}{ll}<-- & \text { BRILEVEL2 }\end{array}$ & 1.333 & .090 & 14.877 & $* * *$ & \\
\hline FS1 & $<---\quad$ FS & 1.000 & & & & \\
\hline FS2 & <--- FS & .945 & .036 & 26.551 & $* * *$ & \\
\hline FS3 & $<---\quad$ FS & .779 & .036 & 21.914 & $* * *$ & \\
\hline STC1 & $<---$ STC & 1.000 & & & & \\
\hline STC2 & $<---$ STC & .933 & .039 & 23.683 & $* * *$ & \\
\hline STC3 & $<--\quad$ STC & 948 & .041 & 23.060 & $* * *$ & \\
\hline IMMERSION & <--- BRILEVEL2 & 991 & .074 & 13.483 & $* * *$ & \\
\hline TAGG & $<--$ BRILEVEL1 & .943 & .112 & 8.386 & $* * *$ & \\
\hline
\end{tabular}

Standardized Regression Weights: (Group number 1 - Default model)

\begin{tabular}{|c|c|c|}
\hline & & Estimate \\
\hline PED & <--- BRILEVEL2 & .276 \\
\hline PED & <--- BRILEVEL1 & 477 \\
\hline STC & $<---$ FS & -.067 \\
\hline STC & $<---\quad$ PED & .900 \\
\hline IMMERSION & <--- BRILEVEL1 & .550 \\
\hline DISSONANCE & <--- BRILEVEL1 & .801 \\
\hline CONFORMITY & <--- BRILEVEL1 & .910 \\
\hline TAGG & $<---\quad$ PED & .665 \\
\hline E\&D & $<---\quad$ PED & .859 \\
\hline $\mathrm{AV}$ & $<---$ PED & .817 \\
\hline VR & $<---$ PED & .754 \\
\hline DIS & $<---\quad$ PED & .848 \\
\hline INTERNALIZATION & $<---$ BRILEVEL2 & .743 \\
\hline EMERSION & $<---\quad$ BRILEVEL2 & .919 \\
\hline FS1 & $<--$ FS & .901 \\
\hline FS2 & $<--$ FS & .925 \\
\hline FS3 & $<---$ FS & .812 \\
\hline STC1 & $<---$ STC & .835 \\
\hline STC2 & $<---$ STC & .907 \\
\hline STC3 & $<---\quad$ STC & .891 \\
\hline IMMERSION & <--- BRILEVEL2 & .667 \\
\hline TAGG & <--- BRILEVEL1 & .306 \\
\hline
\end{tabular}


Covariances: (Group number 1 - Default model)

\begin{tabular}{|c|c|c|c|c|c|c|c|}
\hline & & & Estimate & S.E. & C.R. & $\mathrm{P}$ & Label \\
\hline BRILEVEL1 & $\langle--\rangle$ & BRILEVEL2 & -.070 & .019 & -3.710 & $* * *$ & \\
\hline BRILEVEL2 & $\langle-->$ & FS & .103 & .032 & 3.211 & .001 & \\
\hline BRILEVEL1 & $\langle-->$ & FS & .112 & .027 & 4.109 & $* * *$ & \\
\hline e6 & $\langle-->$ & e7 & .276 & .059 & 4.665 & $* * *$ & \\
\hline e4 & $\langle-->$ & e5 & .274 & .046 & 5.916 & $* * *$ & \\
\hline
\end{tabular}

Correlations: (Group number 1 - Default model)

\begin{tabular}{|lll|r|}
\hline & & Estimate \\
\hline BRILEVEL1 & $<-->$ & BRILEVEL2 & -.235 \\
BRILEVEL2 & $<-->$ & FS & .179 \\
BRILEVEL1 & $<-->$ & FS & .237 \\
e6 & $<-->$ & e7 & .296 \\
e4 & $<-->$ & e5 & .429 \\
\hline
\end{tabular}

Variances: (Group number 1 - Default model)

\begin{tabular}{|l|rrrrr|}
\hline & Estimate & S.E. & C.R. & P & Label \\
\hline BRILEVEL1 & .242 & .038 & 6.391 & $* * *$ & \\
BRILEVEL2 & .363 & .045 & 8.150 & $* * *$ & \\
FS & .918 & .080 & 11.515 & $* * *$ & \\
e17 & .773 & .097 & 8.000 & $* * *$ & \\
e18 & .490 & .073 & 6.739 & $* * *$ & \\
e1 & .340 & .031 & 10.896 & $* * *$ \\
e2 & .331 & .033 & 10.008 & $* * *$ \\
e3 & .157 & .032 & 4.984 & $* * *$ \\
e4 & .687 & .059 & 11.670 & $* * *$ \\
e5 & .597 & .056 & 10.594 & $* * *$ \\
e6 & .870 & .075 & 11.664 & $* * *$ \\
e7 & 1.004 & .080 & 12.519 & $* * *$ \\
e8 & .896 & .081 & 11.049 & $* * *$ \\
e9 & .294 & .027 & 10.760 & $* * *$ \\
e10 & .118 & .033 & 3.585 & $* * *$ \\
e11 & .213 & .026 & 8.118 & $* * *$ \\
e12 & .138 & .022 & 6.398 & $* * *$ \\
e13 & .289 & .024 & 12.020 & $* * *$ \\
e14 & 1.037 & .087 & 11.853 & $* * *$ \\
e15 & .447 & .049 & 9.070 & $* * *$ \\
e16 & .556 & .056 & 9.966 & $* * *$ \\
\end{tabular}


Squared Multiple Correlations: (Group number 1 - Default model)

\begin{tabular}{|l|r|}
\hline & Estimate \\
\hline PED & .242 \\
STC & .795 \\
STC3 & .794 \\
STC2 & .823 \\
STC1 & .698 \\
FS3 & .659 \\
FS2 & .856 \\
FS1 & .812 \\
EMERSION & .845 \\
INTERNALIZATION & .552 \\
DIS & .720 \\
VR & .568 \\
AV & .667 \\
E\&D & .738 \\
TAGG & .703 \\
CONFORMITY & .829 \\
DISSONANCE & .642 \\
IMMERSION & .576 \\
\hline
\end{tabular}

Matrices (Group number 1 - Default model)

Covariances: (Group number 1 - Default model)

\begin{tabular}{|c|c|c|c|}
\hline & & M.I. & Par Change \\
\hline e17<-- & & 5.700 & -.105 \\
\hline e18<-- & BRILEVEL1 & 6.089 & .057 \\
\hline e15<-- & BRILEVEL1 & 6.410 & .050 \\
\hline e14<-- & BRILEVEL2 & 9.965 & .104 \\
\hline e14<-- & BRILEVEL1 & 4.578 & -.057 \\
\hline e13<-- & BRILEVEL2 & 19.131 & .076 \\
\hline e13<-- & BRILEVEL1 & 7.795 & -.039 \\
\hline e13<-- & e15 & 11.131 & -.077 \\
\hline e13<-- & e14 & 13.057 & .114 \\
\hline e11<-- & BRILEVEL2 & 7.705 & -.046 \\
\hline e11<-- & e16 & 5.491 & -.056 \\
\hline e11<-- & e15 & 14.616 & .085 \\
\hline e11<-- & e14 & 5.233 & -.070 \\
\hline e10<-- & e18 & 4.418 & .055 \\
\hline e10<-- & e13 & 11.278 & .053 \\
\hline e10<-- & e12 & 4.541 & -.029 \\
\hline
\end{tabular}




\begin{tabular}{|c|c|c|c|c|}
\hline & & & M.I. & Par Change \\
\hline e9 & $\mid\langle--\rangle$ & FS & 28.622 & .145 \\
\hline e9 & $<-->$ & BRILEVEL1 & 13.509 & -.052 \\
\hline e9 & $\langle--\rangle$ & e17 & 5.480 & -.064 \\
\hline e9 & $\langle--\rangle$ & e13 & 6.545 & .042 \\
\hline e8 & $<-->$ & FS & 14.998 & -.191 \\
\hline e8 & $<-->$ & e15 & 10.545 & -.137 \\
\hline e8 & $\langle--\rangle$ & e14 & 40.420 & .367 \\
\hline e8 & $<-->$ & e11 & 5.528 & -.069 \\
\hline e7 & $<-->$ & e16 & 8.404 & -.121 \\
\hline e6 & $<-->$ & e12 & 4.565 & .049 \\
\hline e6 & $<-->$ & e11 & 6.741 & -.067 \\
\hline e5 & $<-->$ & BRILEVEL2 & 4.010 & -.045 \\
\hline e5 & $<-->$ & BRILEVEL1 & 4.027 & .036 \\
\hline e5 & $<-->$ & e18 & 11.544 & -.117 \\
\hline e5 & $<-->$ & e14 & 8.580 & -.120 \\
\hline e5 & $<-->$ & e13 & 4.617 & -.046 \\
\hline e5 & $<-->$ & e6 & 11.290 & .115 \\
\hline e4 & $<-->$ & FS & 4.750 & .078 \\
\hline e4 & $<-->$ & e18 & 12.726 & .129 \\
\hline e4 & $<-->$ & e15 & 30.341 & .170 \\
\hline e4 & $<-->$ & e14 & 12.609 & -.150 \\
\hline e4 & $\langle-->$ & e11 & 10.572 & .069 \\
\hline $\mathrm{e} 3$ & $\langle-->$ & FS & 19.272 & .119 \\
\hline e3 & $<-->$ & e11 & 4.659 & .035 \\
\hline e2 & $<-->$ & FS & 6.649 & -.077 \\
\hline e2 & $<-->$ & e14 & 5.047 & .078 \\
\hline e2 & $<-->$ & e4 & 7.394 & -.066 \\
\hline e1 & $\langle-->$ & FS & 21.637 & -.138 \\
\hline $\mathrm{e} 1$ & $<-->$ & e17 & 18.915 & .129 \\
\hline $\mathrm{e} 1$ & $\langle-->$ & e13 & 8.363 & -.053 \\
\hline e1 & $\langle--\rangle$ & e3 & 5.018 & -.040 \\
\hline
\end{tabular}

Variances: (Group number 1 - Default model)

M.I. Par Change 
Regression Weights: (Group number 1 - Default model)

\begin{tabular}{|c|c|c|c|c|}
\hline & & & M.I. & Par Change \\
\hline PED & $\overline{<---}$ & FS & 4.926 & -.112 \\
\hline STC2 & $<---$ & FS & 6.244 & .108 \\
\hline STC2 & $<---$ & BRILEVEL1 & 11.549 & .291 \\
\hline STC2 & $<---$ & FS2 & 4.764 & .089 \\
\hline STC2 & $<---$ & FS1 & 12.449 & .132 \\
\hline STC2 & $<--$ & TAGG & 15.857 & .104 \\
\hline STC2 & $<--$ & CONFORMITY & 9.389 & .127 \\
\hline STC1 & $<--$ & BRILEVEL2 & 12.511 & .339 \\
\hline STC1 & $<---$ & BRILEVEL1 & 12.011 & -.406 \\
\hline STC1 & $<--$ & FS1 & 5.121 & -.116 \\
\hline STC1 & $<--$ & EMERSION & 12.336 & .218 \\
\hline STC1 & $<--$ & INTERNALIZATION & 9.863 & .210 \\
\hline STC1 & $<--$ & DIS & 7.912 & .085 \\
\hline STC1 & $<--$ & E\&D & 6.586 & -.092 \\
\hline STC1 & $<--$ & TAGG & 15.352 & -.140 \\
\hline STC1 & $<---$ & CONFORMITY & 11.599 & -.193 \\
\hline FS3 & $<--$ & BRILEVEL2 & 27.823 & .264 \\
\hline FS3 & $<--$ & BRILEVEL1 & 16.574 & -.249 \\
\hline FS3 & $<---$ & STC2 & 4.140 & -.036 \\
\hline FS3 & $<--$ & EMERSION & 28.886 & .175 \\
\hline FS3 & $<---$ & INTERNALIZATION & 27.835 & .185 \\
\hline FS3 & $<---$ & E\&D & 8.405 & -.055 \\
\hline FS3 & $<--$ & TAGG & 13.784 & -.069 \\
\hline FS3 & $<---$ & CONFORMITY & 11.204 & -.099 \\
\hline FS3 & $<--$ & DISSONANCE & 8.516 & -.086 \\
\hline FS2 & $<---$ & VR & 4.773 & .035 \\
\hline FS2 & $<--$ & AV & 5.733 & .036 \\
\hline FS1 & $<---$ & BRILEVEL2 & 11.467 & -.164 \\
\hline FS1 & $<--$ & BRILEVEL1 & 7.343 & .160 \\
\hline FS1 & $<--$ & STC1 & 4.281 & -.031 \\
\hline FS1 & $<--$ & EMERSION & 9.042 & -.094 \\
\hline FS1 & $<--$ & INTERNALIZATION & 6.042 & -.083 \\
\hline FS1 & $<--$ & DIS & 4.312 & -.032 \\
\hline FS1 & $<--$ & AV & 6.530 & -.043 \\
\hline FS1 & $<--$ & TAGG & 4.836 & .040 \\
\hline FS1 & $<--$ & CONFORMITY & 8.593 & .084 \\
\hline INTERNALIZATION & $<---$ & FS & 19.088 & .136 \\
\hline INTERNALIZATION & $<--$ & BRILEVEL1 & 4.370 & -.129 \\
\hline INTERNALIZATION & $<--$ & PED & 8.715 & -.087 \\
\hline
\end{tabular}




\begin{tabular}{|c|c|c|c|}
\hline & & M.I. & Par Change \\
\hline INTERNALIZATION & $<---\quad$ STC & 11.326 & -.065 \\
\hline INTERNALIZATION & $<---$ STC3 & 9.757 & -.054 \\
\hline INTERNALIZATION & $<---$ STC2 & 11.822 & -.062 \\
\hline INTERNALIZATION & $<---$ STC1 & 4.705 & -.034 \\
\hline INTERNALIZATION & $<---$ FS3 & 22.965 & .149 \\
\hline INTERNALIZATION & $<--$ FS2 & 17.925 & .124 \\
\hline INTERNALIZATION & $<---\quad$ FS1 & 13.947 & 100 \\
\hline INTERNALIZATION & $<---\quad$ AV & 4.109 & -.036 \\
\hline INTERNALIZATION & $<---\quad E \& D$ & 10.632 & -.062 \\
\hline INTERNALIZATION & $<---$ TAGG & 9.164 & -.057 \\
\hline INTERNALIZATION & $<---$ DISSONANCE & 5.529 & -.070 \\
\hline DIS & $<---$ FS & 14.957 & -.218 \\
\hline DIS & <--- BRILEVEL1 & 4.569 & -.239 \\
\hline DIS & $<---$ STC1 & 15.196 & 109 \\
\hline DIS & $<---$ FS3 & 4.430 & -.119 \\
\hline DIS & $<---$ FS2 & 13.938 & -.198 \\
\hline DIS & $<---\quad$ FS1 & 17.553 & -.205 \\
\hline DIS & <--- CONFORMITY & 5.041 & -.122 \\
\hline VR & <--- BRILEVEL2 & 4.646 & .182 \\
\hline $\mathrm{AV}$ & $<---$ BRILEVEL1 & 4.036 & -.199 \\
\hline $\mathrm{AV}$ & $<---\quad$ FS1 & 4.690 & -.094 \\
\hline $\mathrm{AV}$ & $<---$ CONFORMITY & 5.156 & -.109 \\
\hline$E \& D$ & $<---$ BRILEVEL2 & 6.266 & -.162 \\
\hline$E \& D$ & $<---$ BRILEVEL1 & 7.611 & .218 \\
\hline$E \& D$ & $<---$ STC1 & 6.126 & -.049 \\
\hline$E \& D$ & <--- EMERSION & 4.704 & -.091 \\
\hline$E \& D$ & <--- INTERNALIZATION & 6.939 & -.119 \\
\hline$E \& D$ & $<---\quad$ AV & 4.343 & .047 \\
\hline$E \& D$ & $<---$ CONFORMITY & 7.899 & .108 \\
\hline$E \& D$ & <--- DISSONANCE & 4.853 & .084 \\
\hline TAGG & $<---$ STC2 & 8.254 & .069 \\
\hline TAGG & $<---\quad$ FS1 & 7.522 & .098 \\
\hline CONFORMITY & $<--\quad$ FS & 18.009 & .132 \\
\hline CONFORMITY & $<---$ STC1 & 4.426 & -.032 \\
\hline CONFORMITY & $<---\quad$ FS3 & 12.929 & .112 \\
\hline CONFORMITY & $<---$ FS2 & 14.290 & .110 \\
\hline CONFORMITY & $<---\quad$ FS1 & 19.779 & .120 \\
\hline CONFORMITY & $<---$ AV & 4.601 & -.038 \\
\hline DISSONANCE & $<---$ FS & 6.156 & -.085 \\
\hline DISSONANCE & $<---$ FS2 & 5.882 & -.078 \\
\hline DISSONANCE & $<---\quad$ FS1 & 6.013 & -.072 \\
\hline
\end{tabular}




\begin{tabular}{|c|c|c|c|}
\hline & & M.I. & Par Change \\
\hline IMMERSION & $\begin{array}{ll}<-- & \text { FS } \\
\end{array}$ & 18.741 & -.147 \\
\hline IMMERSION & $<---\quad$ PED & 13.482 & .119 \\
\hline IMMERSION & $<---\quad$ STC & 14.206 & .079 \\
\hline IMMERSION & $<---$ STC3 & 10.100 & .060 \\
\hline IMMERSION & $<---$ STC2 & 14.194 & .074 \\
\hline IMMERSION & $<---$ STC1 & 6.728 & .044 \\
\hline IMMERSION & $<---\quad$ FS3 & 24.417 & -.168 \\
\hline IMMERSION & $<---$ FS2 & 12.528 & -.113 \\
\hline IMMERSION & $<---\quad$ FS1 & 19.044 & -.128 \\
\hline IMMERSION & $<---\quad$ DIS & 12.458 & .062 \\
\hline IMMERSION & $<---\quad$ VR & 9.024 & .062 \\
\hline IMMERSION & $<---\quad A V$ & 10.294 & .062 \\
\hline IMMERSION & $<---\quad E \& D$ & 9.907 & .065 \\
\hline IMMERSION & $<---$ TAGG & 8.838 & .061 \\
\hline
\end{tabular}

\section{Model Fit Summary}

\section{CMIN}

\begin{tabular}{|l|rrrrr|}
\hline Model & NPAR & CMIN & DF & P & CMIN/DF \\
\hline Default model & 43 & 419.555 & 93 & .000 & 4.511 \\
Saturated model & 136 & .000 & 0 & & \\
Independence model & 16 & 5201.348 & 120 & .000 & 43.345 \\
\hline
\end{tabular}

RMR, GFI

\begin{tabular}{|l|rrrr|}
\hline Model & RMR & GFI & AGFI & PGFI \\
\hline Default model & .103 & .880 & .825 & .602 \\
Saturated model & .000 & 1.000 & & \\
Independence model & .859 & .290 & .195 & .256 \\
\hline
\end{tabular}

Baseline Comparisons

\begin{tabular}{|l|rrrrr|}
\hline Model & $\begin{array}{r}\text { NFI } \\
\text { Delta1 }\end{array}$ & $\begin{array}{r}\text { RFI } \\
\text { rho1 }\end{array}$ & $\begin{array}{r}\text { IFI } \\
\text { Delta2 }\end{array}$ & $\begin{array}{r}\text { TLI } \\
\text { rho2 }\end{array}$ & CFI \\
\hline Default model & .919 & .896 & .936 & .917 & .936 \\
Saturated model & 1.000 & & 1.000 & & 1.000 \\
Independence model & .000 & .000 & .000 & .000 & .000 \\
\hline
\end{tabular}




\section{Parsimony-Adjusted Measures}

\begin{tabular}{|l|rrr|}
\hline Model & PRATIO & PNFI & PCFI \\
\hline Default model & .775 & .712 & .725 \\
Saturated model & .000 & .000 & .000 \\
Independence model & 1.000 & .000 & .000 \\
\hline
\end{tabular}

\section{NCP}

\begin{tabular}{|l|rrr|}
\hline Model & NCP & LO 90 & HI 90 \\
\hline Default model & 326.555 & 266.743 & 393.909 \\
Saturated model & .000 & .000 & .000 \\
Independence model & 5081.348 & 4848.641 & 5320.382 \\
\hline
\end{tabular}

FMIN

\begin{tabular}{|l|rrrr|}
\hline Model & FMIN & F0 & LO 90 & HI 90 \\
\hline Default model & 1.001 & .779 & .637 & .940 \\
Saturated model & .000 & .000 & .000 & .000 \\
Independence model & 12.414 & 12.127 & 11.572 & 12.698 \\
\hline
\end{tabular}

\section{RMSEA}

\begin{tabular}{|l|rrrr|}
\hline Model & RMSEA & LO 90 & HI 90 & PCLOSE \\
\hline Default model & .092 & .083 & .101 & .000 \\
Independence model & .318 & .311 & .325 & .000 \\
\hline
\end{tabular}

AIC

\begin{tabular}{|l|rrrr|}
\hline Model & AIC & BCC & BIC & CAIC \\
\hline Default model & 505.555 & 509.191 & 679.286 & 722.286 \\
Saturated model & 272.000 & 283.502 & 821.475 & 957.475 \\
Independence model & 5233.348 & 5234.702 & 5297.992 & 5313.992 \\
\hline
\end{tabular}

\section{ECVI}

\begin{tabular}{|l|rrrr|}
\hline Model & ECVI & LO 90 & HI 90 & MECVI \\
\hline Default model & 1.207 & 1.064 & 1.367 & 1.215 \\
Saturated model & .649 & .649 & .649 & .677 \\
Independence model & 12.490 & 11.935 & 13.061 & 12.493 \\
\hline
\end{tabular}




\section{HOELTER}

\begin{tabular}{|l|rr|}
\hline \multirow{2}{*}{ Model } & HOELTER & HOELTER \\
& .05 & .01 \\
\hline Default model & 117 & 128 \\
Independence model & 12 & 13 \\
\hline
\end{tabular}


APPENDIX C

QUESTIONNAIRES AND SURVEYS 


\section{Perceived Ethnic Discrimination Questionnaire}

\begin{tabular}{|c|c|c|c|}
\hline Variable & $\begin{array}{l}\text { Conceptual } \\
\text { Definition }\end{array}$ & $\begin{array}{l}\text { Instrumental } \\
\text { Definition }\end{array}$ & $\begin{array}{l}\text { Operational } \\
\text { Definition }\end{array}$ \\
\hline $\begin{array}{l}\text { Perceived Ethnic } \\
\text { Discrimination }\end{array}$ & $\begin{array}{l}\text { Reflects exposure to } \\
\text { individual, } \\
\text { institutional or } \\
\text { cultural events or } \\
\text { conditions } \\
\text { (Brondolo et al., } \\
\text { 2005) }\end{array}$ & $\begin{array}{l}\text { "Because of your } \\
\text { race or ethnicity ..." } \\
\text { how often have you } \\
\text { ever "had these } \\
\text { experiences during } \\
\text { their lifetime," } \\
\text {-Each item is rated } \\
\text { on a 5-point Likert- } \\
\text { type scale, } \\
\text {-1 indicating that the } \\
\text { event "never } \\
\text { happened" } \\
\text {-5 indicating the } \\
\text { event "happened } \\
\text { very often." }\end{array}$ & $\begin{array}{l}\text { Take the mean of the } \\
\text { items (according to } \\
\text { subscale) and the } \\
\text { higher the mean the } \\
\text { more they have } \\
\text { experienced that } \\
\text { subscale }\end{array}$ \\
\hline $\begin{array}{l}\text { Subscales: } \\
\text { Disvaluation }\end{array}$ & $\begin{array}{l}\text { The feeling of being } \\
\text { de-valued or } \\
\text { unimportant } \\
\text { (Contrada et al., } \\
\text { 2001) }\end{array}$ & $\begin{array}{l}12 . \text { How often } \\
\text { have others had low } \\
\text { expectations of you } \\
\text { because of your } \\
\text { ethnicity? } \\
13 . \text { How often } \\
\text { has it been implied } \\
\text { or suggested that } \\
\text { because of your } \\
\text { ethnicity you must } \\
\text { be unintelligent? } \\
14 . \overline{H o w} \text { often } \\
\text { has it been implied } \\
\text { or suggested that } \\
\text { because of your } \\
\text { ethnicity you must } \\
\text { be dishonest? } \\
15 . \\
\text { has it been implied } \\
\text { or suggested that } \\
\text { because of your } \\
\text { ethnicity you must } \\
\text { be violent or } \\
\text { dangerous? } \\
16 . \overline{\text { How often }} \\
\text { has it been implied } \\
\text { or suggested that } \\
\text { because of your } \\
\text { ethnicity you must } \\
\text { be dirty? }\end{array}$ & $\begin{array}{l}\text { Take the mean of the } \\
\text { items and the higher } \\
\text { the mean the more } \\
\text { exclusion/rejection } \\
\text { they feel. }\end{array}$ \\
\hline
\end{tabular}




\begin{tabular}{|c|c|c|c|}
\hline & & $\begin{array}{l}17 . \text { How often } \\
\text { has it been implied } \\
\text { or suggested that } \\
\text { because of your } \\
\text { ethnicity you must } \\
\text { be lazy? }\end{array}$ & \\
\hline Avoidance & $\begin{array}{l}\text { The act of being } \\
\text { avoided (Contrada } \\
\text { et al., 2001) }\end{array}$ & $\begin{array}{l}\text { 4. How often } \\
\text { have others avoided } \\
\text { physical contact } \\
\text { with you because of } \\
\text { your ethnicity? } \\
5 . \quad \text { How often } \\
\text { have others avoided } \\
\text { social contact with } \\
\text { you because of your } \\
\text { ethnicity? } \\
6 . \text { How often } \\
\text { have others outside } \\
\text { of your ethnic group } \\
\text { made you feel as } \\
\text { though you don't fit } \\
\text { in because of your } \\
\text { dress, speech, or } \\
\text { other characteristics } \\
\text { related to your } \\
\text { ethnicity? }\end{array}$ & $\begin{array}{l}\text { Take the mean of the } \\
\text { items and the higher } \\
\text { the mean the more } \\
\text { avoidance they feel. }\end{array}$ \\
\hline Verbal Rejection & $\begin{array}{l}\text { The act of being } \\
\text { rejected verbally } \\
\text { (Contrada et al., } \\
\text { 2001) }\end{array}$ & $\begin{array}{l}1 . \text { How often } \\
\text { have you been } \\
\text { subjected to } \\
\text { offensive ethnic } \\
\text { comments aimed } \\
\text { directly at you, } \\
\text { spoken either in } \\
\text { your presence or } \\
\text { behind your back? } \\
2 . \text { How often } \\
\text { have you been } \\
\text { exposed to offensive } \\
\text { comments about } \\
\text { your ethnic group } \\
\text { (e.g. stereotypic } \\
\text { statements, } \\
\text { offensive jokes), } \\
\text { spoken either in } \\
\text { your presence or } \\
\text { behind your back? } \\
3 . \quad \text { How often } \\
\text { have you been } \\
\text { subjected to ethnic }\end{array}$ & $\begin{array}{l}\text { Take the mean of the } \\
\text { items and the higher } \\
\text { the mean the more } \\
\text { verbal rejection they } \\
\text { feel. }\end{array}$ \\
\hline
\end{tabular}




\begin{tabular}{|c|c|c|c|}
\hline & & $\begin{array}{l}\text { name calling (e.g. } \\
\text { "wop", "nigger")? }\end{array}$ & \\
\hline Threat/ Aggression & $\begin{array}{l}\text { The act of being } \\
\text { threatened with } \\
\text { physical harm or } \\
\text { physically harmed } \\
\text { (Contrada et al., } \\
\text { 2001) }\end{array}$ & $\begin{array}{l}18 . \text { How often } \\
\text { have others } \\
\text { threatened to hurt } \\
\text { you because of your } \\
\text { ethnicity? } \\
19 . \quad \text { How often } \\
\text { have others } \\
\text { threatened to } \\
\text { damage your } \\
\text { property because of } \\
\text { your ethnicity? } \\
20 . \quad \text { How often } \\
\text { have others } \\
\text { physically hurt you } \\
\text { or intended to } \\
\text { physically hurt you } \\
\text { because of your } \\
\text { ethnicity? } \\
21 . \text { How often } \\
\text { have others } \\
\text { damaged your } \\
\text { property because of } \\
\text { your ethnicity? } \\
22 . \text { How often } \\
\text { have you been } \\
\text { subjected to } \\
\text { nonverbal } \\
\text { harassment because } \\
\text { of your ethnicity } \\
\text { (e.g. being } \\
\text { framed/set up, being } \\
\text { given "the finger")? }\end{array}$ & $\begin{array}{l}\text { Take the mean of the } \\
\text { items and the higher } \\
\text { the mean the more } \\
\text { discrimination at } \\
\text { threat \& aggression } \\
\text { they experience. }\end{array}$ \\
\hline $\begin{array}{l}\text { Exclusion \& Denial of } \\
\text { Equal Treatment }\end{array}$ & $\begin{array}{l}\text { The act of being } \\
\text { excluded or denied } \\
\text { equal treatment } \\
\text { (Contrada et al., } \\
\text { 2001) }\end{array}$ & $\begin{array}{l}7 . \text { How often } \\
\text { have you been } \\
\text { denied access to a } \\
\text { public facility or } \\
\text { organization because } \\
\text { of your ethnicity? } \\
8 . \quad \text { How often } \\
\text { have you felt that } \\
\text { certain places were } \\
\text { off limits or that } \\
\text { barriers were erected } \\
\text { to keep you out of } \\
\text { certain places } \\
\text { because of your } \\
\text { ethnicity? }\end{array}$ & $\begin{array}{l}\text { Take the mean of the } \\
\text { items and the higher } \\
\text { the mean the more } \\
\text { exclusion and denial } \\
\text { they experience. }\end{array}$ \\
\hline
\end{tabular}




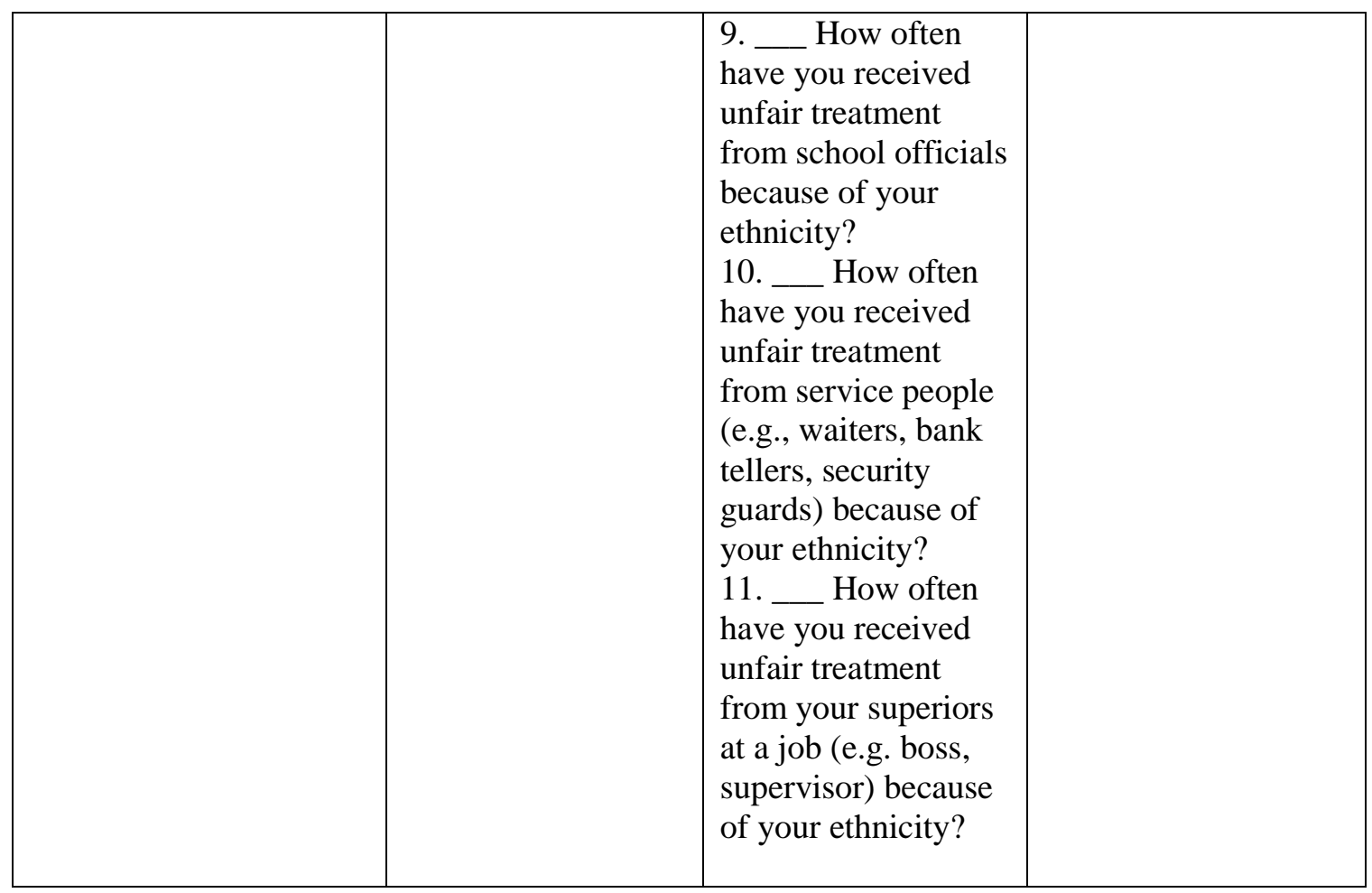


Black Racial Identity Attitude Scale

\begin{tabular}{|c|c|c|c|}
\hline Variable & Conceptual Definition & $\begin{array}{l}\text { Instrumental } \\
\text { Definition }\end{array}$ & Operational Definition \\
\hline $\begin{array}{l}\text { Black Racial } \\
\text { Identity }\end{array}$ & & $\begin{array}{l}\text { Respondents use 5- } \\
\text { point Likert scales } \\
\text { (1=strongly } \\
\text { disagree, } 5=\text { strongly } \\
\text { agree) to indicate } \\
\text { how well an item } \\
\text { describes their own } \\
\text { attitudes. }\end{array}$ & $\begin{array}{l}\text { Statuses that receive the } \\
\text { highest scores are } \\
\text { referred to as dominant } \\
\text { statuses and used most } \\
\text { frequently for interpreting } \\
\text { racial stimuli in one's } \\
\text { internal and external } \\
\text { environment. Statuses } \\
\text { that receive the lowest } \\
\text { scores are referred to as } \\
\text { recessive statuses and are } \\
\text { infrequently used for } \\
\text { interpreting racial stimuli. }\end{array}$ \\
\hline Pre-Encounter & $\begin{array}{l}\text { Idealization of White } \\
\text { people and White } \\
\text { culture and denigration } \\
\text { of black people and } \\
\text { black culture }\end{array}$ & $\begin{array}{l}\text { Items } 4,8,9,17,21, \\
25,, 31,35,38,40, \\
41,43,46,47,53 \& \\
58\end{array}$ & $\begin{array}{l}\text { Take the sum of scores } \\
\text { the higher the score the } \\
\text { more dominant the status }\end{array}$ \\
\hline $\begin{array}{l}\text { Post- } \\
\text { Encounter }\end{array}$ & $\begin{array}{l}\text { Attitudes, behaviors and } \\
\text { emotions that follow } \\
\text { from personally } \\
\text { troubling or impacting } \\
\text { racial events }\end{array}$ & $\begin{array}{l}\text { Items } 13,19,24,42 \\
49,52,55 \& 57\end{array}$ & $\begin{array}{l}\text { Take the sum of scores } \\
\text { the higher the score the } \\
\text { more dominant the status }\end{array}$ \\
\hline Immersion & $\begin{array}{l}\text { Psychological } \\
\text { withdrawal into black } \\
\text { environments, } \\
\text { characterized by } \\
\text { denigration of White } \\
\text { people and White } \\
\text { culture and idealization } \\
\text { of black people and } \\
\text { experiences. }\end{array}$ & $\begin{array}{l}\text { Items, } 11,14,15 \\
18,23,27,28,33 \\
34,36,39,54 \& 59\end{array}$ & $\begin{array}{l}\text { Take the sum of scores } \\
\text { the higher the score the } \\
\text { more dominant the status }\end{array}$ \\
\hline Emersion & $\begin{array}{l}\text { Joy and contentment in } \\
\text { own group environment }\end{array}$ & $\begin{array}{l}\text { Items 5, 20, 26, 29, } \\
32,44,51 \& 56\end{array}$ & $\begin{array}{l}\text { Take the sum of scores } \\
\text { the higher the score the } \\
\text { more dominant the status }\end{array}$ \\
\hline Internalization & $\begin{array}{l}\text { a humanist orientation } \\
\text { derived from a positive } \\
\text { commitment to Black } \\
\text { people and Black culture } \\
\text { and a consequent } \\
\text { valuing of the life } \\
\text { experiences of other } \\
\text { non-dominant groups }\end{array}$ & $\begin{array}{l}\text { Items } 1,2,6,7,10 \\
16,22,30,37,45 \\
48,50 \& 60\end{array}$ & $\begin{array}{l}\text { Take the sum of scores } \\
\text { the higher the score the } \\
\text { more dominant the status }\end{array}$ \\
\hline
\end{tabular}


Family Satisfaction Scale

\begin{tabular}{|c|c|c|c|}
\hline Variable & Conceptual Definition & Instrumental Definition & $\begin{array}{l}\text { Operational } \\
\text { Definition }\end{array}$ \\
\hline $\begin{array}{l}\text { Family } \\
\text { Satisfaction }\end{array}$ & $\begin{array}{l}\text { the degree to which } \\
\text { family members feel } \\
\text { happy and } \\
\text { fulfilled with each } \\
\text { other (Olson, n.d.) }\end{array}$ & $\begin{array}{l}\text { Please circle the appropriate } \\
\text { number for each statement } \\
\text { depending on whether you are: } \\
\text { very dissatisfied, somewhat } \\
\text { dissatisfied, generally satisfied, } \\
\text { very satisfied or extremely } \\
\text { satisfied } \\
\text { 1=Very dissatisfied } \\
\text { 5=Extremely Satisfied } \\
\text { 1. The degree of closeness } \\
\text { between family members. } \\
\text { 2. Your family's ability to cope } \\
\text { with stress. } \\
\text { 3. Your family's ability to be } \\
\text { flexible. } \\
\text { 4. Your family's ability to share } \\
\text { positive experiences. } \\
5 . \text { The quality of } \\
\text { communication between family } \\
\text { members. } \\
6 . \text { Your family's ability to } \\
\text { resolve conflicts. } \\
\text { 7. The amount of time you } \\
\text { spend together as a family. } \\
\text { 8. The way problems are } \\
\text { discussed. } \\
\text { 9. The fairness of criticism in } \\
\text { your family. } \\
\text { 10. Family members concern } \\
\text { for each other. }\end{array}$ & $\begin{array}{l}\text { Total scores } \\
\text { range from } 10 \\
\text { to } 50 \text { and higher } \\
\text { scores represent } \\
\text { greater family } \\
\text { satisfaction }\end{array}$ \\
\hline Communication & $\begin{array}{l}\text { the positive } \\
\text { communication skills } \\
\text { utilized in the family } \\
\text { system (Olson, 2011) } \\
\text { *This scale is added } \\
\text { by the researcher to } \\
\text { assess for levels of } \\
\text { communication }\end{array}$ & $\begin{array}{l}\text { Please circle the appropriate } \\
\text { number for each statement } \\
\text { depending on whether you are: } \\
\text { 1=Very dissatisfied } \\
\text { 5=Extremely Satisfied } \\
\text { 4. Your family's ability to share } \\
\text { positive experiences. } \\
\text { 5. The quality of } \\
\text { communication between family } \\
\text { members. } \\
\text { 8. The way problems are } \\
\text { discussed. }\end{array}$ & $\begin{array}{l}\text { Total scores } \\
\text { range from } 3 \text { to } \\
15 \text { and higher } \\
\text { scores represent } \\
\text { greater family } \\
\text { communication. }\end{array}$ \\
\hline
\end{tabular}


Stereotype Confirmation Scale

\begin{tabular}{|c|c|c|c|}
\hline Variable & Conceptual Definition & $\begin{array}{l}\text { Instrumental } \\
\text { Definition }\end{array}$ & $\begin{array}{l}\text { Operational } \\
\text { Definition }\end{array}$ \\
\hline $\begin{array}{l}\text { Stereotype } \\
\text { Confirmation } \\
\text { Concern }\end{array}$ & $\begin{array}{l}\text { conceptualized as the } \\
\text { relatively enduring } \\
\text { or recurring } \\
\text { experience of } \\
\text { stereotype threat (e.g., } \\
\text { "The way I dress and } \\
\text { speak may fit } \\
\text { negative stereotypes } \\
\text { that people hold about } \\
\text { my ethnic group"). } \\
\text { Stereotype } \\
\text { confirmation concern } \\
\text { is defined at one } \\
\text { extreme by those } \\
\text { individuals who } \\
\text { chronically } \\
\text { experience } \\
\text { uncertainty and } \\
\text { apprehension about } \\
\text { appearing to confirm } \\
\text { as self-characteristic a } \\
\text { stereotype about a } \\
\text { group to which they } \\
\text { belong, and at the } \\
\text { other extreme by } \\
\text { individuals who are } \\
\text { free of such concern } \\
\text { (Contrada et al., } \\
\text { 2001). }\end{array}$ & $\begin{array}{l}\text { Respondents rate how } \\
\text { frequently over the } \\
\text { past } \\
3 \text { months they have } \\
\text { been "concerned that } \\
\text { by you } \\
\text { might appear to be } \\
\text { confirming a } \\
\text { stereotype." } \\
\text { Items are rated on a } \\
\text { 7-point Likert type } \\
\text { scale of } 1 \text { (never) to } 7 \\
\text { (always) } \\
\text { 1. Owning certain } \\
\text { things } \\
\text { 2. Attending or } \\
\text { participating in } \\
\text { certain social } \\
\text { activities } \\
\text { 3. The way you look } \\
\text { (your physical } \\
\text { performance) } \\
\text { 4. Shopping in certain } \\
\text { stores or eating in at } \\
\text { certain restaurants } \\
\text { 5. Eating certain } \\
\text { foods } \\
\text { 6. Doing certain } \\
\text { households tasks } \\
\text { 7. Dressing a certain } \\
\text { way } \\
8 . \text { Playing certain } \\
\text { sports } \\
\text { 9. Taking your } \\
\text { studies too seriously } \\
\text { 10. Talking in a } \\
\text { certain way } \\
\text { 11. Revealing your } \\
\text { socioeconomic status }\end{array}$ & $\begin{array}{l}\text { Total scores } \\
\text { range from } 11 \text { to } 77 \\
\text { and higher scores } \\
\text { represent greater } \\
\text { concern }\end{array}$ \\
\hline
\end{tabular}




\section{Demographics Questionnaire}

\section{Qualifiers:}

1. Do you consider yourself African or "Black"-American? Yes or No

2. Are you of African or Black descent?

Yes or No

3. Were you born in America \& are you a US citizen?

Yes or No

4. Have you spent your whole life in America (besides vacations and trips)? Yes or No

5. Are both your parents of African or Black descent or considered African or "Black" American

Yes or No

6. Gender

Male or Female

\section{General Questions:}

1. How old are you?

2. What college do you attend?

3. What is your major?

4. What city and state is your college located in?

5. What is your classification in school (i.e freshman, sophomore, junior, etc...)

6. What year are you in school (i.e $1^{\text {st }}$ year, $2^{\text {nd }}$ year, $3^{\text {rd }}$ year, etc...) 
APPENDIX D

INFORMED CONSENT 


\section{INFORMED CONSENT}

\section{Purpose}

You are invited to participate in a research project titled The Impact of Racial Identity, Family Satisfaction and Perceived Discrimination on African- American College Students' Susceptibility to Stereotype Threat. The purpose of this research is to determine if certain factors have effects on African-American college students' susceptibility to stereotype threat.

\section{Researchers}

This research is being conducted by Erica Featherson, a PhD student in the department of Graduate Psychology and Counseling at Andrews University in Berrien Springs, Michigan. Dr. Elvin Gabriel, ED.D, is supervising the research. Results from this research will be used in Erica Featherson's dissertation and may be published in professional journals or presented at conferences.

\section{Procedure}

If you choose to participate in this research, you will be asked to complete a survey that asks questions about your race, racial identity, aspects of your family life and discrimination experiences. It will take between 30-40 minutes to complete this survey.

\section{Participation}

In order to participate, you must be over 18 years of age and be currently enrolled fulltime in college. Your participation in this study is completely voluntary. It is your choice whether to participate or not. You may quit the survey at any time.

\section{Risks, Benefits, and Compensation}

There are no foreseeable risks or benefits associated with participating in this project. However, some of the questions asked may trigger unpleasant memories.

\section{Confidentiality}

Your survey responses will be strictly confidential and data from this research will be reported only in the aggregate. Your information will be coded and will remain confidential.

\section{Contact Information}

If you have questions at any time about the survey, your participation in this research, or your rights as a participant, you may contact the principle investigator, Erica Featherson at (707) 712-4387 or featherson@ andrews.edu. You may also contact her research advisor, Dr. Elvin Gabriel at (269) 471-6223 or gabriel@ andrews.edu.

\section{Consent}

Thank you very much for your time and support. Please start the survey by clicking on the Continue button below. By clicking this button, you are giving your consent to participate in the research described above. 
APPENDIX E

APPROVAL LETTERS 


\title{
Andrews Q University
}

September 21, 2017

Erica Featherson

Tel. 707-712-4387

Email: ericafeatho7@yahoo.com

\begin{abstract}
RE: APPLICATION FOR APPROVAL OF RESEARCH INVOLVING HUMAN SUBJECTS IRB Protocol \#:17-120 Application Type: Original Dept.: Graduate Psychology \& Counseling Review Category: Exempt Action Taken: Approved Advisor: Elvin Gabriel

Title: The impact of racial identity, family satisfaction and perceived discrimination on African American college students' susceptivility to stereotyp threat.
\end{abstract}

Your IRB application for approval of research involving human subjects entitled: "The impact of racial identity, family satisfaction and perceived discrimination on African American college students' susceptivility to stereotyp threat" IRB protocol \# 17-120 has been evaluated and determined Exempt from IRB review under regulation 46.101 (b) (2). You may now proceed with your research.

Please note that any future changes (see IRB Handbook pages 11-12) made to the study design and/or informed consent form require prior approval from the IRB before such changes can be implemented. Incase you need to make changes please use the attached report form.

While there appears to be no more than minimum risks with your study, should an incidence occur that results in a research-related adverse reaction and/or physical injury, (see IRB Handbook pages 12) this must be reported immediately in writing to the IRB. Any research-related physical injury must also be reported immediately to the University Physician, Dr. Katherine, by calling (269) 473-2222.

We ask that you reference the protocol number in any future correspondence regarding this study for easy retrieval of information.

Best wishes in your research.

Sincerely,

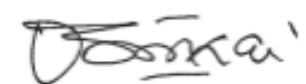

Mordekai Ongo

Research Integrity and Complaince Officer 


\section{REFERENCES}




\section{REFERENCES}

Adams-Bass, V., Stevenson, H. C., \& Kotzin, D. S. (2014). Measuring the meaning of black media stereotypes and their relationship to the racial identity, black history knowledge, and racial socialization of African-American youth. Journal of Black Studies, 45(5), 367-395.

Albritton, T. J. (2012). Educating our own: The historical legacy of HBCUs and their relevance for educating a new generation of leaders. The Urban Review, 44(3), 311-331. Retrieved from http://dx.doi.org/10.1007/s11256-012-0202-9

Anglin, D. M., \& Wade, J. C. (2007). Racial socialization, racial identity, and Black students' adjustment to college. Cultural Diversity and Ethnic Minority Psychology, 13(3), 207-215.

Aronson, J., \& Inzlicht, M. (2004). The ups and downs of attributional ambiguity: Stereotype vulnerability and the academic self-knowledge of African-American college students. Psychological Science, 15(12), 829-836. Retrieved from http://dx.doi.org/10.1111/j.0956-7976.2004.00763.x

Aronson, J., Fried, C. B., \& Good, C. (2002). Reducing the effects of stereotype threat on African-American college students by shaping theories of intelligence. Journal of Experimental Social Psychology, 38(2), 113-125. Retrieved from http://dx.doi.org/10.1006/jesp.2001.1491

Armah, T. (2015). The next Black America: Obstacles amidst opportunities for Black families. American Journal of Orthopsychiatry, 85(5), S55-S66.

Baker, J. A. (1998). The social context of school satisfaction among urban, low-income, African-American students. School Psychology Quarterly, 13(1), 25-44. Retrieved from https://search.proquest.com/docview/614403655?accountid=8313

Bell, D. C., \& Bell, L. G. (1989). Micro and macro measurement of family systems concepts. Journal of Family Psychology, 3(2), 137-157.

Behrens, J. T. (1997). Does the White racial identity attitude scale measure racial identity? Journal of Counseling Psychology, 44(1), 3-12. Retrieved from https://search.proquest.com/docview/614320097? accountid=8313 
Bianchi, F. T., Zea, M. C., Belgrave, F. Z., \& Echeverry, J. J. (2002). Racial identity and self-esteem among Black Brazilian men: Race matters in Brazil too! Cultural Diversity and Ethnic Minority Psychology, 8(2), 157-169.

Bikmen, N. (2015). History as a Resource: Effects of Narrative Constructions of Group History on Intellectual Performance. Journal of Social Issues, 71(2), 309-323. doi:10.1111/josi.12112

Blank, R. M., Dabady, M., \& Citro, C. F. (2004). Measuring racial discrimination (pp. 23-55). Washington, DC: National Academies Press.

Bourke, B. (2010). Experiences of black students in multiple cultural spaces at a predominantly White institution. Journal of Diversity in Higher Education, 3(2), 126-135. Retrieved from http://dx.doi.org/10.1037/a0019025

Brittian, A. S., Kim, S. Y., Armenta, B. E., Lee, R. M., Umaña-Taylor, A. J., Schwartz, S. J., . . Hudson, M. L. (2015). Do dimensions of ethnic identity mediate the association between perceived ethnic group discrimination and depressive symptoms? Cultural Diversity and Ethnic Minority Psychology, 21(1), 41-53.

Brondolo, E., Kelly, K. P., Coakley, V., Gordon, T., Thompson, S., Levy, E., . . . Contrada, R. J. (2005). The Perceived Ethnic Discrimination Questionnaire: Development and Preliminary Validation of a Community Version1. Journal of Applied Social Psychology, 35(2), 335-365. doi:10.1111/j.15591816.2005.tb02124.x

Broudy R., Brondolo, E., Coakley, V., Brady, N., Cassells, A., Tobin., J., \& Sweeney, M.. Perceived ethnic discrimination in relation to daily moods and negative social interactions. In Journal of Behavioral Medicine, 30(1), 31-43. doi:10.1007/s10865-006-9081-4

Brower, A. M., \& Ketterhagen, A. (2004). Is there an inherent mismatch between how Black and White students expect to succeed in college and what their colleges expect from them? Journal of Social Issues, 60, 95-116. doi:10.1111/j.00224537.2004.00101.x

Brown II, C. M., \& Dancy II, E. T. (2010). Predominantly White institutions. In K. Lomotey (Ed.), Encyclopedia of African-American education. (pp. 524-527). Thousand Oaks, CA: SAGE Publications, Inc. Retrieved from http://dx.doi.org/10.4135/9781412971966.n193

Bulhan, H. A. (2011). Frantz Fanon and the psychology of oppression. Brantford, Ontario: W. Ross MacDonald School Resource Services Library. 
Camera, L. (2016). The college graduation gap is still growing. U.S. News and World Report [Online]. Retrieved March 22, 2018, from https://www.usnews.com/news/blogs/data-mine/2016/03/23/study-collegegraduation-gap-between-blacks-whites-still-growing

Campbell, S. D. (2010). Race still matters: How race influences success and satisfaction for African-American college students. (Doctoral Dissertation). Available from ProQuest Dissertations and Theses Global. (UMI: No. 3423311)

Carlsson, J., Wängqvist, M., \& Frisén, A. (2016). Life on hold: Staying in identity diffusion in the late twenties. Journal of Adolescence, 47, 220-229. doi:10.1016/j.adolescence.2015.10.023

Census, (2011, September). The Black population: 2010. Retrieved from https://www.census.gov/prod/cen2010/briefs/c2010br-06.pdf

Chang, D. F., \& Demyan, A. L. (2007). Teachers' stereotypes of Asian, Black, and White students. School Psychology Quarterly, 22(2), 91-114. Retrieved from http://dx.doi.org/10.1037/1045-3830.22.2.91

Chao, R. C., Mallinckrodt, B., \& Wei, M. (2012). Co-occurring presenting problems in African-American college clients reporting racial discrimination distress. Professional Psychology: Research and Practice, 43(3), 199-207.

Chavez, A. F., \& Guido-DiBrito, F. (2001). Racial and ethnic identity. New Directions for Adult and Continuing Education, 1(84), 40. Retrieved from http://isites.harvard.edu/fs/docs/icb.topic551690.files/Chavez and Guido Debrito.pdf

Clark, R., Anderson, N. B., Clark, V. R., \& Williams, D. R. (1999). Racism as a stressor for African-Americans: A biopsychosocial model. American Psychologist, 54(10), 805-816. Retrieved from http://dx.doi.org/10.1037/0003-066X.54.10.805

Cohen, G. L., \& Garcia, J. (2005). I am us: Negative stereotypes as collective threats. Journal of Personality and Social Psychology: Interpersonal Relations and Group Processes, 89(4), 566-582. Retrieved from http://dx.doi.org/10.1037/00223514.89.4.566

Cohen, G. L., \& Sherman, D. K. (2005). Stereotype threat and the social and scientific contexts of the race achievement gap. American Psychologist, 60(3), 270-271. Retrieved from http://dx.doi.org/10.1037/0003-066X.60.3.270

Cokley, K. O. (2002). Testing Cross's revised racial identity model: An examination of the relationship between racial identity and internalized racialism. Journal of Counseling Psychology, 49(4), 476-483. 
Cokley, K. O. (2005). Racial(ized) identity, ethnic identity, and afrocentric values: Conceptual and methodological challenges in understanding African-American identity. Journal of Counseling Psychology, 52(4), 517-526.

Contrada, R. J., Ashmore, R. D., Gary, M. L., Coups, E. , Egeth, J. D., Sewell, A., ... Chasse, V. (2001), Measures of ethnicity-related stress: Psychometric properties, ethnic group differences, and associations with well-being. Journal of Applied Social Psychology, 31: 1775-1820. doi:10.1111/j.1559-1816.2001.tb00205.x

Corenblum, B., \& Armstrong, H. D. (2012). Racial-ethnic identity development in children in a racial-ethnic minority group. Canadian Journal of Behavioural Science/Revue Canadienne Des Sciences Du Comportement, 44(2), 124-137. Retrieved from http://dx.doi.org/10.1037/a0027154

Creswell, J. (2008). Educational research, planning, conducting and evaluating quantitative and qualitative research (3rd ed.). Upper Saddle River, NJ: Pearson/Merrill Prentice Hall.

Cumsille, P. E., \& Epstein, N. (1994). Family cohesion, family adaptability, social support, and adolescent depressive symptoms in outpatient clinic families. Journal of Family Psychology, 8(2), 202-214.

Davis, C., Aronson, J., \& Salinas, M. (2006). Shades of threat: Racial identity as a moderator of stereotype threat. Journal of Black Psychology, 32(4), 399-417.

Davis, R. S. (2012). The deconstruction of ambition: Campus climate, stereotype threat, and the motivational goals of African-American students at a selective small liberal arts college (Order No. AAI3467349). Available from PsycINFO (1018477249; 2012-99070-354). Retrieved from http://search.proquest.com/docview/1018477249?accountid=8313

Demo, D., \& Hughes, M. (1990). Socialization and racial identity among Black Americans. Social Psychology Quarterly, 53(4), 364-374.

Donders, N. C., Correll, J., \& Wittenbrink, B. (2008). Danger stereotypes predict racially biased attentional allocation. Journal of Experimental Social Psychology, 44(5), 1328-1333. Retrieved from http://dx.doi.org/10.1016/j.jesp.2008.04.002

Dovidio, J. F., Brigham, J. C., Johnson, B. T., \& Gaertner, S. L. (1996). Stereotyping, prejudice, and discrimination: Another look. Stereotypes and stereotyping, 276, 319.

Dovidio, J. F., Hewstone, M., Glick, P., \& Esses, V. (2010). The SAGE handbook of prejudice, stereotyping and discrimination. London: SAGE. 
Family. (n.d.). Family. Retrieved June 21, 2018, from https://www.merriamwebster.com/dictionary/family

Fischer, M. J. (2010). A longitudinal examination of the role of stereotype threat and racial climate on college outcomes for minorities at elite institutions. Social Psychology of Education: An International Journal, 13(1), 19-40. Retrieved from http://dx.doi.org/10.1007/s11218-009-9105-3

Fischer, A. R., Tokar, D. M., \& Serna, G. S. (1998). Validity and construct contamination of the Racial Identity Attitude Scale-Long Form. Journal of Counseling Psychology, 45(2), 212-224. Retrieved from http://dx.doi.org/10.1037/00220167.45.2.212

Franklin, A. J., \& Boyd-Franklin, N. (2000). Invisibility syndrome: A clinical model of the effects of racism on African-American males. American Journal of Orthopsychiatry, 70(1), 33-41. Retrieved from http://dx.doi.org/10.1037/h0087691

Fries-Britt, S., \& Griffin, K. A. (2007). The Black box: How high-achieving Blacks resist stereotypes about Black Americans. Journal of College Student Development, 48(5), 509-524.

Gopinath, R. (2014, Aug 10). What is the purpose and benefit of SEM. ResearchGate. Retrieved from https://www.researchgate.net/post/What_is_the_purpose_and_ benefit_of_SEM_Structural_Equation_Modeling_to_the_researcher_today

Gordon, B. M. (2012). Give a brotha a break!: The experiences and dilemmas of middleclass African-American male students in White suburban schools. Teachers College Record, 114(5), 26. Retrieved from http://search.proquest.com/docview/ 1361843563 ? accountid $=8313$

Grajales, T., Johnson, C., \& Featherson, E. (2018). Structural validation of the BRIAS-60 items: An exploratory and confirmatory analysis. Submitted for publication.

Helms, J. (2010). Catalog for Helms racial identity measures: PRIAS, WRIAS, BRIAS.[Ethnic Attitude Assessment Scales]. Boston, MA. Retrieved from http://www.bc.edu/content/dam/files/schools//soe_sites/isprc/pdf/Huentity_Psych ological_Consulting_Ca.pdf

Herman, K. C., Ostrander, R., \& Tucker, C. M. (2007). Do family environments and negative cognitions of adolescents with depressive symptoms vary by ethnic group? Journal of Family Psychology, 21(2), 325-330. Retrieved from http://dx.doi.org/10.1037/0893-3200.21.2.325 
Hernandez, E. (2010). The unchosen me-race, gender, and identity among Black women in college. Journal of College Student Development, 51(6), 732-734. Retrieved from http://search.proquest.com/docview/807532778?accountid=8313

Hogg, M. (2006). Social identity theory. In P. Burke (Ed.), Contemporary social psychological theories (pp. 111-136). Standford, CA: Standford University Press.

Hope, E. C., Hoggard, L. S., \& Thomas, A. (2015). Emerging into adulthood in the face of racial discrimination: Physiological, psychological, and sociopolitical consequences for African-American youth. Translational Issues in Psychological Science, 1(4), 342-351.

Intercorrelation. (n.d.). Retrieved July 9, 2018, from https://www.merriamwebster.com/dictionary/intercorrelation

Inzlicht, M., \& Kang, S. K. (2010). Stereotype threat spillover: How coping with threats to social identity affects aggression, eating, decision making, and attention. Journal of Personality and Social Psychology, 99(3), 467-481.

Inzlicht, M., Tullett, A.M. \& Gutsell, J.N. (2011). Threat spillover: The short-term and long-term effects of coping with threats to social identity. In M. Inzlicht, \& T. Schmader (Eds.), Stereotype threat: Theory, process and application. New York, NY: Oxford University Press.

Jamieson, J. P., \& Harkins, S. G. (2007). Mere effort and stereotype threat performance effects. Journal of Personality and Social Psychology, 93(4), 544-564.

Johnson-Ahorlu, R. (2013). “Our biggest challenge is stereotypes”: Understanding stereotype threat and the academic experiences of African-American undergraduates. Journal of Negro Education, 82(4), 382-392. Retrieved from http://dx.doi.org/10.7709/jnegroeducation.82.4.0382

Johnson, S. B., \& Anderson, P. L. (2014). Stereotype confirmation concern and fear of negative evaluation among African-Americans and Caucasians with Social Anxiety Disorder. Journal of Anxiety Disorders, 28(4), 390-393. Retrieved from http://doi.org/10.1016/j.janxdis.2014.03.003

Kelly, S., Maynigo, P., Wesley, K., \& Durham, J. (2013). African-American communities and family systems: Relevance and challenges. Couple and Family Psychology: Research and Practice, 2(4), 264-277. Retrieved from https://search.proquest.com/docview/1492504730?accountid=8313

Kerr, M. E.. (2000). One family's story: A primer on Bowen Theory. The Bowen Center for the Study of the Family. Retrieved from http://www.thebowencenter.org. 
Kolonder, M. (2018). Even when graduation rates rise, Black students at many colleges are left behind. Retrieved March 22, 2018, from https://www.huffingtonpost.com/ entry/graduation-rates-black-students_us_56f1f844e4b04c4c37608667

Lamont, M., Guetzkow, J. A., Herzog, H., Silva, G. M., Mizrachi, N., Reis, E. P., \& Welburn, J. S. (2016). Getting respect: Responding to stigma and discrimination in the United States, Brazil, and Israel. Princeton, NJ: Princeton University Press.

Lee, D. L., \& Ahn, S. (2013). The relation of racial identity, ethnic identity, and racial socialization to discrimination-distress: A meta-analysis of Black Americans. Journal of Counseling Psychology, 60(1), 1-14. Retrieved from http://dx.doi.org/10.1037/a0031275

LaMothe, R. (2012). Potential space: Creativity, resistance, and resiliency in the face of racism. Psychoanalytic Review, 99(6), 851-876. doi:10.1521/prev.2012.99.6.851

Linnabery, E., Stuhlmacher, A. F., \& Towler, A. (2014). From whence cometh their strength: Social support, coping, and well-being of Black women professionals. Cultural Diversity and Ethnic Minority Psychology, 20(4), 541-549. Retrieved from http://dx.doi.org/10.1037/a0037873

Love, K., Tyler, K., Thomas, D., Garriott, P., Brown, C., \& Roan-Belle, C. (2009). Influence of multiple attachments on well-being: A model for African-Americans attending historically Black colleges and universities. Journal of Diversity in Higher Education, 2(1), 35-45. Retrieved from https://search.proquest.com/ docview/614531252? accountid=8313

Mandara, J., \& Murray, C. B. (2000). Effects of parental marital status, income, and family functioning on African-American adolescent self-esteem. Journal of Family Psychology, 14(3), 475-490. Retrieved from https://search.proquest.com/ docview/614349030? accountid=8313

Mary. (2011, April 01). African-Americans'social \& racial identity under attack. Retrieved from http://www.racismreview.com/blog/2011/04/01/africanamericans'-social-racial-identity-under-attack/

Massey, D. S., \& Owens, J. (2014). Mediators of stereotype threat among Black college students. Ethnic and Racial Studies, 37(3), 557-575. Retrieved from http://dx.doi.org/10.1080/01419870.2013.786110

Matlin, S. L., Molock, S. D., \& Tebes, J. K. (2011). Suicidality and depression among African-American adolescents: The role of family and peer support and community connectedness. American Journal of Orthopsychiatry, 81(1), 108-117.

Meyers, L., Gamst, G., \& Guarino, A. (2013). Applied multivariate research: Design and interpretation. (2nd ed., Vol. 1, pp. 850-902). Thousand Oaks, California: SAGE. 
McMillan, J., \& Schumacher, S. (2010). Research in education: Evidence-based inquiry. (7 ed., pp. 117-125). Upper Saddle River, NJ: Pearson.

Microaggression. (n.d.). Retrieved July 9, 2018, from https://www.merriamwebster.com/dictionary/microaggression

Miller, M. J., Alvarez, A. N., Li, R., Chen, G. A., \& Iwamoto, D. K. (2016). Measurement invariance of the people of color racial identity attitudes scale with Asian Americans. Psychological Assessment, 28(1), 116-122. Retrieved from https://search.proquest.com/docview/1697758221 accountid=8313

Miller, D. B. (1999). Racial socialization and racial identity: Can they promote resiliency for adolecents. Adolescence, 34(135), 493.

Molina, L. E., Phillips, N. L., \& Sidanius, J. (2015). National and ethnic identity in the face of discrimination: Ethnic minority and majority perspectives. Cultural Diversity and Ethnic Minority Psychology, 21(2), 225-236.

Mossakowski, K. N. (2003). Coping with Perceived Discrimination: Does Ethnic Identity Protect Mental Health? Journal of Health and Social Behavior, 44(3), 318-331. doi:10.2307/1519782

Najdowski, C. J., Bottoms, B. L., \& Goff, P. A. (2015). Stereotype threat and racial differences in citizens' experiences of police encounters. Law and Human Behavior, 39(5), 463-477.

Nichols, M. P. (2014). Family therapy: Concepts and methods (6th ed.). Boston, MA: Pearson.

Nuru-Jeter, A., Dominguez, T. P., Hammond, W. P., Leu, J., Skaff, M., Egerter, S., \& Braveman, P. (2009). It's the skin you're in: African-American women talk about their experiences of racism: An exploratory study to develop measures of racism for birth outcome studies. Maternal and Child Health Journal, 13(1), 29-39. Retrieved from http://dx.doi.org/10.1007/s 10995-008-0357-x

Owens, J., \& Lynch, S. M. (2012). Black and Hispanic immigrants' resilience against negative-ability racial stereotypes at selective colleges and universities in the United States. Sociology of Education, 85(4), 303-325. Retrieved from http://search.proquest.com/docview/1086348221 ?accountid=8313

Okeke, N. A., Howard, L. C., Kurtz-Costes, B., \& Rowley, S. J. (2009). Academic race stereotypes, academic self-concept, and racial centrality in African-American youth. Journal of Black Psychology, 35(3), 366-387. Retrieved from http://dx.doi.org/10.1177/0095798409333615 
Olson, D. (1986), Circumplex model vii: Validation studies and FACES III. Family Process, 25 (3): 337-351. doi:10.1111/j.1545-5300.1986.00337.x

Olson, D. (2000). Circumplex model of marital and family systems. Journal of Family Therapy, 22(2), 144-167. Retrieved from http://dx.doi.org/10.1111/14676427.00144

Olson, D. (2011). FACES IV and the circumplex model: Validation study. Journal of Marital and Family Therapy, 3(1), 64-80. Retrieved from http://www.buildingrelationships.com/facesiv_studies/Validation_Study_JMFT_2 011.pdf

Olson, D. (n.d.) Family Satisfaction Scale. Minneapolis, MN: Life Innovations, Inc. Retrieved from http://www.laviecounseling.org/vfh/vfhasm/FACESIV.Family SatisfactionScale.pdf

Parent, J., Jones, D. J., Forehand, R., Cuellar, J., \& Shoulberg, E. K. (2013). The role of coparents in African-American single-mother families: The indirect effect of coparent identity on youth psychosocial adjustment. Journal of Family Psychology, 27(2), 252-262. Retrieved from https://search.proquest.com/ docview/1285624346? accountid=8313

Parham, T. A., \& Helms, J. E. (1981). The influence of Black students' racial identity attitudes on preferences for counselor's race. Journal of Counseling Psychology, $28(3), 250-257$.

Parham, T. A., \& Helms, J. E. (1985). Relation of racial identity attitudes to self actualization and affective states of black students. Journal of Counseling Psychology, 32, 431-44

Patterson, S. V. (2009). Beyond color, beyond name: African-American youth perceptions of historically Black colleges and universities (HBCUs) and predominately White universities (PWIs). (Doctoral Dissertation). Available from ProQuest Dissertations and Theses Global. (UMI: No. 3382160)

Pickett, J. T., Chiricos, T., Golden, K. M., \& Gertz, M. (2012). Reconsidering the relationship between perceived neighborhood racial composition and Whites' perceptions of victimization risk: Do racial stereotypes matter? Criminology: An Interdisciplinary Journal, 50(1), 145-186. Retrieved from http://dx.doi.org/ 10.1111/j.1745-9125.2011.00255.x

Pierre, M. R., \& Mahalik, J. R. (2005). Examining African self-consciousness and Black racial identity as predictors of Black men's psychological well-being. Cultural Diversity and Ethnic Minority Psychology, 11(1), 28-40. Retrieved from http://dx.doi.org/10.1037/1099-9809.11.1.28 
Ponterotto, J. G., \& Wise, S. L. (1987). Construct validity study of the racial identity attitude scale. Journal of Counseling Psychology, 34(2), 218-223. Retrieved from http://dx.doi.org/10.1037/0022-0167.34.2.218

Preacher, K. J., \& Merkle, E. C. (2012). The problem of model selection uncertainty in structural equation modeling. Psychological Methods, 17(1), 1-14. Retrieved from http://dx.doi.org/10.1037/a0026804

Rodriguez, J., Umaña-Taylor, A., Smith, E. P., \& Johnson, D. J. (2009). Cultural processes in parenting and youth outcomes: Examining a model of racial-ethnic socialization and identity in diverse populations. Cultural Diversity and Ethnic Minority Psychology, 15(2), 106-111. Retrieved from http://dx.doi.org/10.1037/ a0015510

Rhone, F. G. (2010). The college life experience: Factors in the racial identity development of Black students attending predominantly White institutions. (Doctoral Dissertation). Available from ProQuest Dissertations and Theses Global. (UMI: No. 3397593)

Rosenthal, J. A. (1996). Qualitative descriptors of strength of association and effect size. Journal of Social Service Research, 21(4), 37-59.

Sanchez, D. (2013). Racial and ego identity development in Black Caribbean college students. Journal of Diversity in Higher Education, 6(2), 115-126. Retrieved from https://search.proquest.com/docview/1322251303 accountid=8313

Schaller, M., Park, J. H., \& Mueller, A. (2003). Fear of the dark: Interactive effects of beliefs about danger and ambient darkness on ethnic stereotypes. Personality and Social Psychology Bulletin, 29(5), 637-649. Retrieved from http://dx.doi.org/ 10.1177/0146167203029005008

Schmitt, M. T., \& Branscombe, N. R. (2002). The meaning and consequences of perceived discrimination in disadvantaged and privileged social groups. European review of social psychology, 12(1), 167-199.

Schwartz, S.J., Donnellan, B., Ravert, R., Luyckx, K., \& Zamboanga, B. (2012). Identity development, personality, and well-being in adolescence and emerging adulthood. Handbook of Psychology, 6(2), 339-364.

Schwartz, S. J., Kim, S. Y., Whitbourne, S. K., Zamboanga, B. L., Weisskirch, R. S., Forthun, L. F., . . . Luyckx, K. (2013). Converging identities: Dimensions of acculturation and personal identity status among immigrant college students. Cultural Diversity and Ethnic Minority Psychology, 19(2), 155-165. Retrieved from https://search.proquest.com/docview/1151919480?accountid=8313 
Seaton, E. K., Yip, T., Morgan-Lopez, A., \& Sellers, R. M. (2012). Racial discrimination and racial socialization as predictors of African-American adolescents' racial identity development using latent transition analysis. Developmental Psychology, $48(2), 448-458$.

Sellers, R. M., \& Shelton, J. N. (2003). The role of racial identity in perceived racial discrimination. Journal of Personality and Social Psychology, 84(5), 1079-1092.

Shih, M. J., Pittinsky, T. L., \& Ho, G. C.. (2011). Stereotype boost: positive outcomes from the activation of positive stereotypes. In M. Inzlicht, T. Schmader, Stereotype threat: Theory, process, and application. New York, NY: Oxford University Press, pp. 5-6, 141-143.

Skowron, E. A. (2005). Parent differentiation of self and child competence in low-income urban families. Journal of Counseling Psychology, 52(3), 337-346.

Spears Brown, C., \& Bigler, R. S. (2005). Children's perceptions of discrimination: A developmental model. Child Development, 76(3): 533-553. doi:10.1111/j.14678624.2005.00862.x

Steele, C. M., \& Aronson, J. (1995, November). Stereotype threat and the intellectual test performance of African-Americans. Journal of Personality and Social Psychology, 69 (5): 797-811. doi:10.1037/0022-3514.69.5.797

Syed, M., \& Juang, L. P. (2014). Ethnic identity, identity coherence, and psychological functioning: Testing basic assumptions of the developmental model. Cultural Diversity and Ethnic Minority Psychology, 20(2), 176-190.

Tantillo, M. (2006). A relational approach to eating disorders multifamily therapy group: Moving from difference and disconnection to mutual connection. Families, Systems, \& Health, 24(1), 82-102.

Thames, A. D., Hinkin, C. H., Byrd, D. A., Bilder, R. M., Duff, K. J., Mindt, M. R., ... Streiff, V. (2013). Effects of Stereotype threat, perceived discrimination, and examiner race on neuropsychological performance: Simple as Black and White? Journal of the International Neuropsychological Society, 19(5), 583-593.

Thomas, A., Hammond, W. P., \& Kohn-Wood, L. (2015). Chill, be cool man: AfricanAmerican men, identity, coping, and aggressive ideation. Cultural Diversity and Ethnic Minority Psychology, 21(3), 369-379.

Thomas, M. B., \& Dansby, P. G. (1985). Black clients: Family structures, therapeutic issues, and strengths. Psychotherapy, 22(2), 398-407.

Thomas, R. M. (2003). Blending qualitative \& quantitative research methods in theses and dissertations. Thousand Oaks, CA: Corwin Press. 
Thompson, C. P., Anderson, L. P., \& Bakeman, R. A. (2000). Effects of racial socialization and racial identity on acculturative stress in African-American college students. Cultural Diversity and Ethnic Minority Psychology, 6(2), 196210.

Townes, D. L., Chavez-Korell, S., \& Cunningham, N. J. (2009). Reexamining the relationships between racial identity, cultural mistrust, help-seeking attitudes, and preference for a Black counselor. Journal of Counseling Psychology, 56(2), 330336.

U.S. Department of Education, National Center for Education Statistics. (2017). Status and trends in the education of racial and ethnic groups 2017. In National Center for Education Statistics, Fun facts: Degree conferred by race and sex. Retrieved from https://nces.ed.gov/fastfacts/display.asp?id=72

US Legal, Inc. (2016). USLegal. Retrieved from https://definitions.uslegal.com/a/africanamericans/

Vandiver, B. J., Cross, W. E., Jr., Worrell, F. C., \& Fhagen-Smith, P. (2002). Validating the cross racial identity scale. Journal of Counseling Psychology, 49(1), 71-85.

Vera, E., Thakral, C., Gonzales, R., Morgan, M., Conner, W., Caskey, E., . . . Dick, L. (2008). Subjective well-being in urban adolescents of color. Cultural Diversity and Ethnic Minority Psychology, 14(3), 224-233. Retrieved from http://dx.doi.org/10.1037/1099-9809.14.3.224

Walden, D. L. (2009). I'm not gonna let you define me: A qualitative investigation of racial identity development in black men. (Doctoral dissertation). Available from ProQuest Dissertations and Theses database Global (UMI: No. 304837029).

Wasserberg, M. J. (2014). Stereotype threat effects on African-American children in an urban elementary school. Journal of Experimental Education, 82(4), 502-517. Retrieved from http://dx.doi.org/10.1080/00220973.2013.876224

Weeks, C. (1998). Racial identity attitudes as predictors of the cognitive correlates of social anxiety in African-Americans (Unpublished Doctoral Dissertation). Virginia Polytechnic Institute and State University, Blacksburg, VA.

Wegmann, K. M. (2017, March 9). His skin doesn't match what he wants to do: Children's perceptions of stereotype threat. American Journal of Orthopsychiatry, 87(6), 615. Advance online publication. Retrieved from http://dx.doi.org/10.1037/ ort0000238

Wei, M., Yeh, C. J., Chao, R. C., Carrera, S., \& Su, J. C. (2013). Family support, selfesteem, and perceived racial discrimination among Asian American male college students. Journal of Counseling Psychology, 60(3), 453-461. 
Weisbuch, M., \& Ambady, N. (2008). Affective divergence: Automatic responses to others' emotions depend on group membership. Journal of Personality and Social Psychology: Interpersonal Relations and Group Processes, 95(5), 1063-1079.

Welleto, A. A. (2000). Resiliency in African-American families (Book). Journal of Comparative Family Studies, 31(1), 128-129.

Woodcock, A., Hernandez, P. R., Estrada, M., \& Schultz, P. W. (2012). The consequences of chronic stereotype threat: Domain disidentification and abandonment. Journal of Personality and Social Psychology, 103(4), 635-646.

Wright, K. (2005). Researching internet-based populations: Advantages and disadvantages of online survey research, online questionnaire authoring software packages, and web survey services, Journal of Computer-Mediated Communication, 10(3), Retrieved from https://doi.org/10.1111/j.10836101.2005.tb00259.x

Yakin, J. A., \& McMahon, S. D. (2003). Risk and resiliency: A test of a theoretical model for urban, African-American youth. Journal of Prevention \& Intervention in the Community, 26(1), 5-19.

Yip, T. (2016). To be or not to be: How ethnic/racial stereotypes influence ethnic/racial disidentification and psychological mood. Cultural Diversity and Ethnic Minority Psychology, 22(1), 38-46. 
CURRICULUM VITA 


\section{CURRICULUM VITA}

\section{ERICA LYNN FEATHERSON}

EDUCATION:

Ph.D., Counseling Psychology, 2018

Andrews University, Berrien Springs, Michigan

MSc., Counseling Psychology, 2016

Andrews University, Berrien Springs, Michigan

B.A., Psychology, 2011

Tuskegee University, Tuskegee, AL

\section{PROFESSIONAL EXPERIENCE}

2017-present

Doctoral Psychology Intern

Connected Psychology

Washington, D.C.

2016-2017

Doctoral Practicum Extern

Andrews University

Berrien Springs, Michigan

2015-2016

Doctoral Practicum

Andrews University

Berrien Springs, Michigan

2014

Master's Practicum

Andrews University

Berrien Springs, Michigan 